\title{
Prevención educativa del embarazo precoz en estudiantes del nivel básico superior
}

Dra. Sonia Patricia Ubillus Saltos Dr. Roberth Olmedo Zambrano Santos Dra. Johanna Mabel Sánchez Rodríguez Lic. Margoth Elizabeth Villegas Chiriboga

Didáctica e Innovación educativa ${ }^{3}$ ciencias 



\section{Prevención educativa del embarazo precoz en estudiantes del nivel básico superior}

Dra. Sonia Patricia Ubillus Saltos

Instituto Tecnológico Superior "Portoviejo" / Ministério de Educación

\section{Dr. Roberth Olmedo Zambrano Santos}

Instituto Tecnológico Superior "Portoviejo" / Universidad Estatal del Sur de Manabí

\section{Dra. Johanna Mabel Sánchez Rodríguez}

Universidad Laica "Eloy Alfaro" de Manabí / Universidad Estatal del Sur de Manabí

\section{Lic. Margoth Elizabeth Villegas Chiriboga}

Universidad Estatal del Sur de Manabí

\section{Ecuador}




\section{${ }^{3}$ ciencias}

Editorial Área de Innovación y Desarrollo, S.L

Quedan todos los derechos reservados. Esta publicación no puede ser reproducida, distribuida, comunicada públicamente o utilizada, total 0 parcialmente, sin previa autorización.

(C) del texto: 3Ciencias

ÁREA DE INNOVACIÓN Y DESARROLLO, S.L.

C/ Els Alzamora, 17 - 03802 - ALCOY (ALICANTE) info@3ciencias.com

Primera edición: diciembre 2016

ISBN: 978-84-946089-8-8

DOI: http://dx.doi.org/10.17993/DidelnnEdu.2016.21 


\section{AGRADECIMIENTOS}

Son muchas las personas que han contribuido a la culminación de esta obra, por ello queremos expresar a ellos el más profundo agradecimiento, especialmente a:

A los tutores, quienes con profesionalismo y orientaciones precisas hicieron posible la culminación de esta investigación.

Un agradecimiento muy especial a los profesores y estudiantes que colaboraron brindando información en el proceso investigativo.

A todos ellos nuestra eterna gratitud.

Los autores 



\section{DEDICATORIA}

Esta obra está dedicada de manera especial:

A nuestras familias, máximas inspiradoras de nuestras vidas, quienes con su amor y sabiduría nos has llevado hacia el camino del éxito.

Los autores 



\section{SÍNTESIS}

En Ecuador, la deficiente educación sexual en la adolescencia, es la causa de connotadas consecuencias sociales e individuales a escala mundial, entre las cuales se connotan: altos índices de embarazo precoz, enfermedades de trasmisión sexual e irresponsabilidad ante la salud sexual y reproductiva. En correspondencia con lo anterior, los investigadores se propusieron diseñar un programa de intervención educativa para la prevención educativa del embarazo precoz en estudiantes del nivel básico superior, sustentado en un modelo educativo-preventivo, centrado en la acción tutorial. En calidad de métodos y técnicas de carácter exploratorio se emplearon entrevistas, encuestas, la observación y el experimento (en su variante pre-experimental), entre otros. El diagnóstico efectuado evidencia la insuficiente educación de la sexualidad en estudiantes de este nivel y justifica la necesidad de la construcción de un modelo educativo y preventivo del embarazo precoz, desde la acción tutorial, en calidad de contribución a la teoría pedagógica. Del mismo modo, es explicativo de la necesidad de su materialización en la práctica, la cual se concreta a través de un programa de intervención educativa. La implementación del programa a través de un pre-experimento, permite constatar su efectividad preliminar a los fines propuestos. 



\section{Prólogo}

Mientras escribía este prólogo, entre los días 21 y 24 de Noviembre de 2016, se celebraba la Novena Conferencia Mundial de Promoción de la Salud en Shangai (China), organizada conjuntamente por el Gobierno de este País y la Organización Mundial de la Salud y siendo, a día de hoy, la última de una serie reuniones que comenzaron en 1986 en Ottawa. En esta Primera Conferencia Mundial, que dio como resultado la redacción de la Carta de Ottawa para el Fomento de la Salud, se acuñó el término de Promoción de la Salud.

Según ese texto, "la promoción de la salud consiste en proporcionar a los pueblos los medios necesarios para mejorar su salud y ejercer un mayor control sobre la misma. Para alcanzar un estado adecuado de bienestar físico, mental y social, un individuo o grupo debe ser capaz de identificar y realizar sus aspiraciones, de satisfacer sus necesidades y de cambiar o adaptarse al medio ambiente. La salud se percibe pues, no como el objetivo, sino como la fuente de riqueza de la vida cotidiana. Se trata por tanto de un concepto positivo que acentúa los recursos sociales y personales así como las aptitudes físicas. Por consiguiente, dado que el concepto de salud como bienestar transciende la idea de formas de vida sanas, la promoción de la salud no concierne exclusivamente al sector sanitario".

En este sentido, el texto también hacía referencia a la importancia de que los responsables de la elaboración de los programas, ya fueran políticos o sanitarios, estuvieran familiarizados y hubieran tomado conciencia de esta herramienta como eje para impulsar la salud de las poblaciones de las que eran y son responsables. Las políticas de promoción de la salud deben desarrollarse con enfoques diversos y complementarios, que incluyan aspectos como la legislación, la educación, las medidas fiscales, el sistema tributario y los

cambios organizativos; resultando imprescindible que se identifiquen y eliminen los obstáculos que impidan la adopción de medidas sociales y políticas que favorezcan la salud en aquellos sectores no directamente implicados en la misma.

Treinta años después, y tras siete conferencias más, en Adelaida (1988), Sundsvall (1991), Yakarta (1997), Ciudad de México (2000), Bangkok (2005), Nairobi (2009) y Helsinki (2013), la situación de salud de los países de ingresos altos, medios y bajos, continúa estando marcada por enfermedades y situaciones sociosanitarias que serían incompatibles con políticas de promoción de la salud adecuadas. 
Los embarazos precoces en adolescentes representan un caso paradigmático, donde las medidas integrales de promoción de la salud podrían tener un impacto significativo reduciendo la incidencia. Este problema de Salud Pública, especialmente relevante en África y América Latina, constituye un claro ejemplo de cómo a través de la promoción de la salud, y de medidas favorables sobre el medio ambiente cultural, político y legislativo, se podría revertir esta grave situación, cuyas complicaciones, relacionadas con el embarazo y el parto, representan la segunda causa de mortalidad entre las mujeres de 15 a 19 años en todo el mundo.

Sin lugar a dudas, el embarazo es uno de los problemas más importantes en la vida de las adolescentes. Sus consecuencias son numerosas, pues pueden ejercer una influencia negativa en la salud, en el futuro y en el proyecto de vida de las parejas afectadas. Existe sobrada evidencia de los riesgos para la salud que esta situación conlleva, destacando el incremento de la probabilidad de aborto involuntario, de muerte intraparto, de trastornos digestivos, de embarazos extrauterinos, de infecciones, de hemorragias posparto y de distocias. Sin embargo, los efectos socioeconómicos tampoco deben ser obviados, pues con la maternidad o paternidad, aparecen múltiples obstáculos para iniciar o continuar la formación escolar, se hace más probable la precarización del trabajo y se incrementa el riesgo de caer o continuar en la pobreza. Además, este hecho puede conllevar una formación deficiente de los niños y niñas, riesgo de maltrato y de ser víctimas del estigma social que acompaña, según las culturas, a las madres adolescentes y solteras. En definitiva, la morbimortalidad, tanto materna como fetal, es mayor en las adolescentes que en la población en general, así como la frecuencia de conflictos socioeconómicos y psicosociales que tienen como consecuencia principal la deserción de los estudios, lo que afecta negativamente a los objetivos vitales y laborales de los progenitores.

Por estos motivos, una las metas específicas del Objetivo de Desarrollo Sostenible relacionado con la salud (ODS 3) de la Organización Mundial de la Salud (OMS), se basa en garantizar, antes de 2030, el acceso universal a los servicios de salud sexual y reproductiva, incluidos los de planificación familiar, información y educación, y la integración de la salud reproductiva en las estrategias y los programas nacionales.

Ecuador no ha sido ajeno a este problema. Ya en la década de los setenta se creó una Cátedra de Educación Sexual en la Facultad de Filosofía, Letras y Educación de la Universidad de Guayaquil y, desde entonces, han sido diversas las iniciativas llevadas a 
cabo en esta línea, cuya culminación, probablemente fuera el desarrollo de la Estrategia Nacional Intersectorial de Planificación Familiar y Prevención de Embarazo de Adolescentes (ENIPLA), que comenzó a aplicarse en 2012.

Sin embargo, y aunque las cifras aportadas por el Instituto Nacional de Estadística y Censos (INEC) de Ecuador, indican un descenso progresivo en las tasas de embarazo precoz, los datos continúan siendo preocupantes. Por cada 1.000 mujeres con edades comprendidas entre los 10 y los 14 años, ocurrieron 3,08 nacimientos en 2012 (no existen registros posteriores) y por cada 1.000 féminas entre los 15 y los 17 años, acaecieron 62,56 en 2014; lo que representa un total de 76.173 nacimientos. En este mismo sentido, las estadísticas internacionales sitúan a Ecuador como el quinto país de América Latina y el Caribe con mayor número de nacidos vivos en adolescentes y el tercero de Sudamérica, con 76,2 nacimientos por cada 1.000 mujeres de entre 15 y 19 años.

Con seguridad, estos datos ratifican la importancia, oportunidad e idoneidad de esta obra, que comienza con unos estudios pormenorizados del contexto histórico, epistemológico y praxiológico de los diferentes escenarios socioculturales en Ecuador, relativos a la concepción del embarazo adolescente como problema sociosanitario. Posteriormente, se expone una propuesta de modelo educativo-preventivo del embarazo precoz, haciendo un especial hincapié en la acción tutorial y en los contenidos socioculturales que juegan un rol fundamental en la sexualidad del adolescente, como son los valores, la autoestima, la vida familiar, etc. Para finalizar, los autores proponen un programa de intervención educativa de prevención del embarazo precoz y presentan los resultados de un pequeño pilotaje con 25 alumnos, exponiendo las valoraciones y resultados positivos de estudiantes y profesores.

Todo ello, hace del presente libro un excelente y riguroso trabajo de equipo del que toda la sociedad ecuatoriana, especialmente adolescentes, educadores y profesionales de la salud, podrán beneficiarse. Estoy convencido de que el camino para elaborar este texto no ha sido fácil. El tesón, esfuerzo y sacrificio de sus autores queda patente en el resultado final. La calidad científica y humana que emanan sus contenidos, solo pueden ser producto de la formación, el rigor y extensas jornadas de trabajo.

Por todo ello, agradezco la oportunidad brindada por los autores de colaborar con esta obra y considero un honor contribuir a la misma con la redacción de este prólogo. Quisiera, para concluir, manifestar mis mejores de deseos para este texto, que no serían otros que 
servir a las autoridades pertinentes para el diseño de programas de promoción de la salud sexual que se traduzcan en un descenso de la incidencia de embarazos precoces.

Profesor Dr. Guillermo Molina Recio Departamento de Enfermería de la Universidad de Córdoba 


\section{ÍNDICE}

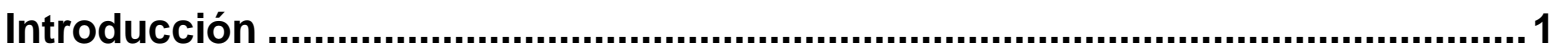

Capítulo I: Análisis histórico, epistemológico y praxiológico de la prevención del embarazo precoz en estudiantes del nivel básico superior, desde el

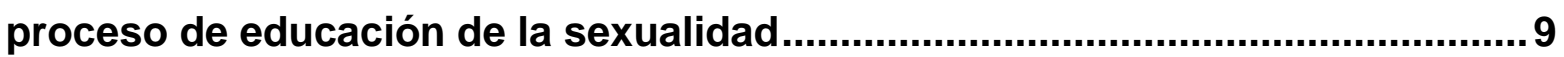

1.1 -Evolución histórica del proceso de educación de la sexualidad en el nivel básico superior en Ecuador. 9

1.2.- El proceso de educación de la sexualidad en estudiantes del nivel básico superior. 16

1.3.- La prevención del embarazo precoz en estudiantes del nivel básico superior. 23

1.4.- Diagnóstico y caracterización del desarrollo inicial de la educación de la sexualidad, con énfasis en la prevención del embarazo precoz en los estudiantes del nivel básico superior de la Unidad Educativa ITSUP, de Portoviejo, Manabí, Ecuador. 34

Conclusiones del capítulo 1 39

Capítulo II: Modelo educativo - preventivo del embarazo precoz en estudiantes del nivel básico superior, desde la acción tutorial

2.1.- Argumentación de los fundamentos teóricos que sustentan el modelo educativo - preventivo del embarazo precoz, desde la acción tutorial. 41 
2.2.- Modelo educativo y preventivo del embarazo precoz, desde la acción tutorial. 46

Conclusiones del capítulo II: 61

Capítulo III: Programa de intervención educativa tutorial para la prevención del embarazo precoz en estudiantes del nivel de educación básica superior y

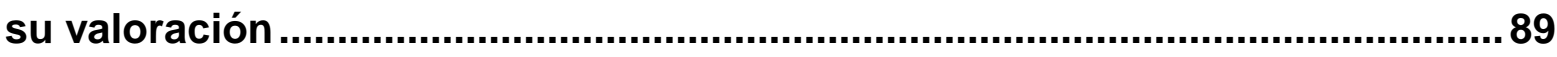

3.1.- Fundamentación del programa de intervención educativa- tutorial para la prevención del embarazo precoz en estudiantes del nivel básico superior. 89

3.2- Valoración teórica del modelo y del programa de intervención educativa tutorial para la prevención del embarazo precoz en estudiantes del nivel básico superior. 100

3.3.- Valoración práctica del programa de intervención educativa tutorial para la prevención del embarazo precoz en estudiantes del nivel básico superior. 77

Conclusiones del capítulo III 82

Conclusiones. .83

Recomendaciones 85

\section{Bibliografía}

\section{Anexos}




\section{INTRODUCCIÓN}

Entendida la educación como acceso a la cultura y a la ciencia - bienes comunes históricamente construidos - el reto que la escuela tiene, en el contexto educativo actual, es que la formación de adolescentes y jóvenes sea cada vez más intencionada, en correspondencia con las nuevas exigencias científicas y sociales.

La necesidad de emprender acciones en cuanto a la educación de la sexualidad de niños, adolescentes, jóvenes y población en general, es actualmente la prioridad de varias instituciones y organismos internacionales como la Organización Mundial de la Salud (OMS), el Fondo de las Naciones Unidas para la Infancia (UNICEF), el Fondo Poblacional de las Naciones Unidas, entre otros, quienes están convencidos de lo necesario del enfrentamiento de esta problemática.

En la actualidad se advierte que un número cada vez mayor de países ha implementado programas de educación en sexualidad a través de la Declaración Ministerial Prevenir con Educación, celebrada en 2008, donde se reconoce la necesidad que tienen los adolescentes y jóvenes de recibir una educación en sexualidad; sin embargo, la insuficiente educación sexual constituye hoy una de las causas de connotadas consecuencias sociales e individuales, entre las que se destacan altos índices de embarazo precoz, infecciones de transmisión sexual, irresponsabilidad ante la salud sexual y reproductiva, entre otras.

Una educación efectiva en sexualidad es importante dado el impacto que tienen los valores culturales y creencias en todas las personas, específicamente en los adolescentes y jóvenes, además, la educación de la sexualidad representa un elemento vital en la prevención de VIH, otras ITS y el embarazo precoz.

El embarazo precoz es un problema común en las sociedades a nivel mundial: 7'3 millones de adolescentes se convierten en madres cada año, de las cuales 2 millones son menores de 15 años, un número que puede aumentar a 3 millones en el año 2030, si la tendencia actual continúa. Esta situación se acentúa especialmente en las sociedades más pobres y con mayor falta de educación. Se estima que unas 70.000 adolescentes de los países en desarrollo mueren cada año por complicaciones durante el embarazo o el parto. Además, las niñas que quedan embarazadas antes de los 15 años en los países de bajo y mediano ingresos, tienen el doble de riesgo de muerte materna. (López, 2011). 
La educación de la sexualidad forma parte de la educación integral del ser humano; sin embargo, su estudio ha sido subestimado durante décadas, y la misma se ha dejado a la espontaneidad de educadores y familiares, matizada por mitos, costumbres y normas sociales de los más diversos contextos culturales. Según Núñez, coordinadora nacional de la Sociedad Ecuatoriana de Sexología y Educación sexual (SESEX), citado por Anchundia (2014), " [...] existe mucho desconocimiento, prejuicios e información equivocada sobre sexualidad, siendo muy general la creencia que sexualidad es igual a relaciones sexuales. Esta realidad requiere cambios urgentes" (Núñez, 2011, p.1).

En la inmensa mayoría de los países latinoamericanos no existe una política oficial que promueva la educación sexual como parte de la educación general y en los pocos países que sí la tienen, aún falta mucho por hacer para que esta política se convierta en realidad. La educación de la sexualidad es un derecho que tiene todo ser humano como parte de una educación integral.

En Ecuador, los profundos cambios sociales, culturales y económicos de los últimos tiempos han ido creando las condiciones para el desarrollo de nuevas concepciones referentes a la educación de la sexualidad. En el caso específico de los adolescentes, el tema de la sexualidad adquiere un espacio importante. En tal sentido esta investigación se centra en el tratamiento de esta temática.

Méndez, B. considera que: “... el embarazo en la adolescencia es mucho más que un problema de salud; es un problema, ante todo, social, de valores [...] es necesario un gran esfuerzo por parte de todos: madres, padres, educadores, personal sanitario, etc.". (Méndez, 2003, p.9).

Los investigadores del contexto internacional como (Santos, 2003; Mena, 2005; Molina, 2007; Cruz, 2011; Fernández y López, 2012; Rodríguez, 2012; Zárate, 2013), entre otros, también han incursionado en la temática de la educación de la sexualidad haciendo importantes propuestas.

En Cuba se han desarrollado diversos estudios relacionados con la educación de la sexualidad, tal es el caso de los trabajos desarrollados por (Castellanos y González, 1995, 2003, 2014; Castro, 1993, 2003, 2006; Ruiz y Azcuy, 2001). Otros investigadores como Sánchez, (2006); Hui, (2006); Armas, (2009); Pérez, (2008); García, E. (2009); García, M. (2009) ofrecen propuestas interesantes para la educación de la sexualidad, específicamente referidas a la 
educación inicial, y a niños y adolescentes con necesidades educativas especiales (NEE). Otras investigaciones consultadas enriquecen la teoría sobre el estudio de la sexualidad, centradas en una perspectiva de género: (López, 2008; Vega, 2008; Infante, 2008). Megna, A. (2014) aporta una concepción pedagógica muy interesante de educación de la sexualidad responsable de estudiantes de la Educación Preuniversitaria, que revela la integración orgánica de lo cognitivo sociocultural, lo personal desarrollador y lo comportamental educativo desde las potencialidades de la dinámica del proceso educativo en estrecho vínculo con la educación familiar y comunitaria, que contribuye al núcleo personológico de la sexualidad en coherencia con las capacidades y potencialidades autoeducativas de los estudiantes. Esta propuesta se distingue por una perspectiva familiar y comunitaria.

En el contexto ecuatoriano, en los últimos años se han realizado investigaciones sobre el embarazo precoz, entre las que se destacan las de Sánchez Olmedo y Villigua Vásquez, (2010); Macías Solís y Murillo Barreto, (2010); Valencia, (2009); Bolaños Orozco y Espinoza Flor, (2010). Sin embargo, la mayoría de estas se caracterizan por concebirlo solamente como un problema de salud, por su carácter descriptivo y de transmisión de información. Adolecen de propuestas educativas en función de argumentar cómo prevenir embarazos no deseados y cómo asumir una actitud de responsabilidad compartida de adolescentes (tanto hembras como varones) ante la maternidad y paternidad, sustentada en fundamentos científicos.

Otras investigaciones lideradas por Mulder, (2014) sobre el embarazo precoz en seis países latinoamericanos aportan algunos factores culturales y sociales determinantes en este, pero evidencian que no están suficientemente estructuradas, no tienen en cuenta las características de la edad, las necesidades y no emplean metodologías específicas.

El basamento teórico esbozado, más la experiencia práctica de la autora en el contexto ecuatoriano ha permitido comprobar que:

- Los adolescentes presentan limitaciones en la comprensión de aspectos relacionados con la educación de la sexualidad, esencialmente en el dominio de los contenidos relacionados con esta temática y sus actitudes al respecto.

- Se aprecia la presencia de mitos y prejuicios en alumnos y docentes; el pobre dominio de procedimientos en los profesores, que les permitan una organización, ejecución y 
control del proceso pedagógico, con la consiguiente influencia en la elaboración y puesta en práctica de alternativas interventivas.

- La orientación sexual y la profilaxis del embarazo precoz en estudiantes adolescentes, no se connota desde una perspectiva educativa y preventiva, con énfasis en la prevención primaria.

- La escasez de propuestas que involucren tanto a varones como a hembras, en la prevención educativa del embarazo durante la adolescencia.

- La jerarquización de la información sexual, como parte de los programas, estrategias y propuestas, en general, para incidir en la educación de la sexualidad, en detrimento de la educación socioemocional.

Aunque se ha aportado a la teoría con el propósito de lograr una sexualidad responsable en estudiantes de preuniversitario, aún se aprecian limitaciones en el abordaje de esta temática desde la óptica de la prevención educativa de embarazos en adolescentes, y la prevalencia de los recursos teórico-metodológicos y pedagógicos, particularmente en el nivel básico superior, lo que se identifica como vacío epistémico, al cual trata de dar solución esta investigación. Lo antes expuesto evidencia la necesidad de que la escuela asuma la educación de la sexualidad responsable de los adolescentes, lo que permitió delimitar en esta investigación, como problema científico, el siguiente: la presencia de comportamientos sexuales poco responsables en estudiantes del nivel básico superior, que limitan su desarrollo y formación integral.

Se determinó como objeto de investigación: el proceso de educación de la sexualidad en estudiantes del nivel básico superior.

En la búsqueda de una solución al problema planteado se ha definido el logro del siguiente objetivo general: diseñar un programa de intervención educativa para la prevención educativa del embarazo precoz en estudiantes del nivel básico superior, sustentado en un modelo educativo-preventivo, centrado en la acción tutorial; se delimitó como campo de investigación: la prevención educativa del embarazo precoz en los estudiantes del nivel básico superior.

Como hipótesis se plantea que la implementación de un programa de intervención educativa tutorial dirigido a estudiantes del nivel básico superior, sustentado en un modelo educativo- 
preventivo basado en la acción tutorial, dinamizado por la contradicción entre la función profiláctica y la función formadora de la educación de la sexualidad, puede contribuir a favorecer la prevención del embarazo precoz en las adolescentes.

Para cumplimentar el objetivo propuesto en el trabajo, fueron trazadas las siguientes tareas científicas:

1. Caracterización de la evolución histórica del proceso de educación de la sexualidad en el nivel básico superior en Ecuador.

2. Caracterización epistemológica del proceso de educación de la sexualidad y la prevención del embarazo precoz en estudiantes del nivel básico superior.

3. Diagnóstico y caracterización del estado inicial actual de la educación de la sexualidad, con énfasis en la prevención educativa del embarazo precoz, en los estudiantes del nivel básico superior de la Unidad Educativa ITSUP, de Portoviejo, Manabí, Ecuador.

4. Argumentación de los fundamentos del modelo educativo-preventivo y del programa de intervención educativa tutorial.

5. Elaboración de un modelo educativo-preventivo y el programa de intervención educativa tutorial para la prevención del embarazo precoz.

6. Valoración teórica del modelo educativo-preventivo y el programa de intervención educativa tutorial para la prevención del embarazo precoz en los estudiantes del nivel básico superior, a través de los talleres de opinión crítica y construcción colectiva.

7. Valoración práctica del programa de intervención educativa tutorial para la prevención del embarazo precoz en los estudiantes del nivel básico superior a partir del desarrollo de un pre-experimento.

Para guiar la orientación y enriquecimiento del objetivo central de la investigación y caracterizar la situación real del problema se utilizaron los siguientes métodos y técnicas:

Del nivel teórico se utilizaron el histórico- lógico, el cual permitió determinar la evolución de la educación de la sexualidad hasta la época actual, lo que facilitó la comprensión de las condicionantes histórico-sociales que caracterizaron el tratamiento de la sexualidad y su educación; el análisis-síntesis, empleado durante todo el proceso investigativo, principalmente en el análisis de las relaciones entre categorías y la propuesta de 
generalizaciones teóricas; el hipotético-deductivo, para la presentación de la suposición que guió la investigación; la modelación sistémico estructural funcional, cuyo uso permitió hacer una explicación teórica, metodológica y práctica del modelo que sustenta la organización estructural del programa de intervención educativa tutorial que se propone.

Del nivel empírico se emplearon el análisis documental, con la finalidad de hacer un análisis del contenido de los programas de Ciencias Naturales, y de constatar el tratamiento de los aspectos referidos a la educación de la sexualidad, así como los objetivos y contenidos de los planes de superación del personal docente; la entrevista, a personal docente y directivos, con el propósito de constatar el estado de preparación y contribución al proceso de conducir la educación de la sexualidad del alumnado y a estudiantes, para identificar el nivel de conocimiento sobre su propia sexualidad y cómo prevenir el embarazo precoz; la encuesta, dirigida al personal docente con el propósito de obtener información sobre el estado actual de su preparación para su desempeño en el desarrollo del trabajo con los aspectos de la educación de la sexualidad de sus educandos. Se emplearon, además:

Talleres de reflexión y construcción colectiva: los que posibilitaron a través del debate, definir las principales necesidades y potencialidades del personal docente para el enfrentamiento de la problemática objeto de estudio y la valoración teórica del modelo y el programa de intervención.

La observación: para constatar en las actividades del proceso docente educativo, el comportamiento sexual de las y los alumnos, y la efectividad del programa propuesto, a partir del análisis de la actitud de los adolescentes y de la actividad del personal docente objeto de estudio.

El análisis del producto de la actividad: para identificar el dominio de contenido y la posición afectiva de los adolescentes con respecto al tema investigado.

Completamiento de frases: para diagnosticar las prioridades personales sobre la prevención de embarazo precoz.

El experimento, en su variante preexperimental: para valorar la efectividad de la implementación del programa interventivo. 
En el orden estadístico, se emplearon, de la estadística descriptiva, tablas de distribución de frecuencias absolutas y relativas, y cálculo porcentual, para apoyar el análisis cualitativo de los resultados.

El aporte teórico lo constituye el modelo educativo y preventivo del embarazo precoz en estudiantes del nivel básico superior, desde la acción tutorial. Lo complementan las tendencias históricas de la educación de la sexualidad en el contexto ecuatoriano. El aporte práctico lo constituye el programa de intervención educativa tutorial para la prevención del embarazo precoz en estudiantes del nivel básico superior.

La novedad científica consiste en develar la lógica de la prevención educativa del embarazo precoz en estudiantes del nivel básico superior, desde la acción tutorial, como parte de la cual se connota en calidad de relación más trascendente, la aprehensión de una conducta sexual responsable y resiliente en estudiantes del nivel básico superior.

La tesis está estructurada en introducción, tres capítulos, conclusiones, recomendaciones, bibliografía y anexos. En el capítulo I se aborda lo relativo a la evolución histórica de la educación de la sexualidad en el nivel básico superior en Ecuador, así como su caracterización epistemológica. Además, se presenta el diagnóstico inicial de la educación de la sexualidad, con énfasis en la prevención del embarazo precoz en los estudiantes del nivel básico superior. En el capítulo II se argumentan los fundamentos teóricos que sustentan el modelo educativo y preventivo del embarazo precoz, desde la acción tutorial y se presenta el referido modelo. En el capítulo III se presenta el programa y se efectúa la valoración teórica del modelo y del programa de intervención educativa tutorial para la prevención del embarazo precoz en estudiantes del nivel básico superior, así como la valoración práctica del programa. 


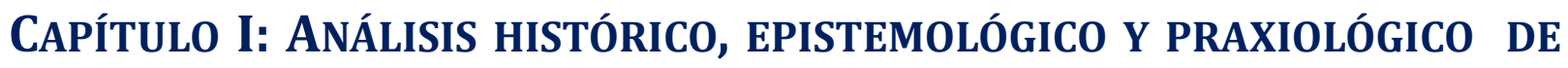 LA PREVENCIÓN DEL EMBARAZO PRECOZ EN ESTUDIANTES DEL NIVEL BÁSICO SUPERIOR, DESDE EL PROCESO DE EDUCACIÓN DE LA SEXUALIDAD}

En este capítulo se expone un análisis histórico del proceso de educación de la sexualidad en el sistema educativo a nivel de Latinoamérica y de manera particular en Ecuador. Se presentan también, los fundamentos teóricos relacionados con la sexualidad y su educación, la repercusión que durante la etapa de la adolescencia tiene la educación de la sexualidad, con un carácter preventivo y en correspondencia con las particularidades del desarrollo psicosexual en los adolescentes. Se abordan, además, los resultados del diagnóstico inicial efectuado, acerca del estado de la educación de la sexualidad y la prevención educativa del embarazo precoz, en estudiantes del nivel básico superior de la Unidad Educativa ITSUP, de Portoviejo, Manabí, Ecuador.

\subsection{Evolución histórica del proceso de educación de la sexualidad en el nivel básico superior en Ecuador}

El tema de la educación de la sexualidad se ha convertido en una de las principales preocupaciones de los gobiernos de muchos países de América Latina, incluido el de Ecuador. La educación de la sexualidad en Ecuador, continúa siendo un tema de discusión permanente. Por un lado, están las personas que creen que la promoción de métodos anticonceptivos originaría más proliferación de embarazos en adolescentes y de infecciones de transmisión sexual y por el otro lado, hay personas que creen que impartir este tipo de conocimientos resulta indispensable, ya que respetan los derechos a la salud y a la información, pero los estudios realizados no son suficientes al respecto.

Para realizar el análisis histórico del proceso de educación de la sexualidad en el nivel básico superior en Ecuador, se tuvieron en cuenta cuatro indicadores:

1) Concepción de la educación sexual (normativas legales existentes, presencia de programas, institucionalización de dichos programas). 
2) Temas o contenidos que se tratan prioritariamente para la educación de la sexualidad.

3) Vías que se utilizan para educar sexualmente a los adolescentes.

4) Alternativas de acción empleadas para la prevención del embarazo precoz.

Del mismo modo se consideraron tres hitos histórico-pedagógicos que marcan el tránsito de los períodos históricos delimitados por la autora, referidos a la educación de la sexualidad en el nivel básico superior en el contexto ecuatoriano. Estos son: la creación de la cátedra de Educación Sexual en la Facultad de Filosofía, Letras y Ciencias de la Educación de la Universidad de Guayaquil, en 1974; la creación del Plan Nacional de Educación de la Sexualidad y el Amor, que posteriormente fue elevado a la categoría de Programa, en el año 2000, con el decreto 3152. Finalmente, el establecimiento del acuerdo ministerial 403, que institucionaliza la educación de la sexualidad en todos los planteles del país, ya sean fiscales, particulares, fiscomisionales municipales del Ecuador en los niveles educación básica y bachillerato; coincidentemente con el año en que se implanta el plan decenal de educación 2006-2015.

A continuación, se describen los períodos delimitados por los autores, a partir del análisis realizado.

Primer período (1974-1999). Iniciación de la educación de la sexualidad formalizada en el Ecuador. En el año 1974, se crea la Cátedra de Educación Sexual en la facultad de Filosofía, Letras y Ciencias de la Educación de la Universidad de Guayaquil, hecho que despertó muchas críticas en la sociedad civil, tanto a favor como en contra, considerándose que la sociedad ecuatoriana es bastante conservadora y tiene muchos tabúes con respecto a este tema. En el año 1998 comienza a cobrar relevancia la educación de la sexualidad con el Plan Nacional de Educación para la Sexualidad y el Amor (PLANESA), el cual, entre otros objetivos incluyó en el currículo nacional de estudios de la educación básica la "Educación para la sexualidad".

Sin embargo, en sus inicios no se le brindó la suficiente importancia, especialmente a nivel de las instituciones educativas fiscales y municipales, ya que no se capacitó lo suficiente a los docentes para la asunción de esta responsabilidad con verdadera vocación y sobre todo con el nivel profesional que el caso requiere, para alcanzar los objetivos planteados.

Por ser este primer período la iniciación de la educación de la sexualidad en Ecuador, no se evidencian mayores aportes teóricos y concepciones de la educación de la sexualidad, no 
existieron bases legales para que se convierta en una política educativa a nivel nacional, solo se evidencia la presencia de un programa aislado con escaso apoyo institucional. Los temas o contenidos que se trataron en este período no fueron de mayor impacto, las vías utilizadas para educar sexualmente a los adolescentes eran únicamente textos muy conservadores que los docentes los utilizaban con mucha reserva y temores y en cuanto al abordaje de alternativas de acción empleadas para la prevención del embarazo, estas eran casi nulas.

Segundo período (2000-2005). La educación de la sexualidad sustentada en el impulso a los programas educativos nacionales. En el año 2000, con el Decreto 3152, se aprueba la creación del Plan Nacional de Educación de la Sexualidad y el Amor, que luego fue elevado a la categoría de Programa.

En el año 2005, mediante Decreto Ejecutivo número 2717, se promulga la Política Nacional de Salud y los Derechos Sexuales y Reproductivos. De la misma manera en Ecuador, mediante acuerdo ministerial del 23 de Septiembre del año 2005, se establece al 26 de septiembre de cada año como el "Día de la Prevención del Embarazo en Adolescentes". Con todos estos antecedentes e imbuidas, cada vez más, las instituciones del Estado acerca de esta problemática, en el año 2006, el Congreso Nacional de ese entonces, decidió aprobar una resolución en la que se permitía que se impartiera la enseñanza de temas sobre sexualidad en los colegios del Ecuador.

En resumen se puede decir, que en este período se concibió la educación de la sexualidad con mayores recursos, se nota la presencia de normativas legales que brindaron apoyo e impulso a los programas educativos nacionales, los cuales se institucionalizaron, los temas o contenidos que se trataron en este período tuvieron un componente más educativo y con un fuerte componente de salud y educación de la sexualidad, se utilizaron textos especializados y materiales digitales como vías para educar sexualmente a los adolescentes y por primera vez se empezaron a tratar temas de anticonceptivos y el uso del preservativo como alternativas de acción empleadas para la prevención del embarazo precoz. Sin embargo, las acciones de prevención sugeridas aún están centradas en el marco de la salud y no alcanzan los niveles necesarios en el orden de la educación y el desarrollo integral de la personalidad. En concordancia con lo anterior, las acciones de intervención socioemocional apenas son consideradas. 
Tercer período (2006-actualidad). Institucionalización de la educación de la sexualidad en la educación básica superior. En el año 2006 se establece el Acuerdo Ministerial 403, que dispone la institucionalización de la educación de la sexualidad en todos los planteles del país, ya sean fiscales, particulares, comisionales municipales del Ecuador en los niveles de educación básica y bachillerato, sin embargo, el $40 \%$ de los planteles del país no cumple esta normativa (Educare, 2008).

En ese mismo año se crea el Plan Decenal de Educación 2006-2015. Este, en su política número 6, titulada: "Mejoramiento de la calidad y equidad de la educación", incorpora la educación de la sexualidad (Ministerio de Educación y Cultura, 2006). Desde el año 2007, los ministerios de Salud del Área Andina declararon esta como una problemática prioritaria a nivel de la región y se construyó un Comité Andino de Prevención de Embarazo Adolescente; a la vez se construyó el Plan Andino y el Plan Nacional, los cuales posibilitan un trabajo integral e intersectorial en cuatro líneas estratégicas, las cuales son:

1. Fortalecimiento de una línea de base, investigaciones y sistema de monitoreo y evaluación.

2. Fortalecimiento de servicios de atención para adolescentes en salud y educación.

3. Participación juvenil y de adolescentes.

4. Abogacía y alianzas.

En consecuencia de la citada política, el 8 de marzo de 2007, mediante Acuerdo Ministerial número 089, se establece la prohibición a las autoridades educativas institucionales de expulsar, suspender o negar matrícula a estudiantes que se hallaren en situaciones de embarazo.

Posteriormente, en el año 2008, mediante Acuerdo Ministerial número 062, del 26 de febrero del ya citado año, se institucionaliza el Plan Nacional para la Erradicación de los Delitos Sexuales en el Ámbito Educativo, de igual forma en ese mismo año, el 21 de noviembre, mediante el Acuerdo Ministerial número 436, se prohíbe a las instituciones educativas solicitar pruebas de salud vinculadas al VIH/SIDA a los estudiantes y el 10 de diciembre de este mismo año se promulga el Acuerdo Ministerial número 482, que dispone la ejecución del Plan Nacional para combatir la trata, explotación sexual, laboral y otros medios, así como garantizar el derecho a la educación a víctimas de tratas de personas en el ámbito educativo. 
Ante toda esa efervescencia por difundir la educación de la sexualidad, es interesante recalcar que, en el currículo nacional poco a poco desde el año 2008 hasta el 2012, se han ido dando mayores espacios a los temas de educación sexual desde los ejes transversales en las asignaturas y en algunas instituciones educativas se ha comenzado tímidamente a aceptar como asignatura de la malla curricular necesaria para la formación del estudiante, pues estos temas constituyen una realidad del ser humano que debe ser abordada y educada desde las edades tempranas, sin tabúes que limiten el desarrollo integral del individuo.

Aunque la educación de la sexualidad en el Ecuador no está completamente consolidada y aceptada por todos los agentes que deben favorecerla, todavía existe la duda de si debe ser abordada como eje transversal o como un espacio curricular específico, en el que se considere, entre otros factores, la etapa de desarrollo de los niños y adolescentes, sus necesidades, intereses y derechos, el nivel educativo y la formación y capacitación de los docentes para desarrollar esta tarea en las instituciones educativas del país. En los casos en que es concebida como eje transversal, no se tiene apenas una noción elemental de qué significa ello.

Ante lo expuesto, se puede decir que en este tercer período ya se concibe la educación de la sexualidad desde una perspectiva diferente: existe una legislación más completa, existen programas institucionalizados en todos los niveles educativos, los temas o contenidos tratados tienen un cierto componente pedagógico y se utilizan vías más didácticas e interactivas para educar sexualmente a los adolescentes, enfocándose alternativas de acción más directas para la prevención del embarazo precoz.

Sin embargo, aún se advierte la pobre sustentación de la educación de la sexualidad de los adolescentes, como eje transversal curricular. Por otro lado, se aprecia una débil integración de los diferentes agentes sociales involucrados en la educación de la sexualidad en el nivel básico superior, en aras de educar para una sexualidad responsable y feliz, incluidos los propios educandos. Ocurre además que la acción tutorial ha sido poco abordada como recurso para incidir en la educación de la sexualidad y la prevención del embarazo precoz. La prevención no se concibe en términos de profilaxis y promoción del desarrollo humano, minimizándose el papel de la educación socioemocional para la prevención educativa de carácter primario. 
Enfocada la evolución histórica en estos tres períodos, se evidencia que en el Ecuador, se han realizado importantes esfuerzos con la finalidad de plasmar un currículo educativo que incorpore el tratamiento y abordaje de la educación de la sexualidad integral, presentándose informes de todos estos avances en esta temática, en conferencias, eventos y encuentros importantes a nivel nacional e internacional y se logra así impulsar el que se firmen importantes acuerdos internacionales aprobados por consensos en Conferencias $y$ Convenciones Internacionales.

Además, en esta materia a nivel mundial se han dado importantes pasos que han facilitado los cambios a nivel nacional, entre los que merece ser destacado la realización de la Convención de Derechos Humanos, que identifica los derechos culturales, sociales, económicos y políticos y determina que la familia, como un grupo fundamental de la sociedad y medio natural para el crecimiento y el bienestar de todos sus miembros, debe recibir protección y asistencia necesaria para poder asumir plenamente sus responsabilidades dentro de la comunidad.

De esta manera se analiza la evolución histórica que ha tenido el proceso de educación de la sexualidad en Ecuador en el nivel básico superior. A modo de resumen, se puede decir que es a partir de la última década del siglo XX, que recién se empieza a hacer conciencia sobre esta problemática y las organizaciones gubernamentales y no gubernamentales empiezan a emprender acciones correctivas en el orden legal inicialmente, hasta llegar luego a concebir procesos metodológicos en las instituciones educativas, para abordar de forma efectiva esta realidad que está afectando a gran parte de la población estudiantil en el país. A continuación, se develan las principales tendencias históricas que se derivan del anterior análisis.

\section{Tendencias de la educación de la sexualidad en el nivel básico superior ecuatoriano}

- Se aprecia, respecto a la concepción de la educación de la sexualidad, un movimiento que va desde la presencia de un programa aislado con escaso apoyo institucional, provisto de un enfoque espontáneo, asistemático y fragmentado en el primer período, hasta la institucionalización -en el período actual- de la educación de la sexualidad en todo el territorio ecuatoriano, vista ya bien como asignatura o como eje transversal curricular, aunque esto último aún no se sustenta teóricamente de modo coherente, ni se traduce convenientemente en las prácticas educativas. 
- Respecto a los contenidos tratados como parte de la educación de la sexualidad, se transita desde temas escasos y de mínimo impacto, hasta el tratamiento de la maternidad/paternidad, la violencia y el abuso sexual, el embarazo precoz adolescente y sus consecuencias, la fecundidad, los derechos del adolescente en materia de sexualidad. Se continúa manifestando la necesidad del abordaje de una educación de la sexualidad integral, que considere a la sexualidad como componente primordial y consustancial a la vida del sujeto.

- En relación con las vías para educar sexualmente durante la etapa adolescente, se transita desde el uso restringido y secreto de algunos textos, por considerarse la sexualidad y su educación como tema tabú, hasta la concreción de programas interventivos, conferencias, cursos, talleres, eventos y encuentros importantes a nivel nacional e internacional, como vías y alternativas para socializar e incidir en la educación de la sexualidad, como parte de la formación integral de los adolescentes. Sin embargo, subsiste la falta de innovación e integración en torno a las vías para concebir y llevar a cabo la educación de la sexualidad.

- Respecto a las acciones destinadas a prevenir el embarazo precoz, estas apenas se realizaban en el período inicial o no se efectuaban al menos, con un carácter formal, para realizarse de un modo más sistemático, como un fin mismo de la educación de la sexualidad, en el momento actual, en el contexto ecuatoriano. Cabe decirse, no obstante, que a pesar de lo expresado, la prevención sigue estando más enfocada en el componente biológico de la sexualidad, que en la educación de la emocionalidad, por lo cual no se logran cambios profundos y duraderos que determinen un comportamiento sexual más responsable de los estudiantes de estas edades.

A continuación se realiza un abordaje de los enfoques epistemológicos de este proceso, para poder analizar su incidencia en la prevención de embarazos precoces en estudiantes adolescentes. 


\subsection{El proceso de educación de la sexualidad en estudiantes del nivel básico superior}

La educación, categoría eterna de la sociedad, en todas sus modalidades está dirigida a la formación del ser humano como un ser social, ya que permite que el mismo se apropie de manera personalizada de su cultura construida por generaciones que le antecedieron. La cultura a su vez, lo prepara y desarrolla para tener una vida satisfactoria y positiva en las condiciones histórico-culturales que le corresponde vivir a cada individuo. De manera que todo acto de educación se encamina a la formación de la personalidad del individuo.

A partir de esta aseveración, se comparte el criterio dado por González F. (1995) al definir la personalidad como "una organización estable y sistémica de los contenidos y funciones psicológicas que caracterizan la expresión integral del sujeto en su funciones reguladora y autorreguladora del comportamiento" (p.19).

En la formación de la personalidad, constituye un referente importante la sexualidad, la cual ocupa un lugar privilegiado, ya que este es un aspecto fundamental en la vida de los seres humanos. Su objetivo es la relación humana, el conocer sus dimensiones comunicativas, sentimentales, afectivas, placenteras y también reproductiva. Su desarrollo es un proceso integral, donde interactúan los aspectos biológicos, psicológicos, culturales, ecológicos y socioeconómicos.

Existen en el contexto internacional y nacional numerosos científicos y pensadores interesados en el tema de la sexualidad; así, (Freud, 1902; Ellis, 1910; Martín, 1987; Master y Johnson, 1987; Proyecto Harimaguada, 1989; Arriagada, 1990; Aller, 1991; González y Castellanos, 1997; OPS/OMS, 2000), han conformado sus definiciones al respecto, en las que con independencia de sus posiciones teóricas, coinciden en comprender la sexualidad como un hecho de vida y parte inseparable de la personalidad.

En este sentido e intentando aclarar mejor las características de la sexualidad humana en su vínculo con la personalidad, la Organización Panamericana de la Salud en conjunto con la Asociación Mundial de Sexología (2 000) consideran a la sexualidad como:

Una dimensión fundamental del hecho de ser un ser humano, basada en el sexo, incluye al género, la orientación sexual, el erotismo, la vinculación afectiva, el amor, la reproducción. Se experimenta, se expresa en forma de pensamientos, fantasías, 
deseos, creencias, actitudes, valores, actividades, prácticas, relaciones y roles. La sexualidad es el resultado de la interacción de factores biológicos, psicológicos, socioeconómicos, culturales, éticos y religiosos o espirituales (p. 6).

De este análisis se asume que, tanto la personalidad como la sexualidad se forman, desarrollan y expresan a partir de la "interacción del ser humano con el mundo que le rodea, con la realidad social histórico concreta en el proceso de la actividad y mediante él y en la comunicación " (Castellanos y González, 1995, p. 15). Independientemente de que cada persona experimenta y manifiesta la sexualidad de forma individual, única e irrepetible, a partir de sus sentimientos, actitudes, valores y convicciones con relación a ella, esta no debe ser caracterizada considerando únicamente las experiencias individuales, sino también la influencia de los factores sociales y fundamentalmente la que ejerce la cultura del medio en que se desenvuelve el ser humano.

Se coincide, además, con Castellanos, (1994), en lo referido a la relación que existe entre sexualidad y personalidad, una relación orgánica e indisoluble. La autora considera que en esta relación es preciso tener en cuenta la posición e importancia que ocupa la sexualidad dentro del sistema de la personalidad y que esta a su vez se sustenta en la concepción que se asuma acerca de la personalidad, de los factores que la determinan y de las fuerzas motrices que intervienen en su formación y desarrollo.

A juicio de la autora, en el establecimiento de la relación sexualidad-personalidad, se hace necesaria la diferenciación entre los conceptos sexo y sexualidad. El término sexo se refiere de forma específica a las características biológicas y físicas que identifican a un individuo como femenino o masculino en el momento del nacimiento, las que le confieren determinadas funciones ante el otro sexo, especialmente en el acto sexual y en la reproducción. (Castellanos, 1994).La sexualidad es considerada como "el conjunto de fenómenos y procesos de la vida psicosexual que se encuentran orgánica y funcionalmente integrados al sistema general de la personalidad" (Ruiz, 1996, p. 12).

En el caso de la sexualidad, la autora coincide con el análisis realizado por Castellanos (1994) en su tesis doctoral, al plantear que:

La sexualidad, es entonces un aspecto propiamente psicológico de la vida sexual, donde se conjugan procesos, prioridades y formaciones psíquicas que están en la 
base del establecimiento de formas de conducta y de relación social interpersonal y que en el transcurso de su desarrollo, adquiere el carácter de fenómeno personológico, de manifestación vital de la personalidad. (p. 24)

Por su parte, la sexualidad es definida por el Proyecto de Educación Sexual del Ministerio de Educación (2003), como:

Una manifestación psicológica rectora de la personalidad, que tiene como núcleo el sentimiento y la conciencia de la propia masculinidad, feminidad o ambivalencia. Esta interviene en la regulación directa o indirecta de todas las manifestaciones comportamentales del ser humano y como manifestación de la personalidad, es un fenómeno complejo de carácter biopsicosocial del ser humano.

García, (2015) coincide con la definición de sexualidad anteriormente expresada y al respecto asevera que, todo fenómeno psicológico es, desde el momento mismo de su génesis, el resultado de la dinámica de los procesos internos y externos que actúan sobre el individuo a lo largo de la vida y que, entre otros, los de naturaleza biológica y social juegan un papel decisivo.

La autora de la presente tesis destaca que en ambas definiciones la conciben como fenómeno complejo, dado por su naturaleza biopsicosocial, el cual se expresa en la personalidad de cada sujeto de manera única e irrepetible. Sin embargo, se asume la definición de Castellanos (2003) al definir la sexualidad como una "manifestación psicológica rectora de la personalidad, que tiene como núcleo el sentimiento y la conciencia de la propia masculinidad, femineidad o ambivalencia, cuando no se identifica plenamente con los patrones de su sexo" (p.172).

En los momentos actuales la educación de la sexualidad es considerada como una necesidad y un derecho inalienable, porque permite establecer el vehículo esencial para favorecer desde una perspectiva científica, el crecimiento de las personas como seres sexuados. Indistintamente son empleados los términos Educación sexual y Educación de la sexualidad para referirse al mismo objeto. Tómese en cuenta que la terminología científica aumenta cada vez más, muchas coincidentes y muchas divergentes, según la teoría en que se enmarcan y según los criterios que las sustentan. Un mismo objeto es proyectado en su definición desde diferentes puntos de vista, atendiendo a la escuela a la que pertenece el investigador, a la 
época y a la teoría que perfila. Se asume en esta tesis el segundo término por su carácter sustantivo, lo cual favorece develar todos los indicios sustanciales que este posee.

Por otro lado, la autora considera que la educación de la sexualidad debe ser asumida como un proceso pedagógico, ya que en ella interactúan aspectos biológicos, psicológicos, sociales, culturales y políticos que en conjunto desarrollan funciones indispensables para la vida de los seres humanos, tales como la función afectiva, erótica, reproductiva y comunicativa de la sexualidad.

Respecto a la educación de la sexualidad o educación sexual (término más empleado), existen diferentes concepciones, que aunque todas tienen un alto valor, no es posible apreciar en sus definiciones, de forma integral la unidad entre lo biológico, lo psicológico y lo social, entre lo social y lo individual, entre lo cognitivo y lo afectivo y la relación entre libertad y responsabilidad en una misma concepción. Por lo general está presente una u otra perspectiva, lo que afecta la visión educativa integral que esta esfera de la personalidad necesita.

González y Castellanos, (2003) definen a la educación de la sexualidad desde un Enfoque Alternativo y Participativo como:

El proceso activo que potencia al individuo para el encuentro libre, pleno y responsable con el otro sexo y con la propia sexualidad, en correspondencia con sus necesidades y las del contexto, garantizando el protagonismo y la capacidad de elegir los límites personales de la sexualidad, así como el respeto a la de las personas con que se relaciona. (p. 161).

Esta conceptualización es contentiva de las cualidades y relaciones, que deben distinguir y manifestarse en el proceso educativo de la sexualidad, al enfatizar en el fomento de relaciones positivas entre ambos sexos, en correspondencia con los principios morales de la sociedad, basados en la igualdad, el respeto, la ayuda mutua, así como en el desarrollo en el individuo de actitudes, valores, convicciones y conocimientos que le permitan comprender su sexualidad como parte y expresión de su personalidad.

Al decir de Molina, Torrivilla, Irsia y Sánchez, (2011), la educación de la sexualidad constituye un proceso formativo, dinámico y permanente, que promueve el desarrollo integral del ser humano, al mismo tiempo que contribuye al desarrollo social de su comunidad. Los trabajos 
investigativos antes mencionados y otros, como los correspondientes a Roa, (2012), Castellanos y González, (2014), González y Castellanos, (2014) realizados en el contexto cubano en los últimos tiempos, sobre el tema de educación de la sexualidad, han demostrado que las problemáticas del embarazo precoz, las infecciones de transmisión sexual en los adolescentes y el abandono de estudios continúan siendo problemas aún no resueltos.

La educación en todas sus modalidades está dirigida a la formación del ser humano como un ser social, ya que permite que el mismo se apropie de manera personalizada de la cultura construida por generaciones que le antecedieron, y esta a su vez lo prepara y desarrolla para tener una vida satisfactoria y positiva en las condiciones histórico-culturales que le corresponde vivir a cada individuo. Una de estas modalidades corresponde a la educación de la sexualidad, entendiéndose por esta: un proceso de preparación de las personas, a lo largo de su vida, para el encuentro libre, responsable y pleno de la sexualidad (desde las dimensiones y funciones de la misma) y con la de los demás (Fernández y López, 2012), definición asumida por la autora de la presente tesis. Las dimensiones reconocidas por las investigadoras de referencia son la biológica, la psicológica, la sociocultural y la ética. Las funciones son la comunicativa, afectiva, reproductiva y erótica (Fernández y López, 2012). La educación de la sexualidad debe fomentar la libertad de elección, lo cual implica ser consciente y responsable de la trascendencia y consecuencia de los actos sobre sí y las otras personas. La formación de la sexualidad sobre los principios enunciados, solo se alcanza cuando se imbrica lo personal con lo social, la libertad con la responsabilidad. La educación de la sexualidad es parte orgánica, inalienable de la preparación del ser humano para la vida, del aprender a ser, mediante la cual cada sujeto tiene que aprender a ser sexuado, a construir de forma personalizada su masculinidad y femineidad y a apropiarse creativamente de valores, conocimientos y habilidades, así como de recursos personológicos eficientes, con vistas a vivir su sexualidad de modo autodeterminado y enriquecedor de sí mismo y de su contexto. El estudio del desarrollo psicosexual del sujeto, desde su temprana infancia hasta su adultez, revela cómo se manifiesta la influencia socio-cultural sobre la sexualidad, principalmente a través de la familia, así como el papel de la propia actividad del sujeto en comunicación con los adultos significativos, en el proceso de apropiación de esta herencia histórica social. Desde esta visión la educación de la sexualidad sistematiza científicamente buena parte de estas influencias, colocando al sujeto en el centro, como protagonista de su actividad de aprendizaje social. La educación de la sexualidad puede considerarse como una preparación del niño y el 
adolescente para la vida adulta independiente, con los recursos de personalidad que posibiliten al individuo dar solución satisfactoria a los diversos problemas que le pueda plantear la vida; y lograr su realización en lo personal, lo familiar y lo social, aspectos estrechamente relacionados. Esta labor va dirigida a influenciar educativamente en la capacidad de amar, contribuir a ese conjunto de sentimientos, motivaciones y actitudes; así como la capacidad de dar amor, y el disfrute de la felicidad en el amor. Significa también, preparar al niño y al adolescente para que desempeñen su futuro papel como padres. Al valorar las diferentes alternativas de los países latinoamericanos, se aprecia que los proyectos auspiciados por el Fondo de las Naciones Unidas para la Población (UNFPA) tienen en común que priorizan la educación formal de los adolescentes. Sus componentes principales comprenden las acciones de educación formal con los estudiantes, capacitación a los docentes así como acciones de comunicación social, formando - al menos en teoría - una tríada que se intercomplementa. El enfoque de programas o proyectos destinados a extensos grupos de sujetos es común a varias experiencias latinoamericanas. Los proyectos se insertan en las corrientes del cambio educativo. Se asocian a la descentralización de los sistemas educativos presionados por la necesidad de flexibilizar los currículos, darle cabida a las necesidades locales e incrementar la participación de los agentes educativos de la base en el desarrollo de la educación formal. Los programas, estrategias y metodologías de educación de la sexualidad que surgen en esta etapa de cambios en los sistemas educativos pueden ser más flexibles, pero surgen diversas dificultades para mantenerlos o generalizarlos, pues la política educativa estatal y los propios recursos disponibles no logran ayudar a todos los centros necesitados. En varios de los países de la región pasan a primer plano las Organizaciones No Gubernamentales (ONG), cuyo papel se acrecienta para tratar de llenar los vacíos que se detectan en el sistema educativo. Es importante destacar la inspiración que han dado las experiencias latinoamericanas en Educación Popular, así como en la investigación acción participativa, lo que impone su sello a varios programas actuales de educación de la sexualidad. La nueva postura significa construir junto a los sujetos de la educación de la sexualidad los espacios, los contenidos, las modalidades de la acción educativa en sexualidad. Se aprecia que las corrientes pedagógicas y las políticas educativas dieron la posibilidad de que varios programas de educación de la sexualidad en Ecuador, fueran diseñados desde las necesidades de los grupos adolescentes identificados, en lugar de someter todas las escuelas a un programa rígido. Sin embargo, solo unos pocos proyectos son consecuentes con la 
anunciada flexibilidad y aseguran realmente el protagonismo de los grupos humanos que constituyen la comunidad educativa.

Por ejemplo, la propuesta de contenidos y materiales para un extenso número de escuelas o de territorios, determina que se lleve a cada comunidad escolar una preconcepción sobre la sexualidad, sus enfoques y métodos, que se impone desde un supuesto saber. Se corre así el riesgo de ignorar las necesidades de cada grupo humano; se limita su protagonismo en la conducción de su propia educación de la sexualidad.

Según Castro, (2006), se puede considerar que el trabajo de educación de la sexualidad en la escuela atraviesa por varios momentos, decisivos para materializar un enfoque participativo, y que están estrechamente relacionados, los cuales son asumidos por la autora de esta investigación:

- La caracterización de las dificultades, las necesidades, entre otros.

- La elaboración de las acciones para resolverlas.

- La ejecución del plan de acciones.

- El seguimiento, la evaluación del resultado de estas acciones.

El trabajo de educación de la sexualidad con este enfoque implica un proceso abierto, progresivo, es decir, que se va enriqueciendo paulatinamente con los primeros resultados alcanzados, y por tanto con la mayor preparación e implicación de los agentes comunitarios interesados. Asegurar la participación activa de los sujetos de la educación de la sexualidad en un proyecto significa crear las condiciones y prepararlos para que protagonicen la construcción y las acciones en la educación de la sexualidad, para que sean parte de la toma de decisiones en este terreno de su vida y educación.

Los sujetos de la educación de la sexualidad, los adolescentes, jóvenes, sus padres, incluso los propios docentes-tutores, cuyas funciones están tipificadas en el artículo 56 del Reglamento a la Ley de Educación Intercultural de Ecuador, Registro Oficial No. 754, (2012), no esperan orientaciones o materiales para adoptar una posición ante la sexualidad. Viven sus actividades y relaciones interpersonales cotidianamente, ahí mantienen sus relaciones de género, expresan su aspiración real, la equidad, como reflejo del condicionamiento histórico de los valores. La caracterización del proceso de educación de la sexualidad en estudiantes del nivel básico superior, 
permite descubrir, cuáles son los problemas y las necesidades de la sexualidad y su educación en estas edades. También indaga los recursos humanos y de otro tipo, que se pueden convocar o disponer para resolver los problemas detectados. La caracterización implica identificar problemas educativos tal y como son vividos y sentidos por las personas, tal y como afectan su vida sexual, de pareja, familiar y reproductiva e impiden el pleno crecimiento y realización individual y colectiva. Pero estos problemas no pueden ser examinados al margen de su contexto. Por tanto, la etapa de la caracterización lleva también implícita la evaluación y caracterización de la escuela, la familia y la comunidad, con vistas a establecer relaciones causales e interpretar los intercondicionamientos. (Castro, 2006) La finalidad de una caracterización de la situación existente en determinados aspectos del comportamiento sexual no radica en acumular datos, sino en llegar a la comprensión de la realidad de los adolescentes en sus diferentes contextos de actuación, lo que permite posteriormente la solución participativa de los problemas detectados. Lo que más contribuye al enriquecimiento de los sujetos es comprometerlos en un proceso de autoconocimiento, hasta arribar a un autodiagnóstico, tal como lo plantean algunos autores que preconizan la educación popular. Se abre paso la concepción del diagnóstico participativo, en contraposición de la evaluación externa que reproduce relaciones de dominación-sumisión.

\subsection{La prevención del embarazo precoz en estudiantes del nivel básico superior}

La problemática planteada en esta fase de la investigación se centra fundamentalmente, sobre el eje del trabajo preventivo del embarazo precoz y se especificó en el contexto ecuatoriano. En consecuencia, se ofrece una propuesta, de modo tal que coadyuve a establecer una política social hacia acciones concretas para evitar el embarazo no deseado en adolescentes, toda vez que se han corroborado los trastornos que estos traen para los estudiantes en este momento de su desarrollo.

El embarazo precoz, se asume como aquel estado de gravidez de una fémina, que se produce entre los inicios de la adolescencia (pubertad), durante y al final de esta. Por lo general, se establece entre los 10 y 19 años. También se les adjudica este término a aquellas mujeres que 
no han alcanzado la edad adulta legal, en correspondencia con las leyes de cada país o en el caso en que estas se encuentran bajo la dependencia de sus padres.

En algunos países como China, la maternidad está controlada por el gobierno y cada pareja solo puede tener un niño. En otras culturas pertenecientes a países de África, embarazo es sinónimo de salud, riqueza y prosperidad. En Brasil, donde hay un escaso control de la natalidad y donde la planificación familiar y la educación de la sexualidad son todavía cuestiones muy discutidas y poco claras, el embarazo supone un grave problema social que hay que resolver.

En Ecuador, dos de cada tres adolescentes de 15-19 años sin educación, son madres o están embarazadas por primera vez. Las proporciones de maternidad adolescente son hasta cuatro veces más altas entre las que no tienen educación (43\%), comparadas con las de niveles educativos más altos ( $11 \%$ con secundaria completa). Los años de escolaridad promedio de nuestros jóvenes es de apenas 6.8 años, de un total de 9 años obligatorios. Solo el $8.3 \%$ de la población juvenil completa sus estudios universitarios.

El 57.8\% de mujeres de entre 15 y 24 años, eran estudiantes cuando supieron de su primer embarazo e interrumpieron sus estudios, de ellas tan solo el $16.5 \%$ volvió a estudiar y el $41.3 \%$ en promedio no volvió a hacerlo. En este sentido, la Organización Mundial de la Salud (OMS) considera que el embarazo precoz es un problema de cultura e insta a las jóvenes a retrasar o prevenir los embarazos demasiados jóvenes o los embarazos no deseados ofreciendo campañas para que las jóvenes aprendan a prevenirlos.

La Organización Mundial de la Salud (OMS) establece la adolescencia entre 10 y 19 años. Según Contreras, R. y Martin, D. (2011), la mayoría de los embarazos en adolescentes, son considerados como embarazos no deseados, provocados por la práctica de relaciones sexuales sin métodos anticonceptivos.

El estado de embarazo en etapas tempranas produce en la pareja de adolescentes un cambio emocional, donde, en la mayoría de los casos, se produce depresión producto de que en dicho estado, la pareja ve paralizados sus proyectos de formación o de vida, por la incapacidad de estudiar o trabajar. Frecuentemente es la hembra la más afectada.

Dentro de las posibles causas que influyen en la aparición de los embarazos no planeados se mencionan factores personales, familiares y sociales. Entre los más sobresalientes están la 
limitada educación de la sexualidad, las cuestiones de género, la doble moral sexual, la baja autoestima, el acceso limitado a servicios especializados de salud sexual y reproductiva destinados a los jóvenes, la escasa prevención con que estos llevan a efecto sus prácticas sexuales, el bajo uso de métodos anticonceptivos seguros, así como la edad de la primera experiencia sexual y como marco el nivel socioeconómico.

Se requiere, pues, de la prevención del embarazo en esta edad, mediante medidas que se tomen de manera anticipada, para evitar que los estudiantes jóvenes caigan en dichas situaciones limitantes para la vida. Para los autores Vaillant, M. (2012) y Revuelta, C. (2013) por la alta incidencia de ocurrencia, este problema social, se ha convertido en un problema de salud pública que afecta a la sociedad en su conjunto. Pero la realidad ha probado que este fenómeno involucra a toda la sociedad, en particular a los educadores en sus respectivas escuelas.

De manera tradicional, el término "prevención” se utiliza más comúnmente en contextos médicos, psicológicos, clínicos, del tránsito, de seguridad laboral, en determinados casos de catástrofes o fenómenos naturales adversos, contaminación atmosférica, etc., que en el ámbito educativo. Hoy se emplea en diversas disciplinas científicas con la finalidad de actuar antes de que ocurra un problema o en los primeros momentos de su aparición, a fin de evitar que cause un deterioro mayor (Núñez, O., 2011).

Según la ONU, la prevención es la adopción de medidas encaminadas a impedir que se produzcan deficiencias físicas, mentales y sensoriales o a impedir que las deficiencias, cuando se han producido, tengan consecuencias físicas, psicológicas y sociales negativas. Algunos autores coinciden en definir la prevención como aquel conjunto de procesos que estimulan el desarrollo humano y que con ello tratan de evitar la aparición y proliferación de problemas socialmente relevantes. Igualmente la prevención Integral se considera un enfoque que incentiva procesos de construcción cultural alternativa propicios al afianzamiento de actitudes que favorezcan el protagonismo social, el desarrollo personal y grupal, la amistad, la solidaridad, el diálogo y la convivencia, en búsqueda de la prevención del consumo de sustancias adictivas y otros problemas socialmente relevantes.

Generalmente, en el ámbito educativo las acciones con carácter preventivo se utilizaban y aplicaban en el área de la Educación Especial; sin embargo, el concepto mismo de prevención en el área educativa adquiere una dimensión y alcance más abarcadores, pues se coloca en el 
centro de toda la actividad docente como estilo y práctica del trabajo pedagógico. La importancia del trabajo de prevención se sustenta en la práctica educacional, ya que muchas deficiencias pueden evitarse si se logra una eficiente atención primaria.

Por ello, la Organización de Naciones Unidas (ONU) en su Programa de Acción Mundial considera la prevención como un propósito central y como la adopción de medidas encaminadas a impedir que se produzcan deficiencias físicas, mentales y sensoriales, o a evitar que, de producirse, tengan consecuencias físicas, psicológicas y sociales negativas tales como la discapacidad y la minusvalía (Núñez, 1997, p.23).

A nivel internacional existen cuatro niveles de prevención (Núñez, 1997, p. 34):

El primer nivel también llamado prevención primaria, dirigido a tomar medidas cuando las deficiencias aún no han aparecido. Se aplica en un marco supuestamente sano compuesto por individuos de grupos de riesgo, o sea, individuos que presentan un mínimo importante de factores causales de orden biológico, psicosocial, económico y ambiental, los que en su conjunto podrían provocar una alteración determinada que afecte el desarrollo normal de las personas.

El segundo nivel denominado prevención secundaria, se aplica ante la aparición de enfermedades, la detección de alteraciones congénitas o en casos de accidentes, para evitar que surja una deficiencia, es decir, la pérdida o anormalidad de una estructura o función psicológica, fisiológica o anatómica, caracterizada por pérdidas o anomalías innatas o adquiridas, de carácter permanente $\mathrm{o}$, sencillamente temporales.

El tercer nivel de prevención, conocido también como prevención terciaria, se aplica a los individuos con deficiencias en la esfera psicológica y fisiológica para evitar el surgimiento de algún tipo de discapacidad. Se identifica con la rehabilitación, considerada como el sistema de acciones que se realizan con el objetivo de lograr que una persona con determinada deficiencia alcance un nivel funcional físico, mental y/o social óptimo, por lo cual se implementan una serie de medidas encaminadas a compensar la pérdida de una función o una limitación funcional.

Por último, el cuarto nivel de prevención o prevención cuaternaria, se dirige a personas discapacitadas para evitar el desarrollo de minusvalías. Se basa en la equiparación de 
oportunidades, o dicho de otro modo, en el proceso mediante el cual el sistema general de la sociedad se hace accesible para todos.

Sin dejar de reconocer el valor de este esquema conceptual, a juicio de esta autora la prevención debe concebirse con un criterio más integral, global y positivo que brinde la posibilidad de apreciarla como un sistema de influencias que deben ejercerse en el ámbito educativo antes de la aparición de las posibles dificultades, eliminando o atenuando las condiciones que las provocan.

En este mismo sentido, la autora considera significativo para la presente tesis lo aportado por la investigadora Díaz, (2001) al aseverar que la prevención educativa es:

Un proceso dialéctico, de orientación sistemática, anticipatorio, continuo y que atiende a la diversidad, que parte del diagnóstico sistémico y holístico del sujeto, dirigido conscientemente a la formación y fortalecimiento de cualidades, motivos, intereses, sentimientos, valores, capacidades intelectuales y actitudinales en los adolescentes, donde se integra lo curricular y familiar, en un contexto interactivo socializado( p.47).

Como resultado de lo temprano que está ocurriendo el comienzo de la relación sexual en los adolescentes, la autora considera, que debe actuarse desde el primer nivel de la prevención y proliferar investigaciones, donde se sienten patrones educativos para prevenir este fenómeno social, que está ocurriendo cada vez con una frecuencia y magnitud mayor en adolescentes. El tema de la educación sobre este tipo de relación entre adolescentes y jóvenes, debe comenzar desde edades tempranas, antes de las prácticas de conductas sexuales que los pongan en riesgo. El trabajo educativo que se realice debe ser de conjunto con todos los actores sociales, para lograr preparar a los adolescentes en el logro de cuidar su salud, para lograr mayor garantía en su desarrollo armónico integral (Vaillant, 2012).

La autora a partir del análisis realizado, considera que la prevención educativa a nivel primario se caracteriza por:

* Carácter de proceso y sistémico.

* Parte de un diagnóstico.

* Carácter orientador y sistemático. 
* Intencionalidad formativa.

* Enfoque personológico, al tener en cuenta la diversidad de los adolescentes.

* Tiene en cuenta el currículo, el contexto escolar, familiar y social en general.

Uno de los factores sociales que más influencia ha ejercido, ha sido la institución educativa, representada fundamentalmente en el rol que tiene el docente, que no siempre ha contado con la preparación necesaria para asumir esta tarea desde la orientación del proceso educativo. También resulta habitual que los padres y familias en general, no cuenten con una apropiada preparación en materia de educación de la sexualidad, que puedan extender a sus hijos. La educación de la sexualidad transmitida en épocas anteriores era muy limitada, con un alto contenido religioso y moralizante, que veía como único fin de la sexualidad la procreación, al ser ignorada su función placentera, y como fuente de comunicación y de relaciones humanas enriquecedoras.

Atendiendo al desarrollo social alcanzado en el mundo, y en especial, en Latinoamérica, en el proceso de educación de la sexualidad de los adolescentes para la prevención de los embarazos en esta edad, influyen diferentes tendencias, vistas como "posturas teóricas y metodológicas que se asumen ante el fenómeno educativo temporalmente en un contexto histórico-concreto y que se expresan como conceptualizaciones y prácticas educativas en el marco escolar" (Valera, 1999, p. 19).

La influencia que han ejercido estas tendencias, se manifiesta en distintos enfoques en los que indistintamente, en ocasiones, predominan o se combinan elementos de carácter tradicional y moderno. Entre estos enfoques se puede citar el represivo-moralizante, como uno de los de mayor incidencia en este proceso. Su influencia se basa fundamentalmente en los elementos tradicionales sobre la educación de la sexualidad, a partir de la imposición de dictados morales, de fuerte carácter religioso, de tradiciones patriarcales en la familia, con sus fuertes estereotipos sexuales, que se manifiestan frecuentemente en la represión y sanción a los adolescentes por cuestiones que resultan naturales y necesarias en estas edades, "a fin de "preservarlos" de los daños que pueden acarrearles los intercambios sexuales". (González, 1999, p. 8).

Por otro lado, la revolución sexual de los años sesenta y setenta del pasado siglo marcó pautas para el proceso de educación de la sexualidad en el mundo, a partir de la ocurrencia de 
acontecimientos trascendentales para el desarrollo social y sexual. La misma se propició por una pluralidad de factores, entre los que se destacan "la facilidad para obtener píldoras anticonceptivas; el movimiento de protesta entre adolescentes y jóvenes adultos; el resurgimiento del feminismo desde una óptica moderna y una mayor franqueza en las conversaciones y manifestaciones de orden sexual". (Masters y Johnson, 1987, p. 28). Del mismo modo influyeron los grandes descubiertos acerca del comportamiento sexual y la respuesta sexual humana.

Estos sucesos conllevaron a una visión diferente hacia la sexualidad, abriéndole paso al reconocimiento del placer como una de las funciones más importantes de la sexualidad. Surge así el enfoque hedonista como otra tendencia, la cual "reivindicó el placer como fin de la sexualidad coexistente con la función reproductiva, pero conscientemente separado de esta" (Castellanos, 1994; p.1), sin asumir, los riesgos de no educar simultáneamente al placer y la libertad con responsabilidad.

En la apertura de una nueva era para la sexualidad, en que la permisividad, el desprejuicio y la libertad la tipifican, surgen y se incrementan paulatinamente, inconvenientes sociales en materia de salud sexual y reproductiva, como la aparición del SIDA, el aumento de infecciones de transmisión sexual, embarazos precoces, abortos, maternidad y paternidad temprana, entre otras, que obligan a la toma de decisiones educativas al respecto, centradas en la transmisión de información al adolescente para prevenir y evitar estos riesgos; pero no lo colocan en el centro del proceso de su educación, de esta manera, surge otra tendencia en la educación de la sexualidad con adolescentes, basada en un enfoque informativo-preventivo.

Esta tendencia enfoca de forma limitada la actividad sexual, pues solo se circunscribe al ámbito de las relaciones íntimas de pareja. La misma promueve el uso de métodos anticonceptivos para evitar infecciones de transmisión sexual (ITS) y embarazos no deseados, y la abstinencia de relaciones sexuales fuera del matrimonio, y a pesar de que estos conocimientos son muy necesarios, sobre todo ante la constante amenaza de la pandemia del SIDA, se considera que se comete un gravísimo error y en ello se coincide con el criterio de René Behar de Huino cuando señala: "El error radica en un enfoque que señala la patología sexual en lugar de privilegiar los aspectos afectivos, placenteros, éticos y creativos de la sexualidad humana" (Behar de Huino, 1992, p. 23). 
La concepción patológica de la sexualidad que se propone evitar embarazos a temprana edad, corre el riesgo de que el educando establezca una relación asociativa entre la sexualidad y el peligro. En este sentido se señala que:

Una educación de la sexualidad con énfasis en lo preventivo, bajo la idea de evitar el embarazo o las infecciones de transmisión sexual, muchas veces deja de lado la transformación psicológica del adolescente, sus verdaderas ansiedades y conflictos, tanto con sus iguales como especialmente con su familia, y no contribuye a la formación de un comportamiento responsable, que precisamente pueda emplear los recursos anticoncepcionales y profilácticos disponibles en el medio (Castro y otros, 2002, p. 25).

Desde su visión de educación de la sexualidad, su carácter alternativo no limita la expresión de la sexualidad a la heterosexualidad o la procreación, sino que ofrece al sujeto opciones para vivirla libre y responsablemente, con respeto a su individualidad y al mismo tiempo considera, los problemas de los demás y los de su entorno. Plantea que esta debe ser basada en el diálogo, la tolerancia y la conversación en la que se brinde toda la información que los estudiantes necesiten y demanden conocer con el rigor científico requerido, de manera tal que promueva su implicación y compromiso con los objetivos educativos que parten de su propia vida cotidiana, así se propicia, que estos adquieran una significación personal que los motive a actuar en consecuencia. A su vez, para que esto fluya reclama la necesidad de preparar a los profesionales (educadores) encargados de la tarea, con el fin de posibilitar actitudes favorables, responsables hacia la sexualidad y la ética en las relaciones.

Al analizar las tendencias educativas en torno a la sexualidad que resultan de mayor interés por su influencia en la sociedad en general y en la educación en particular, se puede plantear que estas son la expresión de concepciones y acciones más o menos sistematizadas. Estas constituyen diferentes alternativas de cómo enfrentar el proceso educativo de la sexualidad y cómo hacerlo más efectivo, en correspondencia con los objetivos educativos generales y sociales. Por eso su conocimiento se hace útil y necesario, para poder definir con claridad lo que se quiere realizar en este campo, sin caer en posiciones eclécticas que puedan conducir a un debilitamiento epistemológico de la Pedagogía Sexual, como disciplina dedicada a los problemas concretos de la educación de la sexualidad. 
Sobre la educación de la sexualidad en adolescentes, existen investigaciones de tesis realizadas, que han contribuido con propuestas encaminadas a acciones preventivas hacia el embarazo precoz, entre ellas se encuentran las de (Cedeño, 2009; Moreira, 2009; Cordero, 2010; Estupiñán, 2011; Ballesteros, 2012; Mero, 2012; Morales, 2012; Carreño, 2013; Zambrano, 2013; Robles, 2013; Carvajal, 2013; Montenegro, 2013). Son elementos recurrentes en ellas: partir de las insuficiencias y deficiencias en el abordaje metodológico de la educación de la sexualidad en la educación básica ecuatoriana, enfatizándose en que existen fuentes teóricas para su tratamiento, que más bien el problema se centra en la deficiente formación docente para tratar estos temas desde la gestión pedagógica, lo que incide directamente en que los adolescentes no se caractericen por su responsabilidad ante la salud sexual y preventiva.

Cada una de estas investigaciones contribuye con información importante sobre las realidades que se viven en las instituciones donde se investigó, plantean estrategias, metodologías y proyectos de intervención para enfrentar esta problemática, desde una perspectiva emocional y afectiva, las cuales concluyen que son las raíces que originan el problema. En ellas se observa la ausencia de un diagnóstico participativo, con sentido educativo trascendente, en la medida en que posibilite a los directivos, docentes, estudiantes y a los padres, conocer mejor, valorarse adecuadamente y buscar alternativas de enfrentamiento a los desafíos vitales.

La educación tradicional se ha centrado en enseñar conocimientos, enfatizando en lo cognitivo, con olvido de la dimensión socio-afectiva y emocional. Sin embargo, se requiere que además de promoverse el desarrollo cognitivo, este debe complementarse promoviendo el desarrollo social y emocional. Ello sería, garantía de prevención de problemas de violencia, acoso y embarazo precoz, entre otros. La orientación educativa es un área trascendente cuando se trata de la educación de la sexualidad de niños, adolescentes y jóvenes. Y dentro de esta, la denominada orientación para la prevención y el desarrollo humano.

La orientación para la prevención y el desarrollo se propone la prevención en sentido amplio y el desarrollo personal y social. Estos se pueden considerar como fines de la orientación y de la educación en general. La convicción de que para ciertos problemas (incluidos los embarazos no deseados), la mejor solución es la prevención primaria, ha dado lugar a un énfasis en la prevención. Como complemento está el desarrollo humano, entendido como el desarrollo de la persona en todos sus aspectos (intelectual, cognitivo, social, y emocional). 
Justamente, la educación emocional (o socioemocional) constituye una forma de prevención primaria inespecífica. Se comprende como tal a la adquisición de competencias o herramientas personales y grupales, que se pueden aplicar a una multiplicidad de situaciones, tales como la prevención del consumo de drogas, la prevención del estrés, la violencia y el embarazo precoz, entre otras problemáticas. La prevención primaria inespecífica pretende minimizar la vulnerabilidad de la persona a determinadas disfunciones o advertir sobre su probable ocurrencia. Cuando todavía no hay disfunción, la prevención primaria tiende a confluir con la educación, para maximizar las tendencias constructivas y minimizar las destructivas (Bisquerra, 2003, 2006, 2009).

Educar en la sexualidad para la prevención del embarazo precoz implica que el adolescente asuma una actitud consciente y responsable del acto que realice, en la que prevalezca su determinación, sus criterios, sus valoraciones y sobre todo su autocontrol y autoestima.

La acción tutorial, tanto en la educación básica como en otros niveles educativos, debe dar respuestas concretas a los problemas del alumnado en relación con su desarrollo personal y social. Sin embargo, el analfabetismo emocional está en la raíz de muchos de los problemas más acuciantes de los adolescentes y no existe una tradición en programas de educación emocional para enfrentar las problemáticas comunes en estas edades de la vida. Es opinión de la autora, que una forma idónea de introducirlos sería a través de la acción tutorial.

La autora hace la anterior afirmación, ya que al decir de Barberá, en el proceso formativo de los adolescentes intervienen diferentes agentes que influyen en la calidad de este desarrollo social y cognitivo, pero uno de los más importantes es el tutor.[...] el rol que desarrolla o se le atribuye al tutor depende de la concepción del proceso de enseñanza y aprendizaje que tiene la institución en la que se ubica o también de la propia concepción del tutor sobre lo que es enseñar y aprender.

En este mismo sentido, Barberá, (s-a) enfatiza en que:

La ayuda pedagógica del tutor tiene, un componente de continuidad e interconexión que tiene por objetivo colaborar en la mejora del proceso de aprender (conceptos, procedimientos, actitudes y valores), mientras este se desarrolla y siempre que esta ayuda sea necesaria. (p.151).

Opinión a la que se afilia la autora de la presente tesis. 
Como resultado del análisis de las fuentes consultadas anteriormente, la autora considera que el tutor, es el docente que se debe distinguir por las siguientes cualidades positivas de la personalidad:

- Amor a la profesión y que predica con el ejemplo personal, en sus actuaciones. El amor le permitiría la entrega pedagógica, su incondicionalidad a la difícil labor de educar. Debe ser un modelo a imitar.

- Debe poseer un gran desarrollo de su capacidad empática y habilidades de escucha, honesto, tacto pedagógico. Ponerse en lugar del otro y saber escuchar son puntos de partida para lograr una buena retroalimentación con los educandos.

- Debe partir siempre de un diagnóstico de necesidades sentidas y conocimiento de sus alumnos para cumplir con la función orientadora. Para orientar primero hay que saber qué necesidades, potencialidades y expectativas tienen los alumnos.

- Debe tener en cuenta las características del grupo etario con el que interactúa, en este caso con etapa de la adolescencia. Cada edad se distingue por características anatomofisiológicas y psicológicas diferentes y en correspondencia con las particularidades del contexto.

- Debe ser un excelente comunicador, solidario, colaborativo, creativo, indagador e independiente desde el punto de vista cognoscitivo y afectivo.

- Debe ser un buen observador, reflexivo y autoreflexivo, que le posibilite intervenir en el momento oportuno y perfeccionar su práctica educativa y al mismo tiempo su propio autoperfeccionamiento; ser un comunicador por excelencia.

Las cualidades anteriormente enunciadas le posibilitarán al tutor, asumir el rol protagónico en la educación y prevención del embarazo precoz. 


\subsection{Diagnóstico y caracterización del desarrollo inicial de la educación}

de la sexualidad, con énfasis en la prevención del embarazo precoz en los estudiantes del nivel básico superior de la Unidad Educativa ITSUP, de Portoviejo, Manabí, Ecuador

El diagnóstico que se presenta a continuación, se apoya en los fundamentos teóricos expresados en los epígrafes anteriores, los cuales constituyen las bases teóricas de la investigación.

Este diagnóstico se realizó cumpliendo el siguiente objetivo: caracterizar el estado inicial de la educación de la sexualidad, con énfasis en la prevención del embarazo precoz en los estudiantes del nivel básico superior de la Unidad Educativa ITSUP, de la ciudad de Portoviejo, provincia de Manabí, en la República del Ecuador, para el cual se establecieron como indicadores: a) nivel de conocimientos sobre el significado y el papel que les corresponde a los agentes educativos en la educación de la sexualidad y la prevención del embarazo; b) mecanismos que se utilizan para promover la educación de la sexualidad y la prevención del embarazo precoz , c) acciones que se realizan para lograr metas específicas en el ámbito de la educación de la sexualidad y la prevención educativa del embarazo precoz en la Unidad Educativa-objeto de análisis; d) nivel de conocimientos que poseen los estudiantes sobre la prevención del embarazo precoz ,e) intencionalidad comunicativa del estudiante sobre temas de prevención educativa del embarazo precoz y f) disponibilidad actitudinal.

La aplicación de las técnicas de investigación de campo para obtener la información requerida en el diagnóstico se llevó a cabo durante el primer quimestre del año lectivo 2013-2014. La Unidad Educativa ITSUP, comprende cuatro niveles educativos establecidos en la Ley Orgánica de Educación Intercultural del Ecuador, los cuales son: Educación Inicial (niños de 3 y 4 años); Educación Básica Elemental (primero a cuarto año); Educación Básica Media (quinto a séptimo año); Educación Básica Superior (octavo a décimo año); y, Bachillerato (que comprende los tres años posteriores). En el caso específico de la presente investigación, la población estudiada es la que corresponde a Educación Básica Superior, en la cual participan adolescentes comprendidos entre los 11 a 15 años de edad.

La población estudiantil está conformada por 422 alumnos matriculados en el ya citado año lectivo, en los diferentes niveles de educación, de los cuales 128 estudiantes ( 72 hombres y 56 
mujeres) corresponden al nivel de Educación Básica Superior. Esta población estudiantil es atendida por 37 docentes (19 mujeres y 18 hombres), de los cuales veintidós (22) son docentes tutores; 5 directivos ( 3 mujeres y 2 hombres) y 12 empleados administrativos (5 mujeres y 7 hombres), todos con dedicación exclusiva a la institución. Además, la Unidad Educativa cuenta con un Departamento de Consejería Estudiantil, el cual es atendido por una psicóloga educativa, una trabajadora social, un médico, una odontóloga y una enfermera, quienes son los responsables de atender las necesidades educativas y el bienestar de todos los estudiantes.

La población está compuesta por 128 y la muestra por 25 adolescentes correspondientes a un grupo del nivel básico superior de la Unidad Educativa (ITSUP).

Las técnicas e instrumentos de investigación seleccionados para su aplicación fueron: observación de las actividades que se desarrollan en el departamento de consejería estudiantil (Anexo 1), análisis de documentos que lleva el departamento de consejería estudiantil, vice-rectorado, tutores y docentes, encuesta a docentes tutores.( Anexo 2), entrevista a docentes (Anexo 4), entrevista a estudiantes de la institución ( Anexo 5), entrevista grupal a profesores (Anexo 7), Análisis de los productos de la actividad, específicamente, la técnica composición a estudiantes (Anexo 9), completamiento de frases (Anexo 11) ) aplicados todos estos instrumentos, se obtuvo la información que permitió realizar la triangulación, que es un procedimiento metodológico que permite revelar los elementos esenciales y generales que se infieren desde esos instrumentos.

En lo relacionado a la credibilidad o consistencia de los datos, se ha cuidado de atender únicamente la información que se deriva de los criterios internos del estudio, por las siguientes vías:

- Las categorías descriptivas empleadas en el trabajo son sencillas, concretas y precisas, señalándose las interpretaciones inmediatas de los hallazgos relevantes del estudio.

- Las notas y registro de la información son sometidas a verificación mediante la opinión de algunos informantes (a través de las encuestas de confirmación y de solicitud de colaboración a los informantes) sobre la credibilidad de las observaciones efectuadas durante la investigación. 
Se examinó el nivel de conocimientos sobre educación de la sexualidad y prevención del embarazo que tienen directivos, docentes y estudiantes, partiéndose de la aplicación de las técnicas de recolección de datos, en la dirección de confirmar las dificultades expresadas en el problema de investigación. Se evidenció una diferenciación muy marcada en cuanto al dominio de las temáticas de educación de la sexualidad que tienen los directivos en contraposición con los niveles de conocimientos que tienen los docentes tutores y en general los docentes de la Unidad Educativa. Estos últimos muestran limitaciones en el dominio de los fundamentos teóricos y metodológicos para abordar esta temática con mayores niveles de efectividad. Varios docentes tienen conocimientos erróneos sobre la sexualidad y la mayoría no conoce metodologías específicas para abordar esta temática desde la docencia.

En cuanto a los mecanismos que se utilizan para promover la educación de la sexualidad y la prevención educativa del embarazo precoz en los procesos sustantivos de la Unidad Educativa Instituto Tecnológico Superior (ITSUP), se evidenció que las planificaciones de los departamentos abordan esta temática desde el punto de vista metodológico; sin embargo, en la praxis poco se trabaja al respecto. Se han emprendido campañas educativas en toda la institución, adecuándose proyectos del Ministerio de Educación, los cuales han carecido de evaluaciones que permitan medir el impacto que han tenido en la población estudiantil. Además, el tema del embarazo precoz es abordado con un elevado grado de superficialidad por parte del Departamento de Consejería Estudiantil y por los docentes tutores a este nivel.

Respecto al tercer indicador, a las acciones que se sugieren hacer para lograr metas específicas en el ámbito de la educación de la sexualidad y el embarazo precoz en la Unidad Educativa (ITSUP), las actividades desarrolladas, evidencian que si bien se realizan algunas acciones en función de promover una educación de la sexualidad que contribuya a la disminución de los casos de embarazos precoces en los adolescentes, no se realizan de manera planificada con marcada intencionalidad formativa. Las mismas no son coordinadas por los directivos de la Unidad Educativa (ITSUP), ni los responsables de los departamentos, a los cuales les corresponden emprender este tipo de acciones.

Respecto al desarrollo de actividades propias de la gestión pedagógica de los docentes, en estas no se pudo evidenciar que exista una heterogénea preparación en los profesores, lo cual impacta en la formación de los estudiantes, de manera particular en su educación de la sexualidad. Se aprecia que se desaprovechan las potencialidades de los contenidos de los 
bloques curriculares, para formar en educación de la sexualidad y prevención del embarazo a temprana edad.

Se analizó el plan anual de trabajo académico presentado por el vice-rectorado y las asesoras pedagógicas, lo que permitió conocer de forma más concreta los mecanismos que se utilizan para el abordaje de esta problemática. Respecto a la educación de la sexualidad y prevención de embarazos precoces, han sido muy limitadas las acciones emprendidas, evidenciándose que no existe un proyecto a tal fin.

El rol que le corresponde a cada sujeto implicado en el proceso de educación de la sexualidad no está explicitado en ninguno de los documentos revisados. Por otro lado, los docentes tutores realizan muy pocas actividades sobre este problema y solo se incide en la educación de la sexualidad del alumnado, desde la asignatura de Ciencias Naturales que se imparte en toda la educación básica.

Se aprecia que algunos tutores asocian la educación de la sexualidad más a una materia, que a un eje articulador que atraviesa todos los procesos sustantivos de la educación general básica. Se coincide en que la educación de la sexualidad debe ser trabajada a través de charlas, talleres, películas y mediante la práctica de jornadas de reflexión orientadas por el Departamento de Consejería Estudiantil.

Los tabúes, las insuficiencias teóricas en el manejo de estas temáticas y las múltiples responsabilidades a atender en el aula de clases, dificultan dar el abordaje necesario a la educación de la sexualidad y la prevención del embarazo en los adolescentes. Los estudiantes, por su parte, reconocen la importancia que reviste la educación de la sexualidad. Expresan ideas como: "formar en educación sexual es imprescindible, por cuanto se hace indispensable desarrollar una correcta salud física y mental de los adolescentes" y "la educación de la sexualidad, permite actuar de manera responsable ante situaciones de embarazos".

Consideran que los profesores no abordan el tema de educación de la sexualidad desde los contenidos de los bloques curriculares; al menos ellos no lo perciben explícitamente. Los estudiantes consideran que no se les incentiva lo suficientemente para ser protagonistas en las actividades que emprende la Unidad Educativa y en la responsabilidad social que tienen como futuros ciudadanos en el nuevo país que se trata de construir. Que se les exhorta a ello, pero no queda con claridad qué hacer y cómo hacerlo. 
Respecto a las acciones que se sugieren hacer para lograr metas específicas en el ámbito de educación de la sexualidad y la prevención del embarazo en el nivel básico superior de la Unidad Educativa ITSUP, es necesario generar lineamientos educativos que incentiven en los estudiantes un total grado de responsabilidad, compromiso y disciplina. Al mismo tiempo se observa la disposición hacia la orientación de una propuesta que permita atender esta problemática que cada día está ganando más terreno y que requiere ser atendida de manera urgente para lograr así la tan ansiada formación integral en la institución educativa.

La triangulación realizada permite llegar a consideraciones reveladoras de potencialidades e insuficiencias. Se aprecian como potencialidades las siguientes:

- Los documentos y registros de la Unidad Educativa ITSUP, declaran una correcta orientación hacia la educación sexual en los estudiantes, tendientes a lograr su educación integral.

- Se dispone de variedad de material bibliográfico y de apoyo en el Departamento de Consejería Estudiantil, para trabajar en todas las asignaturas del currículo temas relacionados con la educación de la sexualidad.

- Disposición de los directivos y la mayoría de los docentes y estudiantes de trabajar en educación de la sexualidad y prevención del embarazo en toda la Unidad Educativa (ITSUP), desde el rol que le corresponde a cada uno.

- Se ha declarado la educación de la sexualidad como un eje transversal de la formación de los estudiantes de la Unidad Educativa ITSUP, aunque ello aún no se traduce en un accionar coherente con este presupuesto.

Las insuficiencias detectadas en el diagnóstico fueron las siguientes:

- Bajo nivel de conocimientos por parte de los docentes y estudiantes, acerca de los fundamentos teóricos y metodológicos de la educación de la sexualidad y la prevención de embarazos precoces.

- Realización de acciones aisladas en cuanto a educación sexual y prevención de embarazos en adolescentes. 
- Poca claridad en la selección de metodologías adecuadas y eficaces para el abordaje intraáulico que favorezca la educación de la sexualidad.

- Diferencias muy marcadas en cuanto al nivel de preparación que alcanzan los directivos y docentes, así como del dominio de las herramientas pedagógicas que lo potencien.

- En algunos estudiantes se aprecian cambios poco perceptibles en su modo de actuación, de acuerdo con los niveles de educación de la sexualidad que se aspira tengan todos.

\section{Conclusiones del Capítulo I}

A partir del análisis histórico efectuado se manifiestan las tendencias del proceso de educación de la sexualidad; con respecto a la concepción de la educación de la sexualidad, se evidencia un movimiento que va desde la presencia de un programa aislado; hasta la institucionalización de los mismos. Sobre los contenidos tratados como parte de la educación de la sexualidad, se evidencia un tránsito desde temas escasos y de mínimo impacto, hasta el tratamiento de la maternidad/paternidad, la violencia y el abuso sexual, el embarazo precoz adolescente y sus consecuencias, la fecundidad, los derechos del adolescente en materia de sexualidad, además, con respecto a las vías para educar sexualmente durante la etapa adolescente, se transita desde el uso restringido y secreto de algunos textos, hasta la concreción de programas interventivos.

Los fundamentos epistemológicos expuestos en este capítulo, muestran las bases para la comprensión del carácter complejo de la educación de la sexualidad y la prevención del embarazo precoz en la educación básica superior, su naturaleza objetiva y subjetiva, la necesaria implicación y participación de los estudiantes en su formación, vista la educación de la sexualidad como parte consustancial de esta.

Se aprecia, como resultado del diagnóstico realizado, potencialidades para la educación de la sexualidad y el tratamiento del embarazo precoz, aspectos que se realzan en los documentos de la institución objeto de estudio, y en algunas acciones de superación, investigación y de trabajo metodológico que se despliegan. Pero también se advierten insuficiencias en el trabajo que se realiza, pues no se aprovechan las potencialidades de la formación para lograr un mejor resultado educativo en los estudiantes, ni hay claridad del rol de cada sujeto en el proceso 
educativo de la sexualidad de los educandos, cuestión que tiene que ser atendida primordialmente. 


\section{CAPÍtulo II: Modelo EDUCATIVo - PREVENTIVo DEL EMBARAZO PRECOZ EN ESTUDIANTES DEL NIVEL BÁSICO SUPERIOR, DESDE LA ACCIÓN TUTORIAL}

En el presente capítulo se presenta un modelo educativo y preventivo del embarazo precoz en estudiantes del nivel básico superior, desde la acción tutorial. Se ofrecen los fundamentos desde lo epistémico general, filosófico, sociológico, psicológico y pedagógico que lo sustentan, así como su estructura y funciones. El modelo, sustentado en el método sistémico estructural funcional permite que se revelen las relaciones esenciales entre los subsistemas, componentes y categorías que lo constituyen, así como las relaciones que se establecen entre ellos y lo caracterizan.

\subsection{Argumentación de los fundamentos teóricos que sustentan el modelo} educativo - preventivo del embarazo precoz, desde la acción tutorial

El modelo que se presenta y argumenta en el presente capítulo se elabora desde la perspectiva del paradigma sistémico de investigación, la teoría de sistemas y el método sistémico estructural funcional. La totalidad constituye una unidad dialéctica de sus componentes y las propiedades del sistema son cualitativamente distintas a las propiedades de estos elementos constituyentes por separados, además, permite revelar el comportamiento del proceso modelado.

El modelo educativo se puede definir como:

Conjunto de factores en interacción dialéctica que deben ser contemplados en el diseño del sistema de influencias educativas a que un ciudadano de una sociedad dada en un momento histórico preciso debe ser sometido, para que con un margen de eficiencia, salga formado con un determinado perfil, que de hecho significa ideal de hombre concretado en una personalidad, donde además de rasgos típicos y comunes a todos los miembros de esta sociedad en cuestión, de cabida al desarrollo de su individualidad y potencialidades. (Valera, 2000, p. 33) 


\section{Los principales referentes teóricos del Modelo educativo-preventivo del embarazo-precoz son los que a continuación se relacionan:}

Desde el referente filosófico, el modelo se fundamenta en las tesis del materialismo dialéctico e histórico, que en calidad de soporte metodológico sustenta el estudio de la sexualidad de los educandos. Se parte de la concepción de la personalidad y su esencia, como el conjunto de todas las relaciones sociales, en las cuales se configura la misma (Marx y Engels, 1888). En consecuencia, se connota la importancia del medio social en el cual tiene lugar el desarrollo del alumno; es decir, bajo el efecto de la educación, de la actividad propia del adolescente, organizada por los adultos y de la comunicación entre este con sus coetáneos y sus educadores, incluidos sus padres y otras figuras adultas de importancia para la vida del educando. Se ubica al sujeto en el centro del desarrollo social y se expresa el papel que este desempeña para transformar la sociedad a partir de condiciones históricas concretas.

Desde el referente sociológico, se destaca la determinación social de la personalidad, como un presupuesto importante para entender las metas de la educación en general y la esencia misma de la educación de la sexualidad, que no está únicamente apegada al disfrute personal, sino también es base de la convivencia entre las personas y condición importante para la conformación de la familia, para la procreación y crianza de los hijos. Se aboga además, por reconocer al educando como ser sexuado, en su calidad de ser social, en sus relaciones con su entorno, en el contexto sociocultural en que se desenvuelven los escolares/adolescentes y donde tienen incidencia la familia, la escuela, la comunidad y demás agencias educativas, que en este contexto es una condición determinante en el desarrollo del adolescente. El estudio del desarrollo psicosexual, revela cómo se manifiesta la influencia socio cultural sobre la sexualidad y cómo esta se configura de acuerdo con las condiciones sociales de vida y educación del sujeto.

Desde el referente psicológico se asumen los postulados del enfoque socio- histórico-cultural, de L S. Vigosky y sus continuadores, dentro de los cuales se realzan:

- El vínculo entre educación y desarrollo de la personalidad

- La relación actividad-comunicación-personalidad

- La necesaria unidad entre lo afectivo y lo cognitivo para favorecer la educación de la sexualidad. 
- La consideración del período etario en que se encuentran los estudiantes de educación básica superior (en particular, su situación social del desarrollo (SSD) (Orengo, 2013).

- El carácter transformador, creativo del alumno, en el proceso de apropiación de la experiencia histórico social, que le convierta en un sujeto que aporta nuevos productos a los ya ofrecidos por la humanidad.

- La personalización e implicación del alumno en el proceso de aprender, la motivación por el contenido y proceso de aprendizaje que le propicien la utilización consciente de sus recursos personológicos en este proceso.

- Los procesos grupales como contextos en los que es posible lograr el crecimiento personal de cada uno de sus miembros y el desarrollo del grupo desde un aprendizaje grupal, en el cual cada uno aporta su experiencia y se genera un espacio de construcción conjunta de la experiencia socio-histórica.

- La responsabilidad que ha de asumir el alumno en su aprendizaje y desarrollo personal, al participar activamente en las decisiones inherentes a estos procesos y establecer compromisos.

En síntesis, en correspondencia con el enfoque socio-histórico-cultural, el desarrollo integral del ser humano es concebido como un proceso socialmente condicionado, en el que la formación ocurre como resultado de la asimilación de la experiencia histórico/cultural de carácter social, a través de la comunicación, la actividad y el carácter de mediadores sociales que adquieren los sujetos que interactúan en el proceso.

Las exigencias sociales, principalmente las escolares y familiares, determinan la situación en que se encuentra el adolescente, pero este tiene además una posición interna: su personalidad en formación da una respuesta propia a esas exigencias. Desde sus motivos y vivencias, el adolescente participa de manera creciente en la autodeterminación de su comportamiento en los diferentes contextos de actuación. Lo anteriormente expuesto se constituye en fundamento de la educación de la sexualidad.

Desde el referente pedagógico, se connotan las categorías de educación y prevención en su estrecha unidad dialéctica. Se asume la educación de la sexualidad desde un enfoque alternativo y participativo, reconociéndose como el proceso activo que potencia al individuo para el encuentro libre, pleno y responsable con el otro sexo y con la propia sexualidad, en 
correspondencia con sus necesidades y las del contexto, garantizando el protagonismo y la capacidad de elegir los límites personales de la sexualidad, así como el respeto a la de las personas con que se relaciona (González, Castellanos, p. 161).

Se destacan, en relación con lo anterior, experiencias latinoamericanas que abogan por significar la importancia de la Educación Popular, así como la Investigación Acción Participativa, lo que impone su sello a varios programas actuales de Educación Sexual, incluidos algunos desarrollados en el contexto ecuatoriano. Esta postura resalta la necesidad de construir junto a los sujetos de la educación de la sexualidad (los alumnos) los espacios, los contenidos y alternativas para educar la sexualidad. Se reconoce, de igual manera, al alumno como ente activo en el proceso educativo de su sexualidad, así como la necesidad de la acción conjunta de los diferentes actores educativos en función de objetivos comunes.

Se defiende la postura de que la educación de la sexualidad es parte consustancial a la preparación del ser humano para la vida, del aprender a ser y a convivir, mediante la cual cada individuo construye de manera única su masculinidad y femineidad, al mismo tiempo que se apropia de conocimientos, desarrolla habilidades y asume actitudes y valores, para vivir su sexualidad de modo autodeterminado y enriquecedor de sí mismo y de sus semejantes. Se asumen de Castro Alegret (2006), los estadios por los que transita la labor de educación de la sexualidad en la escuela, necesarios para materializar un enfoque participativo: caracterización de necesidades y dificultades; diseño de acciones para resolverlas y seguimiento a la implementación de las acciones educativas.

La apertura de una era libertaria y desprejuiciada acerca de la sexualidad, crea el inconveniente del incremento progresivo de riesgos en materia de salud y en el ámbito de la convivencia; así ocurren la aparición del SIDA, el aumento de infecciones de transmisión sexual, embarazos precoces, abortos, maternidad y paternidad temprana, entre otras, que obligan a la toma de decisiones educativas al respecto, centradas en dotar de la información precisa al adolescente para prevenir y evitar estos riesgos. Pero al mismo tiempo, es preciso privilegiar los aspectos placenteros, socioemocionales y éticos, entre otros, que impactan la sexualidad y su educación.

La educación sexual, es asumida por la autora como un proceso de preparación de las personas, a lo largo de su vida, para el encuentro libre, responsable y pleno de la sexualidad propia y con la de los demás (Fernández y López, 2012). 
El embarazo precoz se asume como aquel estado de gravidez de una fémina, que se produce entre los inicios de la adolescencia (pubertad), durante y el final de esta. Por lo general se establece entre los 10 y 19 años. Sus consecuencias para el adolescente, la familia y todo el contexto que le rodea suelen ser muy negativas.

La categoría de prevención asume un rol de esencia conjuntamente con la de educación, entendiéndose la prevención como una alternativa de la orientación educativa dirigida a promover el desarrollo integral de la persona, a la vez que involucra un conjunto de actividades profilácticas, de desarrollo y atención a los sujetos en formación, que integra a los agentes educativos: padres, familia y comunidad, en aras de evitar comportamientos de riesgo. (Molina, s/f). Se privilegia la denominada prevención primaria, que promueve el desarrollo integral de la personalidad para evitar que surjan conductas indeseables para el sujeto y la sociedad.

Se destaca el papel del diálogo, la tolerancia y la conversación, para brindar la información que los estudiantes necesiten, en un lenguaje asequible, para promover que se involucren con los objetivos educativos que parten de su propia vida cotidiana, con el fin de que estos adquieran una significación personal que los motive a actuar de modo coherente. Lo anterior implica, además, el imperativo de fomentar la formación continua del personal docente encargado de la tarea de educar sexualmente a los alumnos del nivel de básica superior, con el fin de posibilitar actitudes maduras y responsables hacia la sexualidad y la ética en las relaciones (Castro, 2002).

Los principales riesgos que se derivan del embarazo afectan al sexo femenino, creando desigualdades entre las y los adolescentes involucrados en un embarazo a esta temprana edad. Se requieren, entonces, acciones de educación de la sexualidad, con un carácter preventivo en la aparición de embarazos precoces. Pero además, influencias de carácter formativo, general, que pertrechen a la adolescente y al adolescente de herramientas para vivir plena y responsablemente su sexualidad, percibiéndola como componente gozoso e importante de su existencia, mediante el fomento de la maternidad y la paternidad como una opción, que requiere ser ejercida de manera comprometida y eficaz.

La tutoría es un instrumento ligado a la docencia que, en el contexto de la educación ecuatoriana, no siempre ha desarrollado sus potencialidades y que cuenta con escasa tradición. En el contexto contemporáneo, y ante la compleja situación de fragmentación de las 
escuelas secundarias, la tutoría surge como una estrategia potente que articula recursos para acompañar las trayectorias escolares de los adolescentes.

La tutoría juega un rol fundamental en la tarea de brindar una formación integral a los estudiantes de la educación básica superior, que los prepare para la vida como personas y miembros de una comunidad, e incluye el prepararlos para la familia, una sexualidad responsable y placentera y para el amor. Tiene por ello un carácter formativo y preventivo. La presunción básica de la tutoría es que cada estudiante necesita de un "adulto cercano" en la escuela, que lo conozca, en quién confíe y que se preocupe personalmente por él. A grandes rasgos, puede decirse que consiste en que los profesores sean asignados como tutores de los distintos grupos-clase; responsabilidad que significa tanto realizar sesiones de tutoría grupal, como dar apoyo individual a cada estudiante y mantener contacto con los padres de familia de su grupo-clase.

La tutoría educativa se erige en la vía que se opta para privilegiar la labor educativa, orientadora, preventiva y de intervención para incidir en la educación de la sexualidad de los adolescentes. Lo anterior, no niega en modo alguno, la necesidad de que los agentes educativos intervinientes en la formación del estudiante de educación básica superior, contribuyan también al trabajo en esta arista, accionando de manera conjunta y consistente.

El referente didáctico, aunque no constituye el centro del resultado que se aporta, sí debe ser tomado en cuenta desde la perspectiva de que la educación de la sexualidad constituye un eje central transversal del aprendizaje y la formación de los alumnos de educación, por lo cual debe favorecerse desde los contenidos de las diferentes materias de estudio, exige apoyarse en métodos atractivos y participativos de enseñanza-aprendizaje, estrategias y recursos didácticos que pudieran incidir en la educación de la sexualidad, a partir del vínculo inexorable entre instrucción y educación.

\subsection{Modelo educativo y preventivo del embarazo precoz, desde la acción tutorial}

En este epígrafe se presenta el modelo educativo y preventivo, referido a la prevención educativa del embarazo precoz, dirigido a los estudiantes del nivel básico superior. 
Se asume como contradicción fundamental, dinamizadora del sistema modelado, la que relaciona, distingue y opone a la función preventiva y la función formadora de la educación sexual de los adolescentes (alumnos del nivel básico superior). Lo anterior se sustenta en que educar al hombre para lograr que sea un ciudadano responsable de su sexualidad y de los actos que se cometen en nombre del amor, supone prevenir por medio de la educación, consecuencias que pudiesen perturbar el futuro exitoso de los estudiantes-adolescentes, como el embarazo precoz.

Una perspectiva consiste en prevenir la incidencia de embarazos tempranos en los adolescentes y otra es la promoción de la paternidad y la maternidad como una opción, que requiere ser ejercida responsable y eficazmente. Pero estos ámbitos de la acción educativa están inexorablemente relacionados y resultan igualmente importantes en el orden de la educación de la sexualidad durante la adolescencia.

A partir de la sistematización teórica de la autora, sustentada en la valoración crítica de la literatura pedagógica consultada, se fundamenta el modelo educativo-preventivo. El modelo expresado como sistema, transita por tres subsistemas que de forma articulada y coherente eslabonan este proceso mediante relaciones de interdependencia que le confieren un carácter de unidad dialéctica: procesos cognitivos relativos a la educación de la sexualidad y la prevención educativa del embarazo precoz; procesos de instrumentación relativos a la educación de la sexualidad y la prevención educativa del embarazo precoz y procesos de actuación relativos a la educación de la sexualidad y la prevención educación del embarazo precoz. De las relaciones entre estos componentes surge la cualidad de orden superior: aprehensión de una conducta sexual resiliente y responsable como resultado del desarrollo cognitivo alcanzado desde la acción tutorial y sus relaciones teóricas relativas a la educación de la sexualidad y la prevención del embarazo precoz (Fig. 1). 


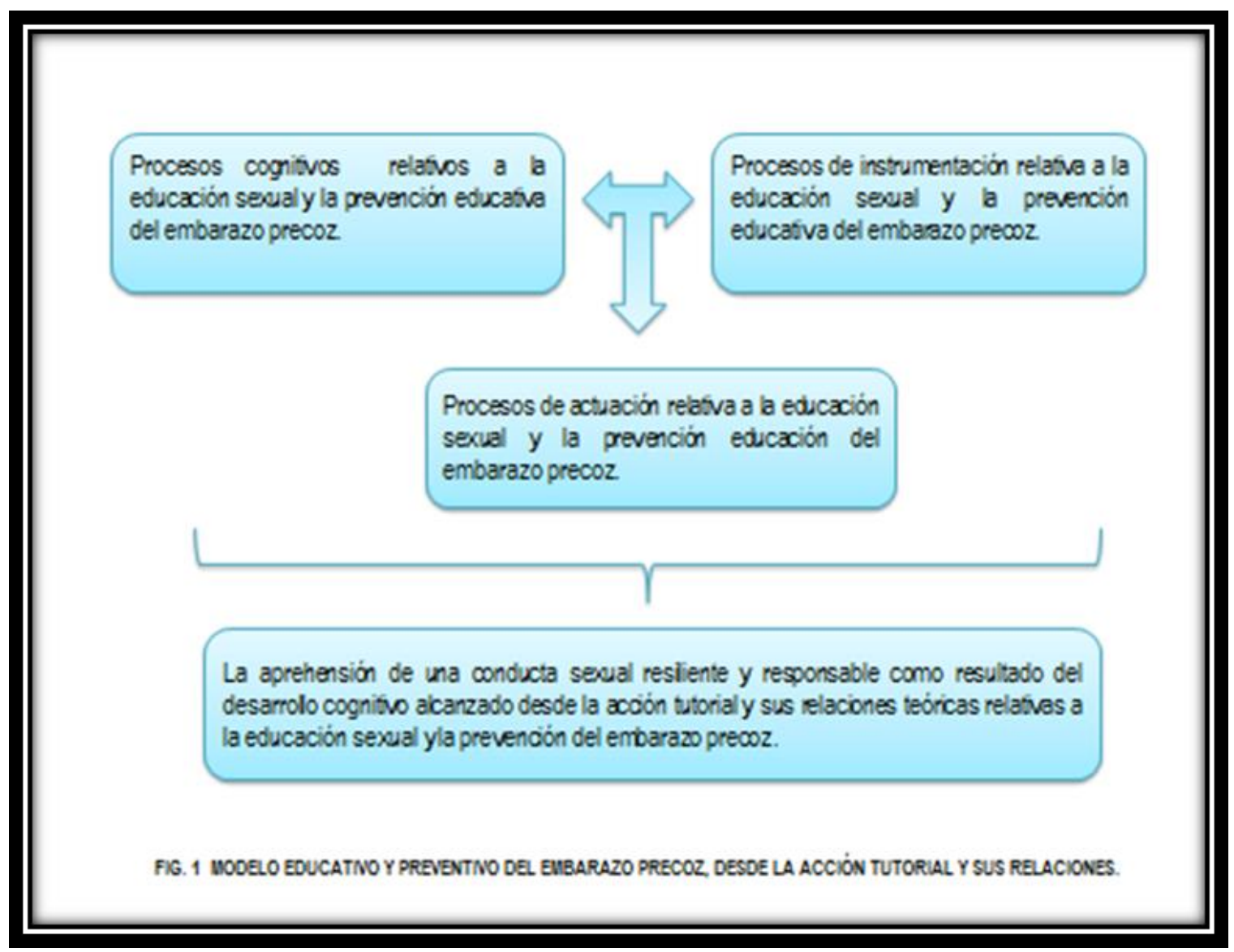

La propuesta se realiza, además, sustentada en la acción tutorial, a partir de las potencialidades que una tutoría educativa integral reviste para la formación de los educandos de estas edades. En tal sentido, aunque la acción educativa se considera centrada en la figura educativa del tutor en su interacción permanente con los tutelados, el modelo tiene en cuenta la confluencia de diferentes factores educativos en esta función de prevención primaria que tiene la educación de la sexualidad, apoyándose en el rol de la familia, los docentes y de los propios adolescentes (estudiantes, hembras y varones), en calidad de actores educativos.

El subsistema Procesos cognitivos relativos a la educación de la sexualidad y la prevención educativa del embarazo precoz tiene la función de organizar coherentemente los contenidos relacionados con la educación de la sexualidad como base para el desarrollo de una sexualidad responsable. Se estructura a partir de dos componentes denominados: procesos de adquisición de conocimientos sobre el cuerpo, los genitales, zonas erógenas y la respuesta sexual y procesos de apropiación de conocimientos sobre fecundación, aborto, embarazo y 
parto. De las relaciones entre estos, surge la cualidad: apropiación teórica de los contenidos relativos a la educación de la sexualidad y la prevención del embarazo precoz (Fig. 2).

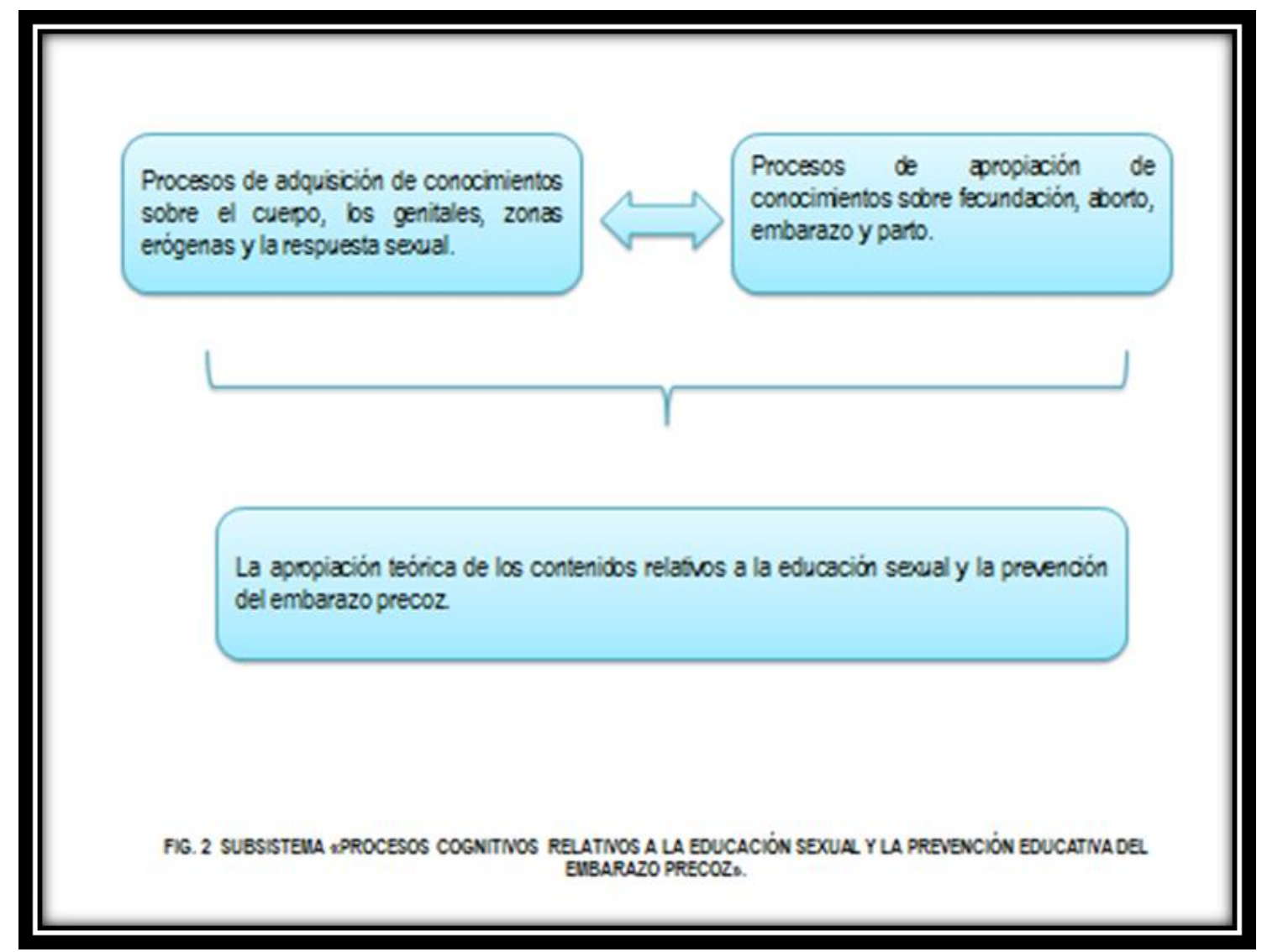

Asumir la educación de la sexualidad en la escuela desde una perspectiva integral demanda un trabajo dirigido a promover aprendizajes en tres niveles: el del intelecto, el de los sentimientos y el de las prácticas concretas. Por propuestas que apuntan a producir cambios de tipo cognitivo, se entiende no solo el suministro de información científicamente validada, acorde a cada etapa evolutiva, sino también al trabajo para contrarrestar los prejuicios y las creencias que sostienen actitudes discriminatorias, como también el conocimiento de derechos y obligaciones de los adolescentes.

Este subsistema hace referencia al proceso a través del cual se adquiere la información de carácter educativo, requerida por el adolescente, en función de prevenir un embarazo precoz. Aunque el conocimiento sobre biología humana, anatomía y fisiología de los órganos sexuales 
no resulta suficiente para la prevención del embarazo precoz, sí constituye un requerimiento necesario en materia de educación sexual, en el orden formativo y preventivo.

El subsistema está centrado en la labor de la comunidad educativa, desde el rol del tutor como principal agente formador, pero también considerando el aporte de los directivos escolares, profesores y padres de familia, en función de que los adolescentes adquieran información básica sobre su sexualidad, sus decisiones y las situaciones que pueden ponerlos en riesgo, especialmente de un embarazo no planificado y cómo prevenirlas. Su función es básicamente formativa.

El componente Proceso de adquisición de conocimientos sobre el cuerpo, los genitales, zonas erógenas y la respuesta sexual, tiene como función la apropiación de información por los adolescentes, relativa a los cambios corporales que tienen lugar durante la etapa de la adolescencia, en especial durante la pubertad y las consecuencias psicológicas, sociales y educativas que se derivan de ello.

Desde el punto de vista biológico el ser humano es un ser sexuado. La existencia de los órganos genitales no solo determina la asignación de sexo, sino que provoca un comportamiento sexual. El concepto de sexualidad transgrede los límites de los órganos genitales e incluye los distintos comportamientos tanto individuales como sociales, que las personas adoptan como alternativas de su vida sexual.

Durante este período en las adolescentes se manifiestan cambios característicos como el crecimiento de los senos, aparición de vello púbico y la primera menstruación o menarquia. En los hombres se hace evidente el cambio de voz, surge vello púbico y se producen las primeras emisiones de esperma. Estas manifestaciones, entre otras, anuncian el inicio de la madurez sexual cuya consecuencia natural es la capacidad reproductiva. Esto está en consonancia con que en la adolescencia se desarrollan los caracteres sexuales primarios y los secundarios, tanto referidos a hembras como a varones, lo cual exige ser explicado convenientemente a los alumnos, ya que los cambios biológicos adquieren un significado especial para la vida y sexualidad de los educandos, por representar la nueva realidad que han de vivir como adultos. La información de la cual se provee a los alumnos del nivel básico superior debe incluir la referida a las zonas erógenas del cuerpo y la respuesta sexual humana, toda vez que la falta de conocimiento y el que este no sea transmitido a través de las figuras de poder en su vida 
(padre, madre, profesor), puede conllevar a buscarlo por vías poco confiables que les provocarán confusiones, dudas, tensiones y que no les permitirán conducir su vida sexual por vías adecuadas. Este componente acentúa el conocimiento sobre la anatomía humana y en particular la relativa a la sexualidad, sin minimizar los aspectos funcionales, inexorablemente conectados con los anatómicos.

El componente denominado Proceso de adquisición de conocimientos sobre fecundación, aborto, embarazo y parto asume como función resaltar la necesidad de preparar a los adolescentes en materia de estos eventos, con vistas a educar y prevenir comportamientos sexuales irresponsables, de los cuales puedan arrepentirse con posterioridad. Su énfasis está colocado en aspectos funcionales relativos a la sexualidad, obviamente conectados con los anatómicos.

Acentúa la necesidad de explicarles que la actividad sexual muestra diferencias entre hombres y mujeres; ambos son capaces de experimentar deseo y excitación, sin embargo, a través de mitos, tabúes o el género algunas mujeres se cohíben en la vida sexual activa mientras no mantengan una relación afectiva, en tanto que los hombres la realizan con mayor libertad y tolerancia.

La doble moral sexual consolida la inequidad sexual, coloca a hombres y mujeres en papeles estereotipados por razones culturales y separa el componente afectivo de la relación sexual. El ejercicio prejuiciado de la sexualidad genera riesgos para la salud y la realización humana, especialmente para las jóvenes, por ignorancia y desigualdad. Muchas adolescentes evitan el control natal porque consideran que ellas no participarán en relaciones sexuales indeseadas o inesperadas. Sin embargo, ello puede traer consigo que se vean involucradas en relaciones sexuales inesperadas y enfrenten embarazos no deseados.

Es necesario que las hembras y también los varones conozcan que durante la gestación, el parto y el posparto, son mucho más probables toda una serie de problemas y complicaciones que pueden sobrevenir a la madre adolescente y al hijo. Durante la gestación son más frecuentes las anemias, las alteraciones de peso, el crecimiento uterino inferior a lo normal y los abortos espontáneos. Las complicaciones durante el parto y el posparto son también frecuentes. La tasa de mortalidad es también más elevada. 
Aun conociendo las vías de anticoncepción, algunas muchachas no las utilizan por diversas razones: por ser mal visto que una mujer tenga iniciativa en esa actividad, por ser cuestionado que ejerza el sexo por placer, porque suponen que los varones tienen experiencia y deben decidir en el terreno de la sexualidad, porque a la mujer se le ha enseñado a ser sumisa respecto a las propuestas del varón, porque considera que la reproducción es su función natural, porque no son capaces de comunicarse asertivamente, por cuestiones morales o religiosas, y por temor a las consecuencias.

Estas son solo algunas de las múltiples causas que es necesario considerar y explicar a las alumnas de estas edades, para evitar comportamientos sexuales de riesgo, del mismo modo que a los varones, para que intervengan en la protección de su pareja sexual. Del mismo modo, resulta imprescindible proveerlos de información relativa a los riesgos del aborto en estas edades, así como de asumir la llegada de un hijo y su crianza, sin estar provistos de la necesaria madurez para ello.

A la vez, este componente representa la necesidad imperiosa de dotar a los adolescentes, de información relativa a los métodos para evitar el embarazo, desde la tutoría grupal educativa y a través de la alianza del docente-tutor con el resto de los agentes educativos que intervienen en la formación del estudiante del nivel básico superior. El rol de los padres de familia, en esta dirección, resulta imprescindible.

La información sobre los métodos anticonceptivos a los que pueden recurrir aquellos que deciden ser sexualmente activos es escasa y muchas veces errónea. En sectores sociales con fuertes carencias económicas se suma la imposibilidad de adquirir preservativos u otros métodos para evitar el embarazo, sobre los cuales requieren recibir información los adolescentes.

Por otro lado, el creciente uso de alcohol y otras drogas desde edades cada vez más tempranas, también tiene una incidencia negativa en el comportamiento sexual por cuanto disminuyen las posibilidades de autocontrol de los muchachos para establecer contactos íntimos desprotegidos. Los adolescentes, bajo los efectos de esas sustancias, están en peores condiciones para prevenir el embarazo.

Este componente hace referencia, de igual manera, al conocimiento del cual debe proveerse a educandos varones y hembras del nivel básico superior acerca de la posible presencia de 
infecciones de transmisión sexual cuando se realizan relaciones sexuales sin la debida protección, riesgo que aumenta en la medida en que exista mayor promiscuidad o cambio de pareja. Estas incluyen el virus de inmunodeficiencia humano y el virus de inmunodeficiencia adquirida)

Los educadores, incluidos tutores, docentes, directivos y padres de familia, han de estar debidamente preparados para poder educar a sus hijos en la sexualidad de una manera responsable e integral, para que estos puedan adquirir un sentido de la vida humana que dé unidad a la persona en todas sus actividades y comportamientos. Este propósito, por supuesto, excede la finalidad y concepción del primer subsistema y permite una aproximación al siguiente.

Entre los componentes de este primer subsistema, centrado en la adquisición de conocimientos acerca de la sexualidad como condición necesaria (aunque no suficiente) para educar y prevenir comportamientos de riesgo, incluidos los conducentes al embarazo precoz, existen relaciones de coordinación e interdependencia. Se acentúa en este primer subsistema la necesidad de considerar el papel educativo del tutor, que funge como mediador de otras influencias educativas esenciales que se ejercen sobre los adolescentes, en el empeño de que estos se conviertan también en agentes procuradores de información para una mejor conducción de sus propias vidas, considerándose el ineludible valor de una sexualidad feliz y placentera para la realización y bienestar del ser humano, como dimensión del ser integral.

La elaboración del modelo, sintetizada en el subsistema Procesos cognitivos relativos a la educación de la sexualidad y la prevención educativa del embarazo precoz, y en particular en sus componentes, demanda la necesidad de colocar en manos de los adolescentes las herramientas imprescindibles para dotarlos de los sistemas de ayuda necesarios y en consecuencia el tránsito al subsistema Procesos de instrumentación relativos a la educación de la sexualidad y la prevención educativa del embarazo precoz. Este consta de cuatro componentes: procesos de desarrollo de estrategias para el rechazo ante comportamientos, peticiones o críticas, apoyándose en las creencias y preferencias propias sobre la sexualidad; procesos de comportamientos (verbales y no verbales) dirigidos a establecer relaciones más personales con sujetos del otro sexo; procesos de anticipación de consecuencias de la toma de decisiones y procesos de acompañamiento a otros para solucionar inquietudes sexuales. Tiene como función ofrecer estrategias y comportamientos que faciliten a los adolescentes prever 
consecuencias de una actitud sexual irresponsable. De las relaciones entre sus componentes surge la cualidad: el carácter preventivo del embarazo precoz (Fig. 3).

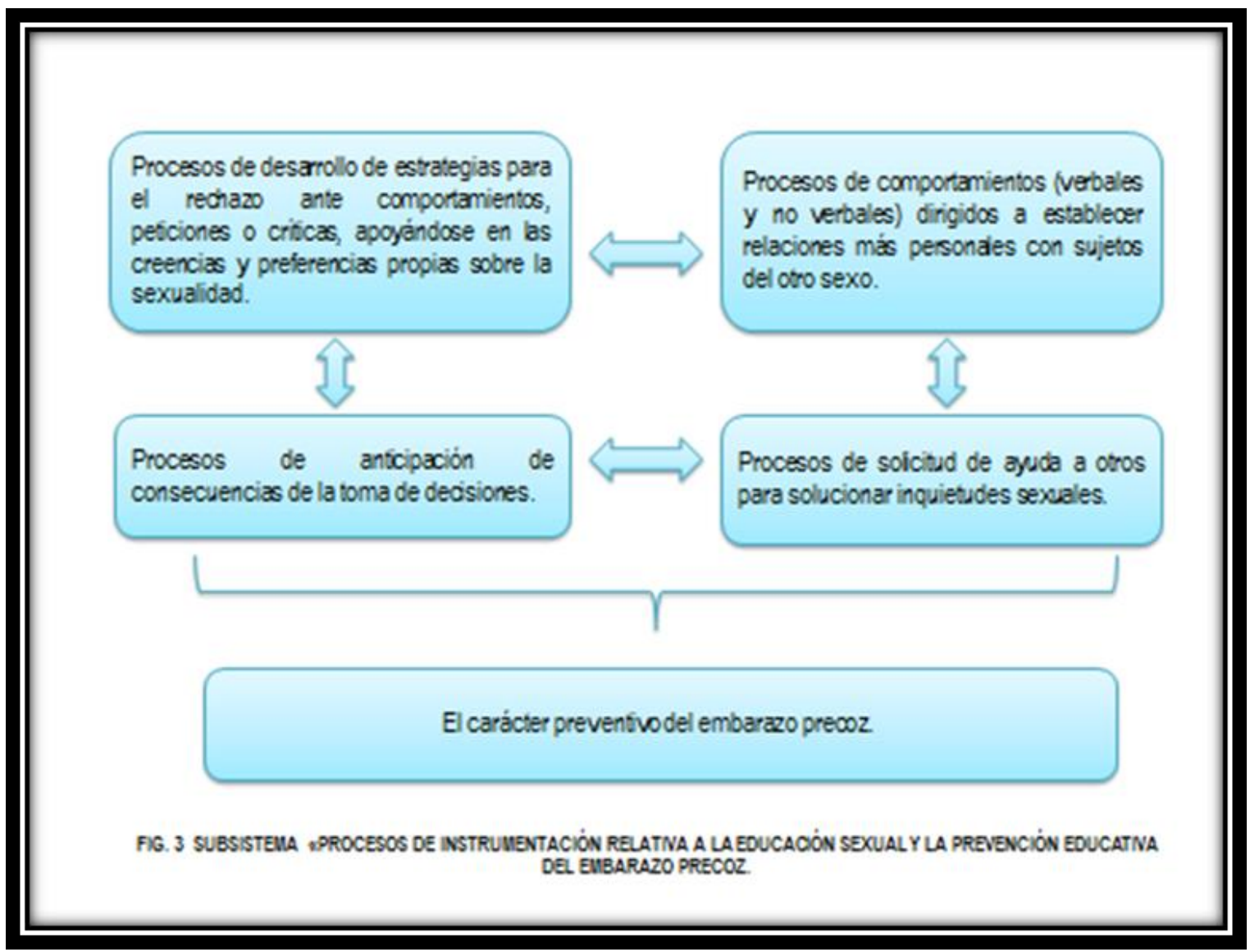

En este subsistema , más relacionada con el "saber hacer", se teoriza acerca de la importancia de la adquisición de capacidades y habilidades socioemocionales tales como la posibilidad de decir no frente a presiones de otros (expresión de comportamiento resiliente), la consolidación de comportamientos de cuidado personal y colectivo de la salud, así como la expresión de sentimientos y afectos. El nivel conductual es el del aprendizaje a través de la práctica.

Su relación con el subsistema antes descrito resulta muy cercana, ya que la adquisición de conocimientos relativos a la sexualidad constituye sustento del desarrollo de habilidades socioemocionales en este ámbito. Pero al unísono, el desarrollo de tales habilidades, incita a la búsqueda de nueva información, lo cual refuerza el conocimiento. El desarrollo de habilidades 
y la estimulación de comportamientos responsables relativos a la sexualidad, se concibe desde la tutoría grupal, en su íntima relación con la atención personalizada al alumno, desde el rol del personal docente de la institución educativa en general, con énfasis en la acción tutorial, en su vínculo indisoluble con la labor educativa de la familia de los adolescentes. Por otra parte, resulta de interés involucrar a los adolescentes en la asunción de determinadas conductas y el desarrollo de las correspondientes habilidades socioemocionales.

El componente Procesos de desarrollo de estrategias para el rechazo ante comportamientos, peticiones o críticas, apoyándose en las creencias y preferencias propias sobre la sexualidad asume como función la necesidad de que los adolescentes defiendan sus propios puntos de vista, convicciones e inclinaciones, al tomar decisiones y ponerlas en práctica, en el ejercicio de la sexualidad.

Enfatiza en preparar especialmente a las hembras, en resistir a las trampas verbales manipulativas y los chantajes afectivos que sus parejas les tienden; rechazando propuestas de los varones que les resulten incómodas, les parezcan indecorosas o fuera de lugar. De igual modo, a declinar las presiones sociales del grupo más allegado de amigas y amigos, negándose a establecer relaciones íntimas cuando es su preferencia, conservando la armonía emocional, sin ofender ni comportarse de manera defensiva. Esta manera de comportarse guarda relación con la resiliencia.

El componente Procesos de comportamientos (verbales y no verbales) dirigidos a establecer relaciones más personales con sujetos del otro sexo posee como función realzar cómo la educación de la sexualidad dirigida por tutores, otros agentes educativos escolares, la familia, los adolescentes, debe permitir un acercamiento y mejora en las relaciones entre adolescentes de diferentes sexos, de manera que los vínculos personales entre ellos se hagan más cercanos y personalizados, lo cual repercutirá en la complacencia de muchachas y muchachos y en su percepción de madurez y desarrollo. El logro de una mayor intimidad en los vínculos comunicativos se expresa a través de la comunicación verbal y no verbal.

Los procesos de comportamientos (verbales y no verbales) dirigidos a establecer relaciones más personales con sujetos del otro sexo, articulan coherentemente con el componente Procesos de anticipación de consecuencias de la toma de decisiones, cuya función reside en la toma de decisiones sexuales responsables. El tema del género no solo se hace evidente en torno a los riesgos de un embarazo adolescente, sino que está presente, además, en las 
raíces que le dan origen, teniendo en cuenta que los comportamientos entre adolescentes están pautados al igual que otras muchas relaciones humanas, por relaciones de poder asimétricas y caracterizadas por roles estereotipados que inhiben la autonomía de los adolescentes para tomar decisiones pertinentes y responsables en la vida sexual.

El embarazo en la adolescencia trae consigo serias consecuencias, particularmente sobre el proyecto de vida de la madre. De ahí la importancia de un acercamiento con base en la comunicación, desde la mirada del género, a esta problemática. Detrás de todos y cada uno de los embarazos que ocurren durante la adolescencia están implicados necesariamente ambos sexos. En estos adolescentes (varones) son más probables la baja autoeficacia personal percibida, la ansiedad y los sentimientos de culpa.

Es preciso fomentar la salud, seguridad y desarrollo intelectual de las hembras, tanto como la de los varones y estimular en ellos el sentido de autoestima. Del mismo modo, se necesita enseñar a los varones a que es irresponsable dejar embarazada a una adolescente si no están preparados para casarse o para mantenerla a ella y a su hijo. Este componente acentúa la necesidad de preparar a los adolescentes del nivel básico superior para que aprendan a tomar decisiones y puedan prever las consecuencias de las mismas antes de que sean ejecutadas.

El componente Procesos de acompañamiento a otros para solucionar inquietudes sexuales, asume como función penetrar en el conocimiento de la esfera sexual. Se privilegia el conversar con sus pares en busca de información y consejo. Sin embargo, la orientación que puede ofrecer un par generalmente es inexacta y aunque bien intencionada, puede impulsar a cometer serios errores. Este componente significa la necesidad de promover que los adolescentes soliciten ayuda para resolver conflictos e inquietudes sexuales, a personas más expertas y en especial a su tutor, maestro, madre o padre de familia.

Entre los componentes de este segundo subsistema, centrado en promover un saber hacer o dominio procedimental en el área de la toma de decisiones vinculadas a la sexualidad, se manifiestan relaciones de doble vía o dependencia recíproca. Se acentúa igualmente, en este subsistema, la necesidad de considerar el papel educativo del tutor, desde su vínculo directo y dialéctico con el quehacer de otros agentes educativos, incluidos los adolescentes, en la aspiración de que estos logren una mejor conducción de sus propias vidas, para una vida sexual plena. 
El subsistema Procesos de actuación relativos a la educación de la sexualidad y la prevención educación del embarazo precoz acentúa la significación de educar para la sexualidad y la prevención del embarazo precoz, desde la estimulación de actitudes y valores. Se estructura a partir de cuatro componentes: procesos de asunción de una postura respecto a la sexualidad como fuente de disfrute, placer y autocomplacencia; procesos de fomento de la autoestima personal, corporal, interpersonal y de género; procesos de solución de conflictos en las relaciones interpersonales y procesos de educación en valores vinculados al ejercicio de la sexualidad: responsabilidad, respeto, tolerancia, equidad, autenticidad, autocuidado. De la sinergia entre sus componentes surge la cualidad: el desarrollo de una conducta sexual responsable (Fig.4).

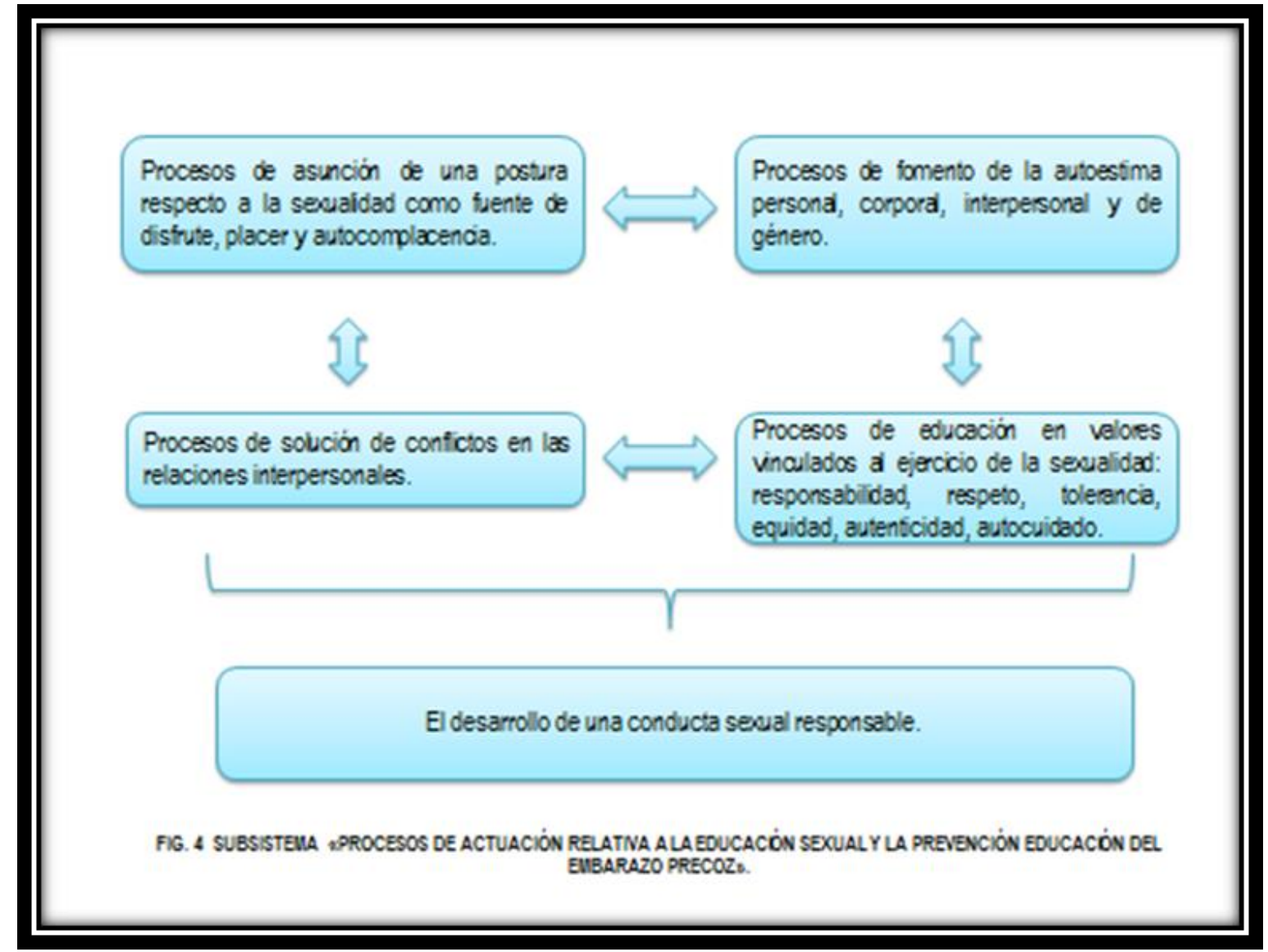

Este subsistema acentúa la significación de educar para la sexualidad responsable y la prevención del embarazo precoz, desde la estimulación de actitudes y valores, que permitan percibir la sexualidad como un aspecto enriquecedor y beneficioso para el ser humano, pero 
que requiere estar asociado a posturas responsables, para ser disfrutada a plenitud. La meta principal de la educación no es imponer preceptos a la persona humana, sino invitarle a ser una persona plena. Educar la sexualidad equivale a educar en el amor hacia el otro. Con respecto al plano de la afectividad, desde la escuela es posible trabajar para desarrollar competencias, valores y actitudes emocionales como la empatía, la solidaridad y la expresión de los sentimientos en el marco del respeto. Sin desmerecer la vía de aprendizaje informal que constituye la experiencia de vivir, es posible diseñar enseñanzas, orientadas a generar formas de expresión de los afectos, que mejoren las relaciones interpersonales y promuevan el crecimiento integral de las personas.

Se requiere educar al hombre para lograr ciudadanos responsables de su sexualidad y de los actos que se cometen en nombre del amor y de esta forma prevenir, por medio de la educación, consecuencias que empañen el futuro exitoso de los adolescentes. La promoción de actitudes y valores para una paternidad responsable, además de ir mucho más allá de la prevención, tiene un efecto preventivo de los embarazos, aunque la prevención del embarazo no implica necesariamente la promoción de la paternidad y la maternidad responsable.

La educación en valores y actitudes socioemocionales favorecedora de una sexualidad responsable y feliz, se concibe desde el rol protagónico del tutor como orientador educativo, pero igualmente desde las contribuciones del resto del personal docente de la institución educativa, de los padres de familia, de los adolescentes de la educación básica superior.

El componente Procesos de asunción de una postura respecto a la sexualidad como fuente de disfrute, placer y autocomplacencia tiene como función destacar la importancia de romper con estereotipos negativos que aluden a la sexualidad como fuente de peligros, riesgos y problemas, por lo cual su educación se circunscribe a prevenir comportamientos de riesgo. Por el contrario, se concibe la sexualidad como fuente de placer, realización personal y su educación, como parte constitutiva de la educación del ser humano como un todo íntegro.

Para valorar la sexualidad adecuadamente, es necesario abordarla con seriedad y responsabilidad, sin olvidar su carácter de satisfacción y bienestar. El fin de las normas objetivas morales no es la represión de la sexualidad, sino proteger y favorecer que el dinamismo profundo de la sexualidad llegue a su plenitud y sentido. No es posible dialogar en términos de una asunción de una postura respecto a la sexualidad como fuente de disfrute, placer y autocomplacencia, si no se fomenta la autoestima personal, corporal, interpersonal y 
de género, de ahí las relaciones de subordinación e interdependencia con el componente Procesos de fomento de la autoestima personal, corporal, interpersonal y de género, que asume como función connotar la necesidad de aumentar la autoestima en los diferentes ámbitos de la vida del adolescente.

Los adolescentes son particularmente sensibles a las críticas, comentarios, gestos o bromas que escuchan sobre su apariencia física y características personales. También, suelen prestar excesiva atención a los cambios en la manera como son tratados por las personas. Por eso, es importante que aprendan a ver y valorarse a sí mismos de forma realista, sin darle una exagerada importancia a algunos mensajes de su entorno. El componente destaca la exigencia de una prevención exitosa del embarazo precoz y una educación de la sexualidad pertinente, respecto a mejorar la autoimagen y autoestima corporal, personal e interpersonal de los estudiantes de estas edades.

El componente Procesos de solución de conflictos en las relaciones interpersonales, tiene como función solucionar la diversidad de conflictos en las relaciones interpersonales. Aparece vinculado a los conflictos y dificultades relacionales que se presentan entre los miembros de las parejas de estas edades, que pueden suponer la práctica o no de relaciones sexuales, la práctica de relaciones protegidas o lo contrario, la decisión de tenencia de un hijo o el abortarlo, de sostener relaciones con otros varones o hembras, entre otros. La mediación, la negociación y el diálogo pueden constituirse en herramientas para el manejo de estos conflictos y deben estimularse desde el rol del tutor grupal y de otros agentes socioeducativos.

Por su parte el componente Procesos de educación en valores vinculados al ejercicio de la sexualidad: responsabilidad, respeto, tolerancia, equidad, autenticidad, autocuidado, posee como función destacar el papel de educar en valores relacionados con la educación de la sexualidad. La educación afectivo-sexual en los valores consiste en ir despertando y estimulando la sensibilidad y el sentido ético de los adolescentes. No presupone transmitir principios teóricos abstractos, si no educar en el amor, la convivencia y para la familia, entre otros fines.

La educación en valores para una sexualidad responsable y plena, implica involucrar, entre otros, la responsabilidad, el respeto, la tolerancia, la equidad, la autenticidad y el autocuidado. La insuficiente educación sexual no solo afecta a chicas y chicos adolescentes acrecentando su 
vulnerabilidad al desproveerlos de conocimientos sobre anatomía, higiene sexual, la respuesta sexual masculina y femenina, entre otros, sino que también los pone en riesgo de un embarazo no planificado y de una vivencia culpabilizada de la sexualidad, cuando no intenta remover las bases de rígidos valores que aún persisten en la sociedad y dañinos estereotipos que responden a modelos sexistas.

A través de una adecuada educación de la sexualidad los adolescentes podrán desarrollar la autoconfianza necesaria para tomar decisiones relacionadas con su sexualidad, que abarquen desde el retardo de la iniciación sexual hasta el respeto a la libre determinación de las adolescentes por parte de sus parejas y la responsabilidad conjunta en cuanto a la salud sexual y reproductiva. Por tanto, la inclusión del enfoque de género responde a una problemática de interés social, vinculada, como principio educativo, a la igualdad en los valores humanos, independientemente del sexo biológico.

Las construcciones de género incrementan la vulnerabilidad de los adolescentes, las cuales carecen de herramientas para entrar en contradicción con las normas aprendidas, y dan inicio a las relaciones sexo-eróticas con el sexo opuesto, a las cuales se enfrentan desprovistas de poder y conocimientos y de una protección adecuada, ya que, según los roles de género prefijados, ellas son el sexo "débil" e "inexperto" que ha de ser "guiado" por el fuerte y "experimentado conocedor" masculino.

La educación de la sexualidad debe favorecer la equidad como base de la relación entre personas de diferente sexo, desde la toma de decisiones compartidas. Es la educación basada en la desaparición de la explotación de un ser humano por otro; en el principio de igualdad de oportunidades a unas y otros; y en el respeto pleno entre las personas.

Los subsistemas se manifiestan de forma simultánea y mediados por las herramientas educativas de que dispone el tutor, en su alianza con los demás agentes educativos.

Las relaciones entre los subsistemas son de coordinación y carácter recíproco y la relación más trascendente del modelo, de orden superior es la aprehensión de una conducta sexual resiliente y responsable como resultado del desarrollo alcanzado desde la acción tutorial y sus relaciones teóricas relativas a la educación de la sexualidad y la prevención del embarazo precoz. Esta relación supone un proceso de actuación resiliente, en el cual se integra la confianza en uno mismo, la capacidad de planificación de la actuación, autocontrol, 
el autorespeto, y la persistencia en el compromiso ante la sexualidad y la prevención del embarazo precoz.

La tipicidad y distinción del modelo aportado radica, en opinión de la autora, en:

1) Acentuar el rol de la tutoría grupal y personalizada en la educación de la sexualidad y la prevención del embarazo en la adolescencia.

2) Destacar la importancia de lograr alianzas entre los factores educativos intervinientes en estos procesos.

3) Connotar la inclusión de hembras y varones en el fin común de evitar el embarazo en estas edades, por las secuelas negativas que trae para sus vidas y las de las figuras de poder que hay a su alrededor, adjudicándoles protagonismo en las acciones preventivo-educativas.

4) Destacar la necesidad de que la prevención combine la información en materia de sexualidad humana (básicamente, de enfoque biologicista, higienista y/o médica), con la educación socioemocional.

\section{Conclusiones del capítulo II:}

El modelo se sustenta en referentes teóricos importantes que incluyen el paradigma sistémico y el método sistémico estructural funcional. Del mismo modo, se soporta en el enfoque sociohistórico-cultural, que preconiza la unidad de lo afectivo y lo cognitivo, así como el imperativo de conocer acerca de la situación social del desarrollo del educando para promover su educación y desarrollo. Desde la perspectiva pedagógica se connotan las categorías educación, prevención educativa y tutoría.

El sistema modelado incluye tres subsistemas estructurales denominados respectivamente: procesos cognitivos, procesos procedimentales y procesos de actuación, todos relativos a la educación de la sexualidad y la prevención del embarazo precoz. Estos enfatizan en la necesidad de que los educandos obtengan información sobre la sexualidad humana y cómo evitar el embarazo precoz y las consecuencias del mismo en el orden personal, social, educativo, psicológico y familiar, entre otras. Asimismo destacan la importancia de la utilización de estrategias para el rechazo ante comportamientos, peticiones o críticas que se 
consideren inaceptables en materia de sexualidad; la anticipación de consecuencias relativas a la toma de decisiones y la solicitud de ayuda a otros para solucionar inquietudes sexuales. Finalmente, connotan la mejora de la autoestima personal, corporal, interpersonal y de género; la educación en valores vinculados al ejercicio de la sexualidad: responsabilidad, respeto, tolerancia, equidad, autenticidad y autocuidado, así como la solución de conflictos relativos al área sexual. 


\section{Capítulo III: Programa DE INTERVEnCión EDUCATIVA TUTORIAL PARA LA PREVENCIÓN DEL EMBARAZO PRECOZ EN ESTUDIANTES DEL NIVEL DE EDUCACIÓN BÁSICA SUPERIOR Y SU VALORACIÓN}

Este capítulo contiene el programa de intervención - educativa tutorial para la prevención del embarazo precoz en el nivel de educación básica superior, y los resultados del proceso de corroboración de su factibilidad y pertinencia respectivamente, a través de talleres de reflexión y construcción colectiva con grupos de especialistas. Se ejemplifica parcialmente el programa concebido para los adolescentes, lo que permitió corroborar las propuestas y sustentar las elaboraciones teóricas que sostienen su estructura. Se valora el modelo y el programa propuestos.

\subsection{Fundamentación del programa de intervención educativa- tutorial} para la prevención del embarazo precoz en estudiantes del nivel básico superior

El presente programa pretende funcionar como un sistema integral de prevención del embarazo en adolescentes, con carácter tutorial, con enfoque de derechos humanos, equidad de género y práctica de valores, el cual garantiza a los adolescentes sus derechos y responde a sus necesidades en materia de educación de la sexualidad y prevención de embarazos y contribuye a la prevención y reducción del embarazo precoz.

Del mismo modo, cumple una función formativa porque los prepara a través del suministro de información sobre sexualidad, a la vez que brinda a los alumnos, educación socioemocional a través del fomento de habilidades y actitudes que les permiten manejar sus emociones, relacionarse asertivamente con sus pares del otro sexo, desarrollar su autonomía emocional y la resiliencia.

Fortalece además la reducción del embarazo en adolescentes, garantiza la igualdad de oportunidades para el desarrollo humano de los adolescentes y promueve la sexualidad sana, 
placentera y responsable, con un trabajo tutorial dirigido a fortalecer la autoestima como mecanismo para favorecer el desarrollo de la inteligencia emocional.

\section{Directrices de intervención}

- Socialización entre las autoridades de la institución, docentes tutores, padres de familia y estudiantes, del marco legal y de políticas internas en materia de educación sexual.

- Fomento a través de la educación de la sexualidad del desarrollo de la autoestima para lograr la resiliencia de los adolescentes.

- Impulso de la participación y organización de los jóvenes en las campañas de educación de la sexualidad, prevención de embarazos, equidad, responsabilidades compartidas y autocuidado.

\section{Etapas}

\section{Primera etapa: Diagnóstico}

El diagnóstico en el presente programa es entendido como el proceso conducente a aportar información, que brinda certidumbre sobre la explicación científica de la realidad, a través de la contextualización de un problema que se plantea. Este enfoque se integra con las teorías, estudios y antecedentes, en general, que se refieran al problema que se pretende dar solución. El diagnóstico en este programa de intervención educativa tiene un carácter científico, por cuanto, obtendrá información procedente de la experiencia, así como de la información obtenida por medio de instrumentos.

\section{Fundamentos del diagnóstico}

El diagnóstico que se prevé en el programa se fundamenta en:

- Sobre los estudiantes giran actividades de orientación. Pretende ayudar a los estudiantes a conseguir un ajuste personal y social adecuado.

- Centrado de forma individualizada en un solo estudiante y los problemas actuales. Es una de las actuaciones educativas indispensables para el tratamiento de los problemas que el alumno puede experimentar en la unidad educativa, puesto que tiene por 
finalidad detectar la información acerca de la educación de la sexualidad que poseen los alumnos, identificar la presencia de casos de embarazos precoces y elaborar planes de intervención educativa para el aumento de su resiliencia, la mejora de las relaciones interpersonales y la toma de decisiones más responsables referidas al comportamiento sexual.

- El diagnóstico educativo es un proceso en el que se analiza la situación de los estudiantes en el contexto de la institución educativa, a fin de proporcionar a los docentes tutores, orientaciones e instrumentos que permitan el abordaje de la educación sexual de manera profesional.

\section{Sujetos participantes en el diagnóstico}

Participa el psicopedagogo, que forma parte del Departamento de Consejería Estudiantil, el cual se halla implicado en diversas actividades de la institución educativa como son: admisión, atención a problemas disciplinarios en coordinación con inspección, comunicación con padres de familia; seguimiento del desempeño académico, entre otros; participan también el docente tutor, los estudiantes, la familia, la comunidad y otros profesionales que intervienen a nivel social. El papel central corresponde al tutor, el cual recibe asesoramiento especializado del psicopedagogo.

\section{Elementos del diagnóstico educativo}

- La derivación. Aplicación de una ficha que recoge la información inicial que el docente tutor rellena, como primer paso del diagnóstico.

- Entrevista con el docente tutor. El docente tutor proporciona al Departamento de Consejería Estudiantil información sobre los estudiantes del curso o paralelo asignado.

- Entrevista con los padres de familia. Ponerse en contacto con los padres de familia para obtener y dar información sobre el estudiante.

- La observación. Observar al estudiante en diferentes áreas, como el salón de clases, en el descanso, en las prácticas de laboratorio, prácticas deportivas o participación en los talleres de arte y cultura. 
- Revisión de los trabajos de clase. Esta actividad completa la observación, al analizar los trabajos del estudiante, así como los materiales con los que trabaja.

- Trabajo individual con el estudiante. Se realiza la entrevista y exploración de los estudiantes para obtener una valoración correcta de las dificultades que presentan y para su orientación posterior.

\section{Segunda etapa: Planeación}

Para lograr una programación acorde con la realidad, los objetivos, resultados esperados y acciones específicas, esta debe responder al diagnóstico y al análisis de la realidad, además requiere seguir una serie de pautas operativas o criterios determinados por la teoría de la Planificación de la Educación, la Administración Educativa y por los aportes del método científico.

Entre esas pautas se pueden resaltar los procesos y elementos necesarios para realizar una programación, como lo son la previsión, la cual permite analizar con anticipación la totalidad de los problemas y factores que afectan el desarrollo del programa. La selección, que ayuda a priorizar lo que se debe hacer. Además de la organización, donde se establecen las relaciones entre todos los elementos de la acción programada, para obtener una estructura planificada. Así mismo, no se pueden dejar de lado los criterios para elaborar programas y proyectos, como lo es la definición de objetivos, los cuales deben establecer la intención que se pretende hacer realidad y los resultados esperados en un determinado período de tiempo.

Los objetivos en este programa tienen una relación clara con los resultados esperados, estas se constituyen en un objetivo específico definido cuantitativamente en un espacio y tiempo dado; la comisión interdepartamental ejecutora del programa debe garantizar que exista siempre relación entre el objetivo, los resultados esperados y las actividades claves. Antes de realizar la ejecución de la programación de acciones, se deben garantizar los insumos necesarios que exigen las actividades programadas, de ahí la gran importancia de un diagnóstico para realizar esta tarea. 


\section{Objetivos derivados de las directrices de intervención}

Objetivo 1: Promocionar y apoyar el marco legal y de políticas institucionales que favorezcan el desarrollo de la educación sexual y la prevención de embarazos en adolescentes.

\section{Resultados esperados:}

- Autoridades, docentes tutores, estudiantes y padres de familia con conocimientos sobre el marco legal y los derechos vinculados a la educación de la sexualidad de los adolescentes.

- Comisión interdepartamental para la ejecución del programa de intervención educativa tutorial para la prevención del embarazo precoz en estudiantes de educación básica superior.

\section{Acciones claves:}

- Realización de investigación sobre legislación nacional e internacional vinculada la educación de la sexualidad en adolescentes.

- Elaboración de documentos con recopilación de legislación nacional e internacional sobre la educación de la sexualidad de los adolescentes.

- Desarrollo de una campaña de comunicación social sobre educación de la sexualidad y la prevención de embarazos.

- Establecimiento de un banco de recursos y materiales de información, educación y comunicación (IEC) sobre educación de la sexualidad y asistencia a adolescentes embarazadas.

- Constitución del comité interdepartamental para la coordinación del presente programa.

- Elaboración del plan operativo anual del Comité interdepartamental para la ejecución del presente programa.

- Elaboración del plan de monitoreo y evaluación del programa. 
- Elaboración y rendición periódica de informes.

- Establecimiento de planes de apoyo psicoeducativo para grupos de adolescentes vulnerables.

- Establecimiento de proyectos de recreación y uso adecuado del tiempo libre para adolescentes.

- Establecimiento de un plan de vigilancia escolar para garantizar la no exclusión de adolescentes embarazadas y promover la reinserción escolar de adolescentes madres.

Objetivo 2: Promover la incorporación de la educación de la sexualidad integral, la autoestima y resiliencia en la educación básica superior, desde la acción tutorial.

\section{Resultados esperados:}

- Proyecto de educación de la sexualidad integral, implementado en el nivel de educación básica superior.

- Currículo revisado y actualizado incorporando la educación de la sexualidad integral como eje transversal.

- Diseño de propuestas pedagógicas para elevar la autoestima en los estudiantes con pautas seleccionadas y recomendadas en concordancia con las necesidades locales e institucionales

- Proyecto de capacitación permanente al docente tutor en un marco de capacitación continua de educación de la sexualidad integral y prevención de embarazos precoces.

\section{Acciones clave:}

- Diseño y elaboración del proyecto de educación de la sexualidad integral.

- Realización de encuentros, jornadas y reuniones con los miembros de la comunidad educativa para consenso y presentación del Proyecto.

- Realización de talleres y jornadas de revisión y actualización curricular. 
- Diseño, elaboración y producción de materiales pedagógicos.

- Desarrollo de experiencias pilotos para validación de materiales pedagógicos.

- Talleres y jornadas de capacitación para docentes tutores.

- Elaboración de materiales de capacitación para formación del docente tutor.

- Encuentros y jornadas informativas y de sensibilización sobre educación de la sexualidad integral dirigidas a familias.

- Elaboración de un plan de monitoreo y evaluación del proceso de incorporación de la educación de la sexualidad integral en el nivel de educación básica superior.

- Presentación periódica de resultados de monitoreo y evaluación al proceso de implementación de la educación de la sexualidad integral.

- Formación de jóvenes como agentes multiplicadores para apoyar la campaña de prevención de los embarazos precoces.

- Producción de materiales informativos y de apoyo para la prevención de embarazos precoces.

Objetivo 3: Impulsar la participación de los adolescentes en las campañas de educación de la sexualidad, prevención de embarazos, equidad, responsabilidades compartidas y autocuidado.

\section{Resultados esperados:}

- Adolescentes con acceso a servicios de educación de la sexualidad amigable y de calidad.

- Estudiantes que reciben una oferta integral de educación de la sexualidad, que incluye servicios dirigidos a la prevención del embarazo en adolescentes.

- Proyectos educativos formadores de docentes tutores que aborden profesionalmente el tema de educación de la sexualidad y prevención de embarazos en adolescentes, autoestima, equidad, responsabilidad y autocuidado. 


\section{Acciones claves:}

- Sensibilización al estudiantado sobre las consecuencias biológicas, psicológicas y educativas de un embarazo precoz.

- Aseguramiento de insumos anticonceptivos en los servicios para adolescentes.

- Desarrollo de acciones de información, educación y comunicación dirigidas a promover la prevención del embarazo.

- Establecimiento de políticas institucionales que garanticen confidencialidad y privacidad para las adolescentes.

- Mejoramiento del trabajo de consejería para prevención de embarazo en los adolescentes.

- Sensibilizar y capacitar a las autoridades académicas para que sea incluido como eje transversal en el currículo, el tema de educación de la sexualidad y prevención del embarazo precoz.

\section{Tercera etapa: Ejecución}

La ejecución lleva implícitos los siguientes aspectos:

- Trabajo en grupo: pone en práctica la filosofía de participación de todos los involucrados en la toma de decisiones o realización de determinados actos. Intervienen autoridades, docentes tutores, padres de familia y estudiantes; los primeros ejercen influencia en los segundos a través de la autoridad y el mando, sobre la base de la comunicación eficaz y efectiva entre los miembros de la organización.

- La delegación de autoridad: forma técnica para comunicar la facultad de decidir sin perder el control de lo que se ejecuta. Permite conducir o retar a otros para que hagan su mejor esfuerzo.

- La ejecución de las tareas asignadas: es la realización de las tareas que se habían orientado, desarrollando el potencial de cada miembro implicado. 
- Estimulación de los logros obtenidos: se satisfacen las necesidades de los estudiantes, incluyendo estímulos materiales y/o reconocimientos morales, por los esfuerzos realizados.

- La supervisión: revisar si las cosas se están haciendo tal y como se habían planeado y ordenado, chequeando la ejecución de las tareas asignadas a la luz de los resultados del control.

El programa en su conjunto será ejecutado con una duración de 3 años; cada uno de los cuales considera actividades planificadas trimestralmente, siguiendo los aspectos antes mencionados, las fases del programa y los objetivos derivados de las directrices de intervención. Plantea el siguiente cronograma (Ver Anexo 14).

\section{Cuarta etapa: Monitoreo y evaluación}

El Comité Interdepartamental que gestionará el cumplimiento del presente programa, es responsable de las acciones de monitoreo y seguimiento del mismo, a partir de los indicadores de resultados ya definidos. Un Plan Operativo Anual (POA) será elaborado, ejecutado y evaluado cada año, de igual forma se espera que los departamentos integren en sus planes y presupuestos anuales, las líneas estratégicas y acciones correspondientes a este programa de intervención.

El monitoreo será continuo a través de los POA, cada fin de año lectivo, será presentado un informe para valorar el alcance de metas y necesidades de ajustes. El fin último de este programa es la reducción del embarazo en las adolescentes, mediante herramientas de la educación socioemocional.

\subsection{Valoración teórica del modelo y del programa de intervención} educativa tutorial para la prevención del embarazo precoz en estudiantes del nivel básico superior

Para valorar teóricamente el modelo de intervención educativa tutorial para la prevención del embarazo precoz en estudiantes del nivel básico superior, se utilizó el método de talleres de opinión crítica y construcción colectiva, tomando como punto de partida la metodología 
planteada por V. Cortina Bover \& Y. Trujillo Baldoquin (2009). El objetivo de los talleres estuvo dirigido a elaborar criterios fiables que desde una dimensión colectiva y sobre la base del análisis y la argumentación, aporten juicios y con posterioridad valoraciones de especialistas sobre la factibilidad del aporte teórico y la herramienta práctica, que sobre el objeto se alcanzan en la investigación pedagógica. El procedimiento utilizado fue el siguiente:

\section{Etapa previa a los talleres:}

1. Se definieron los grupos afines con el tema que será objeto de opinión crítica y construcción colectiva. Esto permitió determinar el número de talleres a realizar, de modo que le correspondiera uno por cada grupo.

2. En la selección de los grupos se consideró que funcionaran regularmente de manera estable, lo cual posibilitó que se estableciera una participación amplia, dado el nivel de relaciones interpersonales que existen entre los miembros del grupo. La experiencia indicó, sin un criterio definitivo adoptado, que el número de personas por sesión, no debía ser menor de diez.

3. Como son grupos constituidos, el estudio de las características particulares de los componentes del grupo se realiza con posterioridad a la realización del taller. No obstante, en la selección de los grupos, desde una percepción global, se escogieron, aquellos que tenían afinidad y conocimientos profesionales del tema a tratar en el taller.

4. Se realizaron cinco talleres. En el primero se escogió el grupo que a priori se consideró tenían los conocimientos y los profesionales en mejores condiciones de aportar al tema, incluso en el orden teórico. El último taller se realizó en el grupo que tenía una sólida experiencia práctica alrededor del tema y que debía ser el introductor fundamental de la propuesta a discutir. Lo anterior se sustenta en el criterio de alcanzar una aproximación gradual a los niveles de organización más ejecutores, lo que permite presentar, una propuesta más acabada. 


\section{Etapa de ejecución del taller:}

1. Introducción del taller: se realizó una presentación del fundamento teórico, el modelo y el programa propuesto, mediante la que se exponen las ideas esenciales, con los argumentos que las respaldan. Se emplearon alrededor de 30 minutos en este aspecto. A partir del segundo taller, la investigadora presentó una síntesis de los aspectos que en el taller anterior le sugirieron perfeccionar, presentando las nuevas propuestas que en su criterio resolvían el problema señalado.

2. Desarrollo del taller: se dio apertura al debate, que es conducido por la propia investigadora. Se auxilió de un registrador que iba documentando las intervenciones realizadas, anotando el nombre del profesor que intervenía. En caso de algún planteamiento polémico, se sometió al análisis colectivo, que la investigadora estimuló con el fin de lograr la suficiente argumentación alrededor del objeto de discusión. Agotado el debate, se dio lectura al registro de la sesión de trabajo, para verificar la fidelidad entre el documento y los planteamientos que se realizaron.

3. Conclusión del taller: a modo de conclusión la investigadora resumió los aspectos en los que concuerda con el auditorio, que fueron suficientemente argumentados y que se aceptaron como elementos a incluir en la propuesta, la cual contribuye a su perfeccionamiento. Apuntó, además, otros aspectos que se tendrán en cuenta para un posterior análisis.

\section{Etapa posterior a cada taller:}

1. Después de cada taller la investigadora realizó un minucioso estudio del registro correspondiente. Elaboró una síntesis de los aspectos destacados y realizó el estudio detallado de los participantes en función de los parámetros seleccionados para caracterizar profesionalmente a los participantes.

2. Reelaboró la propuesta incorporando los elementos que aportó el taller. Preparó el documento a presentar en el siguiente, en el que se confrontaron los aportes realizados en el perfeccionamiento de la propuesta.

3. La investigadora fue contrastando los resultados de cada taller, ponderándolos con la preparación de los participantes, lo que dio fundamento a los criterios manifestados. 
4. Al concluir el último taller se elaboró una síntesis de lo que aportó cada taller a la propuesta, de manera que se evidenciara la dinámica del cambio que conduce al perfeccionamiento del documento que al inicio se presentó.

Como resultado de los talleres quedó documentado un expediente que recogió: la caracterización individual de los integrantes de cada grupo y colectiva del grupo en cuestión, registro de experiencias con la memoria de cada taller, resumen sintético de cada taller, documento resumen en el que se evidenció la dinámica del cambio de las propuestas realizadas y que se incorporaron a la propuesta sometida a los talleres, versión resultante de la propuesta sometida a análisis y documento de evaluación de la calidad de cada taller.

Posteriormente a la delimitación del objetivo, se seleccionó la muestra de los especialistas a participar (10), a partir de la precisión de determinados indicadores, en correspondencia con la intencionalidad de la investigadora que, por una parte, pretende garantizar la calidad de los especialistas en el orden de su preparación, pero a la vez combinar esto con la experiencia en el accionar educativo en el nivel básico superior. Las variables intervinientes consideradas para la selección de los potenciales especialistas fueron:

- Años de experiencia en el desempeño profesional, relacionados con el proceso que se investiga (la educación de la sexualidad de adolescentes).

- Años de experiencia como docente, tutor o directivo en el nivel básico superior.

- Profesión o formación inicial, en su relación con el proceso objeto de análisis.

- Responsabilidad que cumple laboral o institucionalmente (directivo, docente, tutor, psicopedagogo, psicólogo, orientador escolar, médico u otras).

- Título académico o grado científico.

- Producciones científicas realizadas respecto al tema que se valora.

Estos indicadores se comportaron del modo siguiente: el $80 \%$ de los participantes son másteres en ciencias, mientras el $20 \%$ solo poseen título de licenciatura. La media aritmética de los años de ejercicio profesional es de 18 y el de trabajo en el nivel básico superior es de 15 años. Prevalecen en la muestra los que realizan tareas docentes y tienen formación inicial en carreras de perfil educativo, aunque el $30 \%$ son psicólogos y el $10 \%$ médicos, de los primeros dos laboran en el Departamento de Consejería Estudiantil del ITSUP y una es supervisora 
escolar. Las producciones científicas de los participantes en torno al tema son limitadas, por la pobre tradición de publicaciones por parte de los profesionales procedentes del Ecuador. Solo se reconocen escritos del médico y la psicóloga supervisora escolar.

Posteriormente se sugirió a los participantes los temas o criterios privilegiados para la discusión, los cuales consistieron en:

- Pertinencia de los fundamentos teóricos y prácticos que sustentan los aportes científicos propuestos (teórico y práctico).

- Novedad científica del constructo teórico propuesto (modelo).

- Factibilidad de aplicación y pertinencia del constructo práctico propuesto.

- Recomendaciones para el perfeccionamiento de las propuestas científicas (modelo y programa).

- Otras sugerencias para la mejora de los resultados.

Posteriormente, los especialistas procedieron a debatir sus criterios y juicios críticos, los cuales fueron registrados por la investigadora, para posteriormente proceder a su valoración, con vistas al perfeccionamiento y enriquecimiento de su investigación y en particular de sus aportes teórico y práctico. De las valoraciones aportadas, la investigadora determinó cuáles resultaron significativas y trascendentes para el perfeccionamiento de su propuesta, teniendo en cuenta la frecuencia con que fueron expresadas y los argumentos expuestos para su sugerencia, las cuales se enuncian a continuación:

1. Se destaca el valor del modelo como una construcción teórica novedosa y necesaria, que sistematiza los imperativos de la educación de la sexualidad en el nivel básico superior y particularmente las vías para prevenir el embarazo temprano en la adolescencia, connotándose el rol del tutor como agente educativo y el de los propios estudiantes.

2. El programa de intervención educativa tutorial se considera pertinente y viable, aunque se indican algunas recomendaciones para su mejora:

- Se debe fortalecer dentro del buen vivir, la relación del sujeto consigo mismo. 
- Se sugiere conformar un comité de adolescentes, para que ellos propongan las temáticas a ser abordadas a través del programa, en función de darles una orientación asertiva, relativa a su comportamiento sexual.

- Dentro de las acciones clave del programa, es preciso involucrar al padre de familia como agente educativo, de modo tal que este se haga partícipe, de modo protagónico, de la educación de la sexualidad destinada a los hijos. De este modo, la familia se convertiría en aliada del tutor y demás agentes educativos escolares en su labor educativo-preventiva.

- En relación con lo anterior, se sugiere que se deben dar talleres de educación de la sexualidad a los padres de familia, para centrar más al padre de familia en el programa de intervención. Se apunta que es necesario lograr que los adolescentes desarrollen confianza en los padres, para que les comenten sobre su vida sexual, les soliciten apoyo y orientación.

- Se sugiere que los tutores hagan sentir importantes a los estudiantes adolescentes, para alimentar la autoestima y la resiliencia de estos.

Del mismo modo, se debe resaltar más en el programa, el rol del tutor como agente aglutinador de las diferentes influencias educativas, para que estas sean coherentes, en aras de promover la educación de la sexualidad y la evitación del embarazo en estas edades de la vida.

Las sugerencias antes planteadas se tomaron en consideración para el perfeccionamiento de las propuestas y en particular el programa de intervención, previamente a su implementación en la práctica educativa.

El modelo y el programa se perfeccionaron mediante la opinión crítica y la construcción colectiva derivadas de los talleres y los fundamentos teóricos recopilados en la búsqueda bibliográfica, lo que permitió confirmar teóricamente que el programa cumple los requisitos esenciales para su implementación. Una vez terminados los talleres de opinión crítica y construcción colectiva, se procedió en el menor tiempo posible a la reelaboración del programa propuesto a partir de las consideraciones de los participantes en estos talleres. 


\subsection{Valoración práctica del programa de intervención educativa tutorial}

para la prevención del embarazo precoz en estudiantes del nivel básico superior

El pre-experimento pedagógico se concibió con el objetivo de corroborar la validez del modelo educativo y preventivo del embarazo precoz en estudiantes del nivel básico superior, desde la acción tutorial, así como corroborar la eficacia del programa como instrumento práctico, que contribuye a favorecer la prevención del embarazo precoz en el proceso de educación de la sexualidad. Se partió de la hipótesis siguiente: La implementación de un programa de intervención psicoeducativa tutorial dirigido a estudiantes del nivel básico superior, sustentado en un modelo educativo-preventivo basado en la acción tutorial, dinamizado por la contradicción entre la función preventiva y la función formadora de la educación de la sexualidad, puede contribuir a favorecer la prevención del embarazo en las adolescentes.

En la aplicación del programa participó un grupo de 25 estudiantes, del nivel básico superior de la Unidad Educativa ITSUP, de Portoviejo, Manabí, Ecuador. La intervención la desarrollaron los profesores que laboran en la institución y particularmente en el nivel básico superior, bajo la coordinación de profesores-tutores como agentes educativos esenciales y se estructura, en lo fundamental, en tres momentos:

1) Diagnóstico de los estudiantes y preparación de los profesores-tutores y otros agentes educativos.

2) Ejecución del programa para prevenir el embarazo precoz.

3) Evaluación de la efectividad del programa.

Momento 1. Diagnóstico de los estudiantes y preparación de los profesores-tutores y otros agentes educativos

Para la ejecución de este primer momento se requirió la aplicación de varios instrumentos (Ver Anexos 1,2 3, 4, 5, 7, 9, 11,13), los mismos facilitaron el diagnóstico inicial que se constituyó en el punto de partida para la implementación del programa.

Los indicadores para la realización de dicho diagnóstico son los mismos que se consideraron en el diagnóstico fáctico y se relacionan a continuación: 
a. Nivel de conocimientos sobre la significación y el papel que les corresponde a los agentes educativos en la educación de la sexualidad y la prevención del embarazo precoz.

b. Mecanismos que se utilizan para promover la educación de la sexualidad y la prevención del embarazo precoz.

c. Acciones que se realizan para lograr metas específicas.

d. Nivel de conocimientos de los estudiantes sobre la educación de la sexualidad y la prevención del embarazo precoz.

e. La intencionalidad comunicativa referida a temas sobre la prevención del embarazo precoz entre los alumnos, con los profesores-tutores y agentes socioeducativos.

f. Disposición de actitudes para la prevención del embarazo precoz.

Para diagnosticar el nivel de los conocimientos se aplicó un cuestionario a los estudiantes (ver Anexo 13), a través del cual se reveló que existen carencias cognoscitivas y problemas de conducta en la mayoría de los adolescentes, relativos a la educación de la sexualidad y el embarazo precoz.

Del mismo modo, se le aplicó una entrevista a los profesores-tutores y agentes socioeducativos (Anexo 7) para determinar los contenidos y temas que sobre sexualidad y prevención eran tratados con los alumnos, al igual que los mecanismos utilizados desde las diferentes actividades desarrolladas con los alumnos. Los resultados arrojaron cierta correspondencia con lo planteado con los alumnos, ya que varios conocimientos esenciales no se trabajaban, la comunicación sobre esta temática era vedada y los mecanismos utilizados no facilitaban la aprehensión por parte de los alumnos de los contenidos tratados, lo cual se reflejaba a través de sus comportamientos.

Al aplicar una entrevista, una composición (Anexo 5, 9) y un completamiento de frases (Anexo 11) sobre la disposición de actitudes de los estudiantes ante la educación sexual y su prevención, se corroboró que el $40 \%$ de los estudiantes, manifiesta una actitud negativa ante el indicador. La mayoría considera que la prevención del embarazo es una responsabilidad solo de la mujer y de la misma forma, el deber de buscar información científica sobre los métodos anticonceptivos. Dentro de las frases más reiterativas emitidas por los alumnos 
varones están las siguientes: "Es una responsabilidad de la mujer "," por qué ella no se cuidó"," no pensé que de una sola vez se podría embarazar ","por qué no le preguntó a una amiga", "eso es cosa de mujeres", entre otras.

Con respecto al indicador intencionalidad comunicativa entre los alumnos y con los profesores-tutores y agentes socioeducativos, se evidenció que aunque existe buena comunicación entre ellos, casi siempre es sobre temas relacionados con los contenidos de las asignaturas, no así sobre temas relacionados con la sexualidad y mucho menos con los que tienen que ver con la prevención del embarazo. La sexualidad y el embarazo son en alguna medida temas tabú en el contexto ecuatoriano y los adolescentes prefieren procurar información en intercambios con los amigos mayores y por los medios de comunicación. Lo más preocupantes es que el $54 \%$ refiere estar poco satisfecho con los conocimientos que poseen sobre el tema, pero lo dejan a la espontaneidad de los hechos y piensan que a ellos no les va a suceder.

Con respecto al indicador la disposición de actitudes, ante la educación de la sexualidad y su prevención, también se constata que no existen manifestaciones explícitas de altos niveles del mismo.

Como consecuencia se realizó la preparación de un curso para los profesores-tutores y agentes socioeducativos que trabajarían con los estudiantes obteniéndose una buena disposición de los mismos, lo que condujo a una efectiva apropiación de los elementos esenciales del programa de intervención.

\section{Momento 2. Ejecución del programa para prevenir el embarazo precoz}

La ejecución del programa se realizó según lo planificado y considerando los principales resultados de la aplicación de los instrumentos a los alumnos y a los docentes. La primera etapa de aplicación del programa, diagnóstico, aportó información que sustenta la explicación científica de la realidad, a través de la contextualización del problema que se plantea. Se involucraron en este proceso el psicopedagogo, el docente-tutor, los alumnos y alumnas, la familia y otros profesionales que intervienen a nivel social. El papel central le correspondió al tutor, el cual fue asesorado por el psicopedagogo. 
En el diagnóstico se aplicaron técnicas: aplicación de una ficha que recoge la información inicial que el docente tutor rellena, entrevista con el docente tutor y con los padres de familia, observación al estudiante en diferentes áreas, revisión de los trabajos de clase y el trabajo individual con el estudiante.

En la segunda etapa, planeación, se logró:

- La realización por el docente tutor y el psicopedagogo de investigaciones sobre legislación nacional e internacional vinculada la educación de la sexualidad en adolescentes, que derivaron en documentos que sistematizaron esta información.

- Desarrollo de una campaña de comunicación social sobre educación de la sexualidad y la prevención de embarazos que propició el diseño de un plan operativo anual interdepartamental de monitoreo y evaluación y estableció políticas institucionales y planes de apoyo psicoeducativo para grupos de adolescentes vulnerables.

- Establecimiento de un plan de vigilancia escolar para garantizar la no exclusión de adolescentes embarazadas y promover la reinserción escolar de adolescentes madres, a través de proyectos de recreación y uso adecuado del tiempo libre.

- Mejoramiento del trabajo de consejería y formación de jóvenes como agentes multiplicadores para apoyar la campaña de prevención de los embarazos precoces.

- Sensibilización y capacitación de las autoridades académicas para que sea incluido como eje transversal en el currículo, el tema de educación de la sexualidad y la prevención del embarazo precoz.

En la tercera etapa, ejecución, se ponderó el trabajo en grupos, la delegación de autoridad, la ejecución de las tareas asignadas a cada miembro, se estimularon los logros obtenidos y se fue riguroso con la supervisión. La cuarta etapa de monitoreo y evaluación fue responsabilidad del Comité Interdepartamental que gestionó el cumplimiento del programa; es responsable de las acciones de monitoreo y seguimiento del mismo, a partir de los indicadores de resultados ya definidos. Se elaboró un Plan Operativo que integró las líneas estratégicas y acciones de cada departamento. 


\section{Momento 3. Evaluación de la efectividad del programa}

El resultado final de los conocimientos adquiridos por los alumnos evidencia que la motivación por el tema, aunque fue gradual, permitió el dominio de los aspectos fundamentales sobre la educación de la sexualidad y sobre la necesidad de la prevención de embarazo precoz a partir del empleo oportuno y adecuado de los métodos anticonceptivos (femeninos y masculinos).

Con respecto al indicador intencionalidad comunicativa, los resultados coinciden con los obtenidos en los instrumentos aplicados. Se evidencia la toma de iniciativa en el diálogo con docentes y tutores; al igual que el empleo de la terminología científica sobre la temática en los intercambios comunicativos con docentes y entre los adolescentes.

El indicador referido a la disposición de actitudes, ante la educación de la sexualidad y su prevención también se manifestó de la misma forma. Los estudiantes en su mayoría evidencian un cambio de actitud discreta con su pareja. Las hembras manifiestan mayor autorrespeto y exigen derechos que hasta el momento de la investigación les eran limitados. Se manifiestan con mayor responsabilidad ante su propia sexualidad y prevención educativa.

El análisis realizado permite a la autora aseverar que las transformaciones que ocurren en los adolescentes son discretas, pero son suficientes para asegurar que en ellos se han realizado cambios favorables que les posibilitan alcanzar un desarrollo de la sexualidad como dimensión de su personalidad, y específicamente en lo relativo a la prevención del embarazo precoz particularmente y en la esfera de la sexualidad.

Las modificaciones positivas, que suceden en la conducta de las adolescentes, relativas a la esfera de la sexualidad, constituyen un importante logro de la prevención educativa.

En sentido general en los alumnos:

- Se observa mayor permanencia de los adolescentes en el Departamento de Consejería Estudiantil del ITSUP, en busca de información científica y de asesoría científica sobre los temas tratados.

- Se constata la solicitud permanente de Conferencias de actualización sobre los temas estudiados, al igual que de foros interactivos en la red del ITSUP, donde los especialistas interactúen con los adolescentes hembras y varones. 
- Con mayor frecuencia se escuchan juicios referidos sobre el embarazo, como una responsabilidad compartida de la pareja y lo manifiestan en actitudes más respetuosas y dialógicas con la pareja.

- Se aprecia un mayor interés y motivación por conocer la mayor diversidad y efectividad de métodos de anticoncepción adecuados para la edad, no así en el caso de las hembras.

- Se observa que ha disminuido el número de casos de deserción escolar por causa de embarazos en adolescentes.

\section{Con respecto a los profesores:}

- Se evidencia una doble intencionalidad de la preparación sobre educación de la sexualidad y específicamente sobre la prevención del embarazo precoz en calidad de formadores y tutores.

- Se constata que no solo los profesores de ciencias naturales toman la iniciativa en temas relacionados con la educación de la sexualidad y la prevención del embarazo adolescente.

- Se presentan solicitudes de realizar investigaciones sobre educación de la sexualidad y la prevención del embarazo adolescente, en el contexto de Manabí, donde se involucre también a la familia.

\section{Conclusiones del Capítulo III}

El programa de intervención educativa tutorial para la prevención del embarazo precoz en estudiantes del nivel básico superior, constituye la concreción del modelo sustentado.

La validez del modelo educativo y preventivo del embarazo precoz en estudiantes del nivel básico superior, desde la acción tutorial y el programa correspondiente para la prevención del embarazo precoz, fue corroborada a partir de los criterios emitidos en los talleres de reflexión y construcción colectiva y la aplicación del programa en la práctica, realizado en la unidad de estudio seleccionada, lo cual permitió afianzar la sostenibilidad científica de los aportes. 


\section{CONCLUSIONES}

La presente investigación permitió llegar a las siguientes conclusiones:

1. La sistematización de los fundamentos epistemológicos del objeto y el campo, así como el análisis de su evolución histórica, revelaron inconsistencias teóricas sobre la educación de la sexualidad y específicamente sobre la prevención educativa del embarazo precoz en estudiantes del nivel básico superior. Dichas inconsistencias, que tienen su expresión en la práctica, fueron reveladoras de la necesidad de realizar aportes en función de esas carencias teóricas y prácticas.

2. A partir de las deficiencias epistémicas reveladas en el estudio histórico tendencial unido a la sistematización de los referentes teóricos: de tipo filosófico, sociológico, psicológico, pedagógico y didáctico, se elabora un modelo de prevención educativa del embarazo precoz, en el que se concibe el proceso de educación de la sexualidad como un proceso formativo, conducente al desarrollo humano y socioemocional de los adolescentes.

3. Los resultados obtenidos a partir del diagnóstico de la situación actual del proceso de prevención del embarazo precoz de los estudiantes de básica superior, revelaron las insuficiencias que fueron consideradas para la fundamentación de los principales aportes realizados.

4. El modelo educativo - preventivo del embarazo precoz para estudiantes de educación básica superior propuesto, revela la lógica entre los subsistemas :procesos cognitivos relativos a la educación de la sexualidad y la prevención educativa del embarazo precoz; procesos de instrumentación relativos a la educación de la sexualidad y la prevención educativa del embarazo precoz y procesos de actuación relativos a la educación de la sexualidad y la prevención del embarazo precoz, los cuales se conectan mediante relaciones de coordinación e interdependencia recíproca.

5. En especial se significa, que de las relaciones que se establecen entre los subsistemas del modelo, surge una cualidad superior del sistema, denominada la aprehensión de una conducta sexual responsable y resiliente en estudiantes del nivel básico superior. 
6. Los principales resultados científicos expresados en la tesis han sido valorados positivamente a través de los talleres de opinión crítica y construcción colectiva y demuestran necesidad de su perfeccionamiento.

7. La efectividad del programa de intervención se manifiesta en los resultados de la implementación de la misma a través de un pre-experimento pedagógico y se expresa en la incidencia del mismo al minimizar las insuficiencias en la educación de la sexualidad y la prevención educativa del embarazo precoz de los estudiantes de educación básica superior del ITSUP de Manabí Ecuador. 


\section{RECOMENDACIONES}

- Generalizar la presente investigación en otros contextos educativos.

- Realizar nuevas investigaciones dirigidas a favorecer la educación de la sexualidad y la prevención de infecciones de trasmisión sexual en adolescentes. 


\section{BiBLIOGRAFÍA}

Acosta, D. y Gastelo, R. (2012). Embarazo en la adolescencia y proyecto de vida. Caso: liceos públicos de Cumaná, municipio Sucre, estado Sucre año escolar 2010-2011. Trabajo de grado, Universidad de Oriente núcleo de Sucre. [en linea]. Cumaná, Venezuela. Recuperado el 17 de diciembre de 2012, de: < http://ri.bib.udo.edu.ve/handle/123456789/2327/>.

Aguilar, G. (1996). Educación de la sexualidad en la adolescencia: métodos y contenidos. Ponencia presentada en VII Congreso Latinoamericano de Sexología y Educación Sexual - I Congreso Cubano de Educación, Orientación y Terapia Sexual. Memorias. La Habana, Cuba.

Aguilar, J. (1994). Antología de la sexualidad humana, (Vol 3), México: Conapo.

Aller, L.M. (1991). Pedagogía de la sexualidad. Buenos Aires: Editorial Galerna.

Aller, L.M. y Ruiz, M. (1994). Sexualmente Irreverentes. Brasil: Ediçâo Comunicarte.

Álvarez, C. (1987). Educación para la salud. Embarazo en la adolescencia. La Habana: Ed. Científico Técnico.

Andrade, A., Da Silva, P., Escoba, N. \& Ulloa, A. M. (2009). Revisión teórica de factores de riesgo, protección y prevención en el embarazo en adolescentes. [s.I]: [s.n]

Andrade, M. I. (2009). Experiencias de las adolescentes en relación a su primer embarazo y subsecuente; factores condicionantes y sus consecuencias en mujeres de 15 a 19 años que son atendidas en el S.C.S PUENGASì/1 en el año 2009. Trabajo de grado. Universidad Andina Simón Bolívar. Quito. Ecuador.

Antología de la Sexualidad Humana. (1994). (Tomo II) Ciudad de la Habana, Cuba: [s.n]

AUNIES. (2000). Programas institucionales de tutoría. Una propuesta de las AUNIES para su organización y funcionamiento en las instituciones de Educación Superior.[s.l]: [s.n]

Anzoategui, J. (s.a). Plan de intervención educativa para la prevención del embarazo en adolescentes de la comunidad San Rafael. [en línea]. Recuperado el 18 de diciembre de 2015, de monografias.com 
Araguaia de Castro, M. (2016). Sexualidade. [en línea]. Recuperado 16 de marzo 2016, de: <http://mundoeducacao.bol.uol.com.br/sexualidade/>.

Armas, A. (2002). La formación de la identidad de género en niñas y niños retrasados mentales. [s.I]: [s.n].

Armas, A. (2009). Programa de educación sexual destinado a la familia de niños y niñas preescolares con retraso mental presuntivo. Disertación Doctoral no publicada. Universidad de Camagüey "Ignacio Agramonte Loynaz", Camagüey, Cuba.

Armas, E., Genoveva, S. y Toala, B. (2009). La práctica de valores la educación de la sexualidad de los y las estudiantes del Colegio Nacional Olmedo de la ciudad de Portoviejo. [s.I]: [s.n].

Ascuy, A. B. (2001). La educación de la sexualidad en el círculo infantil. Una estrategia para su perfeccionamiento. Disertación Doctoral no publicada. Instituto Superior Pedagógico "Enrique José Varona”, La Habana, Cuba.

Asociación mexicana de educación sexual A.C. (2003). Hablemos de educación y salud sexual. Manual para profesores de la educación. Información, herramientas y recursos. (V I y II.). México.

Bach, R. K. (1986). La educación sexual como preparación de niños y adolescentes para el amor, el matrimonio y la familia. La Habana: Ed. Pueblo y Educación.

Barragán, F. (s.a). Sexualidad, educación sexual y género. Consejería de educación y Ciencia .Sevilla. España: Instituto de Andaluz de la mujer.

Barberà, E. (s.a). Los fundamentos teóricos de la tutoría presencial y en línea: una perspectiva socio-constructivista. Estudios de Psicología y Ciencias de la Educación. Universitat Oberta de Catalunya .Recuperado 15 de diciembre de 2015.

Bar-On, R. \& Parker (2001). The Handbook of Emotional Intelligence. Theory, developmental, and application at home, school, and in the workplace. San Francisco: Jossey-Bass.

Bassedas, E. (2009). Intervención educativa y diagnóstico psicopedagógico. España: Ed. Paidós.

Bisquerra Alzina, R. (2000). Educación emocional y bienestar. Barcelona: Praxis. 
Bisquerra, A, R. (Coord.) (1998). Modelos de Orientación e Intervención Psicopedagógica. Barcelona: Praxis.

Bisquerra, R. (1990). Orientación psicopedagógica para la prevención y el desarrollo. Barcelona. España: Boixareu.

Bisquerra, R. (1996). Orígenes y desarrollo de la Orientación Psicopedagógica. Madrid. España: Narcea.

Bisquerra, R. (2003). Educación emocional y competencias básicas para la vida. Revista de Investigación Educativa, 21, (1) 7-43.

Bisquerra, R. (2006). Orientación psicopedagógica y educación emocional. Estudios sobre Educación. Servicios de publicaciones de Navarra, (11), 9-25.

Bisquerra, R. (2009). Psicopedagogía de las emociones. [en línea]. Madrid: Narcea.

Bolaños, D. y Espinoza, L. (2010). Factores que influyen en el desconocimiento de las adolescentes acerca de la sexualidad y posibles complicaciones de un embarazo precoz no deseado, décimo año del colegio fiscal mixto "17 de septiembre" (diurna, a, b y c) del cantón Milagro. Trabajo de grado, Licenciatura en Enfermería. Milagro, Ecuador.

Bouvier, P. A. (s /a). La resiliencia, una mirada que abre horizontes. [en línea].. Recuperado el 12 de abril de 2012, de: <http://www.uw.es/colomeri/fundacion/resilienciahorizontes.him/>.

Cardona, M. C. (2006). Diagnóstico psicopedagógico: Conceptos básicos y aplicaciones. España: Ed. Club Universitario.

Castellanos, B. (1991). Sexualidad, Salud y Educación. La Habana: Ed. Pueblo y Educación.

Castellanos, B. y González, A. (1995). Sexualidad Humana, Personalidad y Educación. La Habana: Ed. Pueblo y Educación

Castellanos, B. y González, A. (1997). Sexualidad y género: Hacia su comprensión y educación. Revista Educación, (90).

Castellanos, B. y González, A. (2003). Sexualidad y género: Alternativas para su educación ante los retos del siglo XXI. La Habana: Ed. Científico Técnica

Castellanos, B. y González, A. (2014). La educación de la sexualidad en tiempos de cambio. Una mirada al contexto escolar.). [en línea]. Revista Sexología) Recuperado el 15 diciembre 2015, de: revsexologiaysociedad.sld.cu 
Castillo, R. N. (2005). Metodología para la Educación de la Sexualidad de los Adolescentes en el contexto de las Actividades Extradocentes del nuevo Modelo Educativo de Secundaria Básica. Disertación Doctoral no Publicada. Instituto Superior Pedagógico “Rafael María de Mendive”, Pinar del Río. Cuba.

Castillo, S. (1990). Cómo el educador puede intervenir en los problemas familiares del alumno. Revista Pedagógica Cubana, 5.

Castillo L. y Benavides R. (2012). Modelo de resiliencia sexual en el adolescente teoría del rango medio. ). [en línea]. AQUICHAN 12 (2) 169-182. Recuperado el 14 de enero del 2013, de: <http://aquichan.unisabana.edu.co/index.php/aquichan/article/view/1997/html/ $>$.

Castro, P. L. (1993). Familia, Sexualidad y Discapacidad. Ponencia presentada en Pedagogía 95. La Habana, Cuba.

Castro, P. L. (1993). Experiencias en la Orientación y Educación Sexual de las personas con discapacidades físico motoras. Ponencia presentada en Pedagogía 95. La Habana, Cuba.

Castro, P. L. (1998). Educación sexual para niños y adolescentes discapacitados. [Formato Electrónico]. La Habana: MINED.

Castro, P. L. (1998). El enfoque y los métodos de investigación en Educación Sexual. [Formato Electrónico]. La Habana: MINED.

Castro, P. L. (1998). Experiencias y retos de la extensión de la educación sexual en las escuelas especiales. [Formato Electrónico].La Habana: MINED.

Castro, P. L. (2002). Familia, sexualidad y discapacidad desde el paradigma históricocultural. TEMAS. Cultura, ideología, sociedad, (31).

Castro, P. L. (2003). Familia, sexualidad y educación. Ciudad de La Habana: Editorial Pueblo y educación.

Castro, P. L. (2003). La sexualidad de los niños y adolescentes con necesidades educativas especiales su atención en la escuela y la familia. La Habana: Editorial Pueblo y Educación.

Castro, P. L. (2006). Educación sexual con los jóvenes de preuniversitario, educación técnica y universidades pedagógicas. La Habana. Cuba: Ministerio de Educación. 
Castro, P. L. y otros. (1998). Hacia una sexualidad responsable y feliz "Para ti adolescente." La Habana: Ed: Pueblo y Educación.

Chajuelan, G. E. y Caicedo, I. (2010). Evaluar conocimientos, actitudes y prácticas en relación a sexualidad entre los alumnos de primero, segundo y tercero de bachillerato de los colegios universitarios de la ciudad de lbarra en el periodo noviembre 2009-1bril 2010.Ibarra. Ecuador: [s.n].

Colectivo de autores. (1993). Sexualidad en la adolescencia. Segundo seminario colombiano.: Asociación Salud con Prevención. Colombia: [s n].

Colectivo de autores. (1981). Materiales de Consulta para desarrollar el Curso Facultativo de Educación Sexual. La Habana: Ed. Científico Técnica.

Colectivo de autores. (1992). La actividad sexual y la maternidad entre las adolescentes en América Latina y el Caribe: Riesgos y Consecuencias. U.S.A: [s.I]. [s.n].

Colectivo de autores. (1997). Documento Teórico Metodológico del Proyecto Cubano de Educación Formal para una Sexualidad Responsable. La Habana: Ed. Pueblo y Educación.

Colectivo de autores. (1997). Hacia una sexualidad responsable y feliz. Para la familia. La Habana: Ed. Pueblo y Educación.

Colectivo de autores. (2006). El maestro ante la atención de la sexualidad del niño diferente. La Habana: Ed. Pueblo y Educación.

Colectivo de autores. (2011). Sistema nacional de tutorías académicas para el bachillerato general, Tecnológico y profesional técnico. Subsecretaria de educación media Superior. Secretaría de Educación Pública. (SEP). México.

Coll, C., Palacios, J. \& Marchesi, A. (1991). Desarrollo psicológico y educación. Madrid: Alianza Psicología.

Colunga, S. (2000). Intervención educativa destinada al incremento de la autoestima en escolares con dificultades para aprender. Disertación Doctoral no Publicada. ISP "José Martí Pérez". Camagüey. Cuba.

Colunga, S., García, J. \& Álvarez, N. (2012). La profesionalización del personal docente que ejerce la función tutorial en la educación superior. [en línea] Revista Transformación, 8 (1), 20-30. 
Comisión Económica para América Latina/ CEPAL \& Fondo de las Naciones Unidas para la Infancia/UNICEF (2007) “Desafíos”, Boletín Número (4), Santiago. Chile.

Comisión Económica para América Latina/ CEPAL (2008): Nuevos desafíos con los y las jóvenes de Iberoamérica, Santiago, Chile.

Conil, J.A. (2005). Alternativa metodológica que permite dirigir el proceso de educación de la sexualidad del alumnado con trastornos de conducta. Disertación doctoral no publicada. Instituto Superior Pedagógico, "Rafael María de Mendive", Pinar del Río, Cuba.

Conill, J. A. (2002). Estudio sobre las inquietudes sexuales de los adolescentes retrasados mentales. Instituto Superior Pedagógico "Rafael María de Mendive", Pinar del Río, Cuba: [s n].

Conill, J. A. (2006). La educación de la sexualidad del escolar con diagnóstico retraso mental. [Formato electrónico]. La Habana: MINED.

Contreras, R., y Martín, D. (2011). El embarazo en la adolescencia. ¿Un problema social en Santa Clara, Villa Clara, Cuba?, Contribuciones a las Ciencias Sociales, [en línea]. Recuperado 12 de abril 2012, de: <www.eumed.net/rev/cccss/12/>.

Cruz, M. A. (2011). Educación de la Sexualidad para Alumnos y Alumnas Escolares del Bicentenario: Análisis y Propuesta. Disertación Doctoral no publicada [en línea]. Santiago. Recuperado 17 de diciembre del 2015 de <http://bibliotecadigital.academia.cl/bitstream/handle/123456789/683/Tesis\%20 final.pdf/>.

Damasio, A. (1996). El error de Descartes: la emoción, la razón y el cerebro humano. Barcelona: Crítica.

Damasio, A. (2001). La sensación de lo que ocurre. Cuerpo y emoción en la construcción de la conciencia. Madrid: Debate.

De Armas, N. (2011). Resultados científicos de la investigación educativa. La Habana: Pueblo y Educación.

Destrada, M. B. (1996). La sexualidad de personas con discapacidad. En VII Congreso Latinoamericano de Sexología y Educación Sexual / I Congreso Cubano de Educación, Orientación y Terapia Sexual. Memorias. La Habana: Ed. Científico Técnico. 
Díaz, C. (2001). La prevención educativa de los adolescentes, en el contexto de la familia y la escuela. Disertación doctoral no publicada. La Habana. Cuba.

Díaz, M. J. (1986). El papel de la interacción entre iguales en la adaptación escolar y el desarrollo social. Madrid: Centro Nacional de Investigación y Documentación Educativa (C.I.D.E.).

Díaz, L. L. (2011). Orientación de la sexualidad adolescente del octavo año de educación básica del colegio nacional mixto Machala, periodo lectivo 2008-2009. Ecuador: [Formato Electrónico] [s n].

El desarrollo de la sexualidad en nuestras vidas. (2002). Cátedra de Sexología y Educación Sexual [Software Educativo]: Instituto Superior Pedagógico “Enrique José Varona”. La Habana, Cuba.

Estrategia Intersectorial de Prevención del Embarazo Adolescente y Planificación Familiar, (2011). [en línea].Ecuador. Recuperado el 3 de abril de 2013 de: <http://scielo.sld.cu/scielo.php?pid=S156131942012000100015\&script=sci arttxt/>.

Fernández, A. (2015). Algunos resultados en la educación integral de la sexualidad desde la aplicación de la Educación Popular. Revista Sexología y Sociedad. [Versión electrónica] 21(1) 86-101.

Fernández, C. A. \& López, L. I. (2012). La educación sexual como tema transversal de las instituciones públicas educativas de la básica primaria en Armenia, Colombia. Revista Cultura del Cuidado, 8 (2) 46-57.

Fernández, P, Ramos, N. \& Extremera, N. (2001). Inteligencia emocional, supresión crónica de pensamientos y ajuste psicológico. Boletín de Psicología, 70, 79-95.

Fernández, P. (2002). Corazones inteligentes. Barcelona: Kairós.

Fernández, P. y Ramos, N. (1999). Investigaciones empíricas en el ámbito de la inteligencia emocional. Ansiedad y Estrés. 5 (2-3), 247-260.

Fernández, P. y Ramos, N. (1999). Investigaciones empíricas en el ámbito de la inteligencia emocional. Ansiedad y Estrés. 5 (2-3), 247-260.

Fernández, P., Ramos, N. y Extremera, N. (2001). Inteligencia emocional, supresión crónica de pensamientos y ajuste psicológico. Boletín de Psicología, 70, 79-95. 
Flores, I. Y. \& Flores, M. F. (2010). Programa radial especializado para prevenir concientizar y direccionar hacia un manejo adecuado del embarazo adolescente en la comunidad del cantón Milagro". Trabajo de grado, licenciatura en Ciencias de la Comunicación Social mención periodismo, Milagro. Ecuador.

Fuentes, H., Matos, E \& Montoya, J. (2007). El proceso de investigación científica orientada a la investigación en ciencias sociales. Universidad Estatal de Bolívar. Estado Guaranda. [Formato Electrónico] Venezuela: [s n].

García, E. (2009). Estrategia pedagógica de preparación a los agentes educativos para la educación de la sexualidad en el tercer ciclo de la educación preescolar. Disertación doctoral no publicada, Instituto Superior pedagógico "José Martí." Camagüey. Cuba.

García, E., Castro, P. L. \& Cardoso, R. (2015). La sexualidad preescolar: etapas en su educación. [en línea]. Revista Transformación, 11 (2), 56-63.

García, M. M. (2009). Estrategia metodológica para el proceso educativo de la sexualidad con un enfoque bilingüe en los escolares sordos .Disertación doctoral no publicada. Instituto Superior Pedagógico "José Martí", Camagüey. Cuba.

García, R. (2012). La educación desde la perspectiva de género, Revista Facultad de Educación de Albacete, (27), Recuperado 3 de agosto del 2015 de: <http://revistas.uclm.es/index.php/ensayos/>.

Giró, H. (2006). Exigencias teórico- metodológicas para la educación de la sexualidad en el proceso docente-educativo: Instituto superior pedagógico "Raúl Gómez" Disponible en: <http://www.llustrados.com/tema/8124/>.

González, A. \& Castellanos B. (1996). Un modelo procesal participativo para una educación sexual. En VII Congreso Latinoamericano de Sexología y Educación Sexual .La Habana: Ed. Científico Técnica.

González, A. \& Castellanos B. (1997). Sexualidad y género: hacia su comprensión y educación. Revista Educación, 90.

González, A. (1994). Fundamentos y problemas de la educación y la pedagogía sexual. Resumen de Tesis doctoral no publicada. ISP " Enrique José Varona", La Habana. Cuba.

González, A. (s.f). Adolescencia y sexualidad en la sociedad de hoy. [Formato Electrónico] Instituto Superior Pedagógico "Enrique José Varona". La Habana, Cuba. 
González, A. y Castellanos, B. y otros. (1998). Hacia una Sexualidad responsable y feliz. La Habana: Editorial Pueblo y Educación.

González, A. \& Castellanos, B. (1988). Importancia y problemas actuales de la educación sexual en nuestro país". Magíster. Boletín de la Facultad de Pedagogía del ISP. "Enrique José Varona". (4).

González, A. (2011). Diseño e Implementación de Estrategias de Promoción de Salud para la Prevención del Embarazo en Adolescentes de 14 a 17 Años a partir del Análisis de las Percepciones Culturales sobre la Anticoncepción." Parroquia Checa, Año 2009-2010. Tesis de Maestría no publicada, Quito, Ecuador.

González, A. y Castellanos, B. (2014). Reconceptualización de la sexualidad masculina y femenina en los albores del nuevo siglo. [en línea]. Revista Sexología. Recuperado de:

$<$ hhttp://revsexologiaysociedad.sld.cu/ index.php/sexologiaysociedad/article/view/284/0/>.

González, A. y Castellanos, B. (2003). Sexualidad y Género. Alternativas para su educación ante los retos del siglo XXI. La Habana, Cuba: Editorial Científico Técnica.

González, E. (2003). Aspectos sociales de la Adolescente Embarazada. Revista de Salud Sexual y Reproductiva en la adolescencia. Santiago.

González, F. (1985). Psicología de la personalidad. La Habana: Editorial Pueblo y Educación.

González, J (2011). Aplicación de la terapia sistémica para disminuir los factores psicosociales que inciden en jóvenes embarazadas de 14/18 años en el área de ginecobstetricia del Hospital sagrado Corazón de Jesús de la ciudad de Quevedo. Trabajo de grado, Licenciatura en Enfermería, Quevedo, Ecuador.

Guerrero, N. (1985). La educación sexual en la joven generación. La Habana: Ed. Política.

Ibarra, M. (2012). Estudio de la incidencia de la educación sexual en el inicio precoz de la actividad sexual de los pre/adolescentes del octavo año de Educación básica de la Unidad Educativa Ismael Pérez del Cantón Naranjito durante el periodo lectivo Trabajo de Grado Licenciatura en Enfermería, Milagro. Ecuador.

Kitwood, T. (1996). La preocupación por los demás. Una nueva psicología de la conciencia y la moralidad. Bilbao: Desclée de Brouwer.

Kohlberg, L. (1992). Psicología del desarrollo moral. Bilbao: Desclée de Brouwer. 
Kolodny, C. y Masters, W. y Johnson, V. (1985). Tratado de Medicina Sexual. La Habana: Ed. Científico Técnica.

Kolodny, C. y Masters, W. y Johnson, V. (1987). La sexualidad humana. La Habana: Ed. Científico Técnica.

Krause, M. (1985). Algunos temas fundamentales sobre educación sexual. La Habana: Ed. Científico Técnica.

Kurt, B. (1990). La educación sexual como preparación de los niños y adolescentes para el amor, el matrimonio y la familia. La Habana: Editorial Ciencias Sociales.

Lara, A. O. (2012). Propuesta pedagógica. Por el ejercicio de una sexualidad responsable: una mirada a través de la resiliencia" para alumnos y alumnas de tercer grado de educación Secundaria en MILPA ALTA. Universidad pedagógica Nacional. Distrito Federal, México.

Lara, J. E. (2009). La calidad de la educación sexual y su relación con embarazos en adolescentes del colegio Penipe. Trabajo de Grado, Penipe. Chimborazo, Ecuador.

Lazarus, R.S. \& Lazarus, B.N. (1994). Making sense of our emotions. Passion and reason. [s.l]. [s.n]

Lazarus, R.S. (2000). Estrés y emoción. Manejo e implicaciones en nuestra salud. Bilbao: Desclée de Brouwer.

Lazarus, R.S. y Folkman, S. (1986). Estrés y procesos cognitivos. Barcelona: Martínez Roca. Lazarus, R.S., (1966). Psychological stress and the coping process. New York: McGraw-Hill.

Leal, M. L. y Medel, Bertha. (2007). Influencia de la educación sexual en adolescentes embarazadas. Revista SynthesiS. Universidad de Chihuahua Enero/ma de <http://www.uach.mx/extension y difusion/synthesis/2008/05/12/influencia.pdf />.

Legarde, M. (1994).Repensar y politizar la maternidad: Un reto de fin de milenio. México: Grupo de educación popular con mujeres.

Lincoln, J y Cedeño, M. S. (2012). "Módulo instrucción de educación de la sexualidad", Manabí, Ecuador: [s.n].

Lomas, D. y Bravo, S.X. (2011). Guía psicodidáctica para la prevención del embarazo en adolescentes del área de influenza del subcentro San Francisco de la Tulcán. [Formato Electrónico] Ambato. Ecuador. 
López R., Y. (2011). Embarazo en la adolescencia y su repercusión biopsicosocial sobre el organismo de la madre y de su futuro hijo. Revista Cubana Enfermería. 27 (4) Recuperado el 15 de mayo de 2012, de: $<$ http://scielo.sld.cu/scielo.php?pid=S086403192011000400011\&script=sci_arttex t\&tlng=en $>$.

López, F. y Fuertes, A. (1989). Para comprender la sexualidad. España: Editorial Verbo Divino.

Lozoya, J. (2013). Resiliencia: definición, significado y concepto. Recuperado 16 marzo 2016, de: <http://suite101.net/article/resiliencia-definicion-significado-yconcepto a11377\#.VumU-KxI IU/>.

Luna, M. G. (2015). La formación de la competencia comprensión lectora en alumnos de educación primaria, desde la acción tutorial. Disertación doctoral no publicada. Universidad de Camagüey "Ignacio Agramonte Loynaz". Camagüey. Cuba.

Machado, G. (2004). Adolescencia una reflexión necesaria. La Habana: Centro de Estudios sobre la Juventud.

Macias, C. J. y Murillo, E. (2011). Embarazo en adolescentes de 10 a 19 años de edad que acuden a la consulta de gineco-obstetricia del centro materno infantil de Andrés de Vera de enero a septiembre de 2010.Trabajo de Diploma, licenciatura en Medicina, Especialidad cirugía. Universidad Técnica de Manabí, Portoviejo. Ecuador.

Martínez, M. (2005). Metodología de la investigación educacional. La Habana: Editorial Pueblo y Educación.

Masache, J.H. (s.a) Estado nutricional de las adolescentes embarazadas que acuden al control prenatal, en el servicio de atención integral para adolescentes del Hospital Gineco- Obstétrico "Isidro Ayora". Trabajo de grado, Licenciatura en Medicina. Quito. Ecuador.

Masters, W., V. Johnson y R. Kolodny. (1995). Aspectos psicosexuales de la adolescencia. En Enciclopedia de la sexualidad humana, México. Grijalbo

Mayer, J. D., Salovey, P. \& Caruso, D. (2000). Models of Emotional Intelligence.[s.I]: [s.n] In R.

Mcpherson, M. y Torres, M. A. (1997). Para una conducta sexual responsable. Revista Educación. Recuperado de: <https://www.revista-portalesmedicos.com/revistamedica/conducta-sexual-responsable-estudiantes/2/>. 
Megna, A. (2014). Educación de la sexualidad responsable en los /las estudiantes de preuniversitario. Disertación Doctoral no publicada. Universidad de Las Tunas. Cuba. Recuperado de: < http://www.monografias.com/trabajos77/responsabilidad-sexualidadestudiantes-prreuniversitario/responsabilidad-sexualidad-estudiantesprreuniversitario3.shtml/>.

Mena, C. A, Trujillo PY, Pochet P D, Vázquez A L. (2005). Madre adolescente como factor de riesgo en neonatos y lactantes. Un reto para el médico general integral. [Versión electrónica] Revista 16 abril. (221). Recuperado el 28 de julio de 2013, de: <http://www.16deabril.cu.rev/221/adolescentes.html/>.

Méndez, B. (2003). El embarazo adolescente. Revista OBSTARE, n. 8. Barcelona. España.

Méndez, L. (1994). La sexualidad en la infancia. En: Antología de la sexualidad humana. Tomo II.- México: [s n]

Miguel-Tobal, J.J. \& Casado Morales, M.I. (1993). Solución y afrontamiento de problemas personales en sujetos normales y con trastornos psicofisiológicos. Clínica y Salud, 4 (3), 243-252.

Ministerio de Salud Pública del Ecuador. (2009). MSP Quito -Ecuador. Tomado del Manual de Normas y Procedimientos para la Atención Sexual y Reproductiva de la mujer embarazada ecuador.

Molina, C., Molina, T. y González, E. (2007). Madres niñas adolescentes de 14 años y menos. Un grave problema de salud pública no resuelto en Chile. Revista médica de Chile.135, 79-86.

Molina, D. L. (2009). Hacia una educación integral. Los elementos clave en la escuela de la vida. Barcelona: Erasmus Ediciones.

Molina, D. L., Torrivilla, I. R. y Sánchez, Y. G. (2011). Significado de la educación sexual en un contexto de diversidad en Venezuela. Electronic Journal of Research in Educational Psychology, 9 (1), 415-444. ISSN: 1696-2095. 23. Recuperado el 23 de Julio del 2015 de: web: <http://www.investigacionpsicopedagogica.com/revista/articulos/23/espannol/A rt 23 543.pdf/>.

Molina, D. y De Luca, C. (2009). Orientación Integral en los Centros Educativos y en el aula. Electronic Journal of Research in Educational Psychology ,7(3), 1449-1460. 
Money, J. \& Ehrehardt, A. (1982). Desarrollo de la sexualidad humana. Madrid: Ed. Morata.

Mulder, S. (2014). Vivencias y relatos sobre embarazo en adolescentes. Una aproximación a los factores culturales, sociales y emocionales a partir de un estudio en seis países de la región. Informe Final. UNICEF. Panamá: [s n]

Muñoz de Morales, M. (2005). Diseño, desarrollo y evaluación de un programa de educación emocional para la prevención del estrés psicosocial. Disertación doctoral no publicada. Universidad del País Vasco.

Núñez, G. y Martínez, S. (2011). La educación en el amor y la sexualidad en las adolescentes. Trabajo de grado. Milagro, Ecuador.

Núñez, O. L. (2011). Modelo pedagógico de atención temprana a las dificultades en el aprendizaje en niños/as con riesgos biológicos que no impresionan con déficit intelectual. Disertación doctoral no publicada. Universidad de Camagüey, Cuba.

Organización Panamericana de la Salud/ OPS (2009). Prevalencia y tendencia del embarazo en adolescentes. Washington.

Ortega, L. y Betancourt, J. (2011). Prevención educativa: un concepto a debate en el ámbito escolar, familiar y comunitario. Curso 44 presentado al Congreso "Pedagogía 2011", La Habana, Cuba.

Ortiz, M. C. (s-f). Importancia de la orientación educativa y tutoría en algunos niveles de intervención. Ponencia presentada en: 1er Congreso Internacional Tutorías, orientación y docencia. Universidad Juárez del Estado de Durango. México.

Oviedo, M. y García, M. (2011). El embarazo en situación de adolescencia: una impostura en la subjetividad femenina. Revista latinoamericana de Ciencias: Saúde. , Niñez y Juventud, 2 ( 9), 929-943.

Parera, N. (2011). Embarazo adolescente en España. Actas del 31 Congreso Nacional de Ginecología y Obstetricia. Sevilla.

Peláez M. J. (2003). Adolescencia y juventud. Desafíos actuales. La Habana: Editorial Científico Técnica.

Pérez, J. C. (2012). Revisión del aprendizaje social y emocional en el mundo. En R. Bisquerra (Coord.), ¿Cómo educar las emociones? La inteligencia emocional en la infancia y la adolescencia (pp. 56 -69). Esplugues de Llobregat, 56-69. Barcelona: Hospital Sant Joan de Déu. 
Pérez, D. (2008). Estrategia pedagógica para la educación sexual de los adolescentes con retraso mental desde la institución escolar. Tesis doctoral en Ciencias pedagógicas, Pinar del Rio, Cuba.

Pérez, J. R. (2008). Propuesta de una metodología para la Educación sexual de los estudiantes becados del ISP "Rafael María de Mendive". Disertación doctoral no publicada, ISP "Rafael María de Mendive", Pinar del Rio, Cuba.

Piñeiro, V y et. al. (2004). Infancia y sexualidad. Cátedra de Sexología y Educación Sexual (CASES) Instituto Superior Pedagógico “Enrique José Varona”. La Habana, Cuba.

Piñeiro, V. (2003). El Club de Portamores: una alternativa de trabajo con los jóvenes. Tesis de Maestría no publicada. Instituto Superior Pedagógico "Enrique José Varona". La Habana, Cuba.

Posse, F. y Verdeguer, S. (1991). La sexualidad de las personas discapacitadas. Buenos Aires: Ed. ABRN Producciones Gráficas.

Quintanilla P. y otros. (s.a). Fundamentos teóricos sobre la actividad pedagógica profesional del tutor. [en línea]. Recuperado el 15 de diciembre del 2015, en monografias.com

Quintero, P. P., Castillo, N., Roba, B. del C., Padrón, O., \& Hernández, M. E. (2012). Estrategia de intervención educativa para prevenir el embarazo en la adolescencia. [Versión electrónica]. Rev. Ciencias Médicas 16, (1) Recuperado 6 de enero 2013 de: $<$ http://scielo.sld.cu/scielo.php?pid=s156131942012000100015\&script=sci arttex $\mathrm{t} />$.

Ramos, A. (s-f). Conocimiento y prevención del embarazo en adolescentes como tarea social de promotores comunitarios de Salud. [en línea]. Recuperado el 22 de diciembre del 2015 de: Monografias.com.

Rangel V. Marilin (2015). Programa preventivo-educativo de salud bucodental dirigido a los padres y/o representantes del niño/a de educación inicial. Universidad de Carabobo. Tesis de maestría no publicada. Venezuela.

Reglamento a la ley de Educación Intercultural de Ecuador, (2012) Registro oficial 744, 2012, Ecuador. Recuperado el 56 de enero 2013 de <http://www.educaciondecalidad.ec/ley-educacion-interculturalmenu/reglamento-loei-texto.html/>. 
Revuelta, C. (2013). Prevención del embarazo en la adolescencia, Pediatría Atención Primaria, Revista Médica. 15.

Roa, L. C. (2012). Análisis reflexivo del embarazo a temprana edad. Trabajo de grado, Licenciatura en Desarrollo Humano, Universidad Centro Occidental Lisandro Alvarado Barquisimeto, Venezuela.

Rodríguez, G. (1996). Conceptos y métodos en la educación de la sexualidad.- En VII Congreso Latinoamericano de Sexología y Educación Sexual / I Congreso Cubano de Educación, Orientación y Terapia Sexual. Memorias.- La Habana: Ed. Científico Técnica.

Rodríguez, J. (2008). Reproducción en la Adolescencia en América Latina y el Caribe: ¿Una Anomalía a Escala Mundial? Centro Latinoamericano y Caribeño de Población (CELADE)-División de Población de la CEPAL". Ponencia presentada en el III Congreso de la Asociación Latinoamericana de Población, ALAP, Córdoba, Argentina.

Rodríguez, J. (2012). La reproducción en la adolescencia en América Latina: Viejas y nuevas vulnerabilidades. Realidad, datos y espacios. Revista internacional de estadística y geografía: México: 3, (2), mayo agosto, 66-82.

Rodríguez, J. (2013). High adolescent fertility in the context of declining fertility in Latin America. ExpertPaper, No./14. CELADE-Population Division of ECLAC. New York: United Nations.

Rodríguez, J. y Hopenhayn, M. (2007). Maternidad adolescente en América Latina y el Caribe: Tendencias, problemas y desafíos. Desafíos, Boletín de la infancia y la adolescencia. Santiago de Chile: CEPAL-UNICEF.

Rodríguez, M. (2002). Manifestaciones sexistas en el escenario del aula. Revista Sexología y Sociedad. (19) Recuperado 23 de Marzo de 2013 de: <http://www.bing.com/search?q=Manifestaciones+sexistas+en+el+escenario+del +aula.+Revista+Sexolog\%C3\%ADa+y+Sociedad.+\&qs=n\&form=QBRE\&pq=manifest aciones+sexistas+en+el+escenario+del+aula.+revista+sexolog\%C3\%ADa+y+socied ad. $+\& s c=0-0 \& s p=-1 \& s k=\& c v i d=95$ C66AACE35C446C913594C3D0AFEF60 $/>$.

Rodríguez, M. (1997). La educación de los roles de géneros en niñas y niños de tercer grado. Tesis de maestría no publicada. Instituto Superior Pedagógico "Enrique José Varona". La Habana, Cuba. 
Rodríguez, V. Y. (2013). Incidencia del embarazo en la adolescencia en mujeres de 12 a 18 años en Maternidad Mariana de Jesús de septiembre 2012 a febrero del 2013.Trabajo de grado, Universidad de Guayaquil, Ecuador.

Rojas, E, P., y Bersoza, P. P. (2011). Caracterización de la Situación social del desarrollo que presentan las alumnas del primer y segundo año de bachillerato de los colegios "Amazonas" y "Nueve de octubre" de la ciudad de Machala con embarazos precoces durante el periodo lectivo 2010-2011. Trabajo de grado. Machala, Ecuador.

Ruiz, Z. (2001). Pedagogía de la sexualidad. Ponencia presentada en Congreso "Pedagogía 2001". Ciudad de Habana, Cuba.

Sánchez, I. B. (2006). La educación para la sexualidad en la atención a los escolares adolescentes con trastornos de la conducta" .Disertación doctoral no publicada. Universidad de Holguín "Oscar Lucero Moya". Cuba.

Sánchez, M. F. y Villigua , G. C. (2011). Prevalencia de embarazo en adolescentes ingresadas en el áreade gineco-obstetricia del hospital provincial Verdi Cevallos balda durante el periodo enero del 2010 a diciembre del 2010". Trabajo de grado. Licenciatura en medicina, especialidad cirugía. Portoviejo, Ecuador.

Stern, C. (2007). Estereotipos de género, relaciones sexuales y embarazo adolescente en las vidas de jóvenes de diferentes contextos socioculturales en México. Estudios Sociológicos, 25(73), pp. 105 -129. México.

Suárez, A. (2001). Un programa de educación sexual para escolares retrasados mentales. Tesis de Maestría no publicada. CELAEE. La Habana, Cuba.

Suárez, A. (2003). La sexualidad y la diversidad. Cátedra de Sexología y Educación Sexual (CASES). Instituto Superior Pedagógico “Enrique José Varona”, La Habana: [s n].

Tamayo, M. R. (2008). Estrategia educativa para promover el desarrollo de la responsabilidad en la esfera psicosexual en estudiantes universitarios peruanos. Disetación doctoral no publicada. Universidad de Camagüey "Ignacio Agramonte Loynaz". Camagüey, Cuba.

Teixeira, Sania da C, Da Silva, L. \& Teixeira, M (2013). Políticas públicas de atenção às adolescentes grávidas - Uma revisão bibliográfica. [En línea]. Rev. Adolesc. saude. Rio de Janeiro, 10 (1) 37 / 44, recuperado el 16 de marzo 2016, de 
<http://www.adolescenciaesaude.com/detalhe artigo.asp?id=353\&idioma=Espan $\underline{\mathrm{hol}} / \mathrm{s}$.

Torrealday, Agustzane. (1987). Hombre y mujer: masculino y femenino. Bilbao: Ed. Adarra.

Trejo, C., Ortiz C., y Coello T. (2015). Los paradigmas sociales en el embarazo de los adolescentes amparados en el buen vivir y sus impactos a las tasas de mortalidad de Ecuador. [Versión electrónica] Revista Contribuciones a las Ciencias Sociales. Recuperado el 12 de enero de 2016 de: $<$ http://www.eumed.net/rev/cccss/2015/01/embarazo-precoz.html/>.

Trujillo, M. (2013). El embarazo precoz no querido, pero deseado. Universitas, Revista de Ciencias Sociales y Humanas de la Universidad Politécnica Salesiana del Ecuador, $\mathrm{XI},(18) 6$.

Ubillus, S. P. y Amayuela, G. (2015). La prevención del embarazo adolescente: reto de la educación sexual. Revista "Mendive". 52 1-6.

Ubillus, S.P. y Zambrano R. (2016). Intervención psicoeducativa en la prevención del embarazo precoz. Revista Transformación, 12(1), 65-75.

Ubillus, S.P., Colunga, S., Zambrano, R. \& Amayuela, G. (2013). Modelo educativo y preventivo del embarazo precoz en estudiantes del nivel básico superior, desde la acción tutorial. Revista Sinapsis, 3, (2), 60-67.

Salazar, A. Rodríguez, F. y Daza, A. (2007). Embarazo y maternidad adolescente en Bogotá y municipios aledaños. Revista persona y Bioetica.11 (2), 170-185.

Santos, R. y Schort, N. (2003). Vivencias da maternidade na adolescencia precoce. Revista de Saúde Pública, 37 (1).

Sapienza, G. y Pedromonico, M. (2005). Rizco, proteçâo e resilencia no desenvolvimento da criança do adolescente. Psicología em Estudo ,10 (2), 209 -2016.

UNESCO- (2010). Orientaciones técnicas Internacionales sobre educación de la sexualidad: Autor, Recuperado de <http://www.bing.com/search?q=Orientaciones++t\%C3\%A9cnicas+Internacionale s+sobre+educaci\%C3\%B3n+de+la+sexualidad+2010\&qs=n\&form=QBRE\&pq=orien taciones+t\%C3\%A9cnicas+internacionales+sobre+educaci\%C3\%B3n+de+la+sex/>.

UNICEF, (2007).Desafíos. Boletín CEPAL Santiago de Chile, (4). 
Vaillant, M. (2012). Prevención del embarazo en adolescentes, Revista Cubana de Enfermería, (28) 1 -10.

Valera, O. (2000).Tendencias contemporáneas de los modelos pedagógicos. Bogotá, Colombia. [s.n].

Vega, R. E. y Hernández, G. (2008). Factores que intervienen en el embarazo precoz en las mujeres menores de18 años de la comunidad Nueva Libertad Sayaxche peten. Trabajo de Grado, Guatemala.

Vigotsky, L. (1960). El desarrollo de las funciones psíquicas superiores. La Habana: Academia de Ciencias Pedagógicas.

Vigotsky, L. (1998). Pensamiento y Lenguaje. La Habana: Editorial Pueblo y Educación.

Zarate, N. (2013). Maternidad adolescente de las jóvenes tuteladas en Cataluña. Disertación doctoral no publicada. Universidad Autónoma de Barcelona, España.

Zelnik, M., y Kim, Y. J. (1982). Sex education and its association with teen age sexual activity, pregnancy, and contraceptive use. Family Planning Perspectives, 14(3), 117-126. 

Anexo 1

Guía de observación a las actividades que se desarrollaron en el Departamento de Consejería Estudiantil

Objetivo: Conocer cómo se realizan las actividades de educación de la sexualidad y la prevención del embarazo precoz en el gabinete de la unidad educativa.

Hora de comienzo: Hora de Terminación:

\begin{tabular}{|c|c|c|c|}
\hline \multirow[t]{2}{*}{$\mathbf{N}$} & \multirow[t]{2}{*}{ Aspectos a observar } & \multicolumn{2}{|c|}{$\begin{array}{l}\text { Se } \\
\text { observa }\end{array}$} \\
\hline & & sí & No \\
\hline 1 & $\begin{array}{l}\text { Planificación de las actividades que se realizan en el gabinete } \\
\text { Relación del sistema de actividades a realizar con el objetivo formativo de } \\
\text { los estudiantes, específicamente, los relacionados con la educación de la } \\
\text { sexualidad y la prevención del embarazo precoz. }\end{array}$ & & \\
\hline 2 & $\begin{array}{l}\text { Organización de las actividades que se realizan en el gabinete } \\
\text { Se evidencia la coordinación previa con los especialistas y agentes } \\
\text { socioeducativos }\end{array}$ & & \\
\hline 3 & $\begin{array}{l}\text { Ejecución de las actividades planificadas } \\
\text { Las actividades que están planificadas y organizadas se realizan } \\
\text { Participan los especialistas previstos en la realización de las actividades. } \\
\text { Asisten directivos de la institución educativa a las actividades planificadas } \\
\text { Participan los padres de familia en las actividades planificadas }\end{array}$ & & \\
\hline 4 & $\begin{array}{l}\text { Control de las actividades que se realizan para la educación de la } \\
\text { sexualidad de los estudiantes. } \\
\text { Existencia de registro de asistencias y de realización de actividades }\end{array}$ & & \\
\hline
\end{tabular}


Anexo 2

\section{Encuesta a los docentes}

Objetivo: Obtener información acerca del tratamiento que le dan a la Educación de la Sexualidad durante la dirección del proceso de enseñanza aprendizaje en la institución de Educación Básica.

Estimado (a) Profesor (a), estamos realizando un estudio relacionado con el tratamiento de la educación de la sexualidad en el proceso de enseñanza aprendizaje. Por esta razón, necesitamos de su valiosa colaboración. Confiamos en su seriedad y alto sentido profesional. De antemano agradecemos su ayuda.

-Materia que imparte:

- Grado que imparte:

- Años de experiencia docente:

1. ¿Desde su opinión, considera necesario el tratamiento de la educación de la sexualidad en la institución de Educación Básica.

sí NO ¿Por qué?

2. ¿Consideras que para desarrollar el proceso de educación de la sexualidad tiene la preparación

REQUERIDA POCA NINGUNA ?

3. ¿Usted concibe y desarrolla el tratamiento de temáticas de educación de la sexualidad en sus clases?

SIEMPRE CASI SIEMPRE A VECES NUNCA 
4. ¿Qué temáticas de educación de la sexualidad ha tratado en tus clases?

5. Para desarrollar el tratamiento de temáticas de educación de la sexualidad en sus clases usted toma en cuenta:

8. Cuando se trabaja la educación de la sexualidad en las clases, se insiste más en los aspectos de:

Conocimientos.

Valores.

Sentimientos.

__ Habilidades.

__ Otro asunto (señale cuál - reflexión, creatividad, etc.)

9. Marque con una $(\mathrm{x}$ ) las razones por las que ha dado tratamiento a la educación de la sexualidad en las clases.

Concebido por iniciativa propia.

Como orientación de la dirección de la institución.

Como vía de control de las instancias superiores.

Por necesidad objetiva de acuerdo al diagnóstico.

Por petición de estudiantes.

10. A su juicio cuáles son las principales dificultades que ha enfrentado en el tratamiento de la Educación de la Sexualidad en las clases. 
Anexo 3

\section{Encuesta a estudiantes}

Objetivo: Obtener información acerca del criterio de los estudiantes sobre el tratamiento de la educación de la sexualidad en las clases.

Estimado (a) estudiante, estamos realizando un estudio relacionado con el desarrollo de las temáticas de educación de la sexualidad en las clases. Teniendo en cuenta lo importante que es tu criterio, solicitamos tu valiosa colaboración y confiamos en la seriedad de tus criterios. Agradecemos mucho tu colaboración.

Institución

Grado

Edad

Sexo

1. ¿Tienes interés en conocer acerca de la sexualidad?

Sí NO

¿Por qué?

2. Los conocimientos o información sobre temas de sexualidad los obtienes de (marca con una $\mathrm{x}$ tantas como consideres)

_ Escuela (profesores y profesoras) Médico Madre Medios de Difusión Padre Libros

Amistades Novio (a) Otros

¿Cuáles? 
3. En la escuela, cuáles son las actividades que te brindan más información sobre educación de la sexualidad.

Clase ___ Actividades deportivas

Actividades sociales

Otros

¿Cuáles?

4. ¿Cuáles de las actividades anteriores prefieres para conocer acerca de educación de la sexualidad? ¿Por qué?

6. ¿Qué temas de educación de la sexualidad han sido tratados en las clases?

7. ¿Cuáles son tus principales intereses y necesidades respecto a la educación de la sexualidad que desearías fueran tratados?

8. Identifica en las siguientes situaciones, cuáles son posibles observar en tu escuela (marca con una $x$ tantas como consideres)

Empleo de lenguaje vulgar para referirse a aspectos relacionados con la sexualidad, relación de pareja, etc.

En las relaciones entre compañeros, se aprecian ofensas, faltas de respeto, malos tratos y discriminación a los más pequeños y a las niñas.

Parejas de novios besándose en los pasillos de la escuela.

El Profesor desarrolla temas de educación de la sexualidad, aclara dudas, etc., cuando sus estudiantes le preguntan.

_ La participación activa de los estudiantes en las actividades de Educación de la Sexualidad.

Otras. ¿Cuáles? 
9. ¿Aplicas los conocimientos adquiridos acerca de educación de la sexualidad en tu vida cotidiana?

_ SIEMPRE _ CASI SIEMPRE __ A VECES _ NUNCA 
Anexo 4

\section{Entrevista a los docentes}

OBJETIVO: Interrogar a los docentes para conocer sus criterios en cuanto a las vías que utilizan para dar tratamiento a la educación de la sexualidad.

\section{Aspectos a tratar:}

- Importancia que le conceden a la educación de la sexualidad en los adolescentes.

- Dominio que tienen sobre el tema.

- Vías que utilizan para dar tratamiento a la temática en las clases.

- Experiencias que poseen sobre el tratamiento al tema.

- Capacitación recibida sobre el tema.

- Criterios sobre las vías de capacitación utilizadas para tratar el tema.

- Características de los adolescentes de la institución.

- Principales problemas que presentan los estudiantes de su grupo en cuanto a la orientación de la sexualidad.

- Sugerencias para perfeccionar la orientación de la sexualidad desde el proceso de enseñanza aprendizaje. 


\section{Anexo 5}

\section{Entrevista grupal a estudiantes}

Estimados estudiantes: Deseamos saber cómo se sienten y piensan los y las adolescentes de esta Unidad educativa en las cuestiones sobre la sexualidad, y las actividades realizadas sobre la prevención del embarazo precoz. Queremos conversar con ustedes sobre los intereses que tienen en estas actividades, y cualquier sugerencia que deseen hacer.

1) ¿Creen que las y los estudiantes como ustedes necesitan conocer más sobre el amor y las relaciones de pareja?

2) ¿Tienen alguna ocasión para discutir las cuestiones del amor y las relaciones sexuales en la escuela?

3) ¿Qué desean las y los adolescentes de las relaciones de pareja, qué buscan en esas relaciones?

4) ¿Hay estudiantes que mantienen más de una pareja o han tenido alguna otra relación además de su pareja habitual?

5) Cuando una muchacha adolescente sale en embarazada ¿Quién de los dos tiene más responsabilidad? ¿ Por qué?

6) ¿Creen que una pareja de personas muy jóvenes se mantiene por mucho tiempo? ¿por qué?

7) Relaten las actividades de Educación Sexual en las que han participado. ¿Cuáles son las actividades que más les han gustado, y por qué?

8) ¿Cómo les consultan a ustedes las actividades de Educación Sexual que van a realizar?

9) ¿Hay confianza entre alumnos/as y profesores/as para tratar todos estos temas?

10) ¿Sus padres y madres están de acuerdo en que se hable de la sexualidad en la escuela?

11) ¿En el hogar pueden conversar con los familiares sobre estas temáticas? ¿Hay algún tema de sexualidad del que no puedes conversar en la familia?

12) ¿Desean comentar o preguntar algo más sobre estos temas? 
Anexo 6

\section{Cuestionario para la obtención de los criterios valorativos de los especialistas sobre el programa de intervención educativa tutorial}

Estimado colega:

Con la finalidad de someter a su consideración, como experto en la temática abordada en nuestra investigación, los diferentes aspectos del programa destinado a favorecer la educación de la sexualidad y la prevención educativa del embarazo precoz en estudiantes del nivel básico superior, solicitamos su colaboración valorando los mismos. De antemano le agradecemos su valiosa contribución.

Especialidad

Grado científico

Años de experiencia como docente:

Centro de trabajo:

Provincia:

1.- Exprese su criterio, marcando con una $X$, según considere, los aspectos que a continuación relacionamos del programa de intervención educativa para la prevención del embarazo precoz, que se adjunta de manera sintética en esta escala. Sobre el presupuesto de que el programa es la concreción del modelo que revela la investigación, para evaluar cómo percibe cada uno de los aspectos enunciados, usted debe marcar $(\mathrm{X})$ una de las categorías que a continuación se especifican:

C1: Muy adecuado, C2: Bastante adecuado, C3: Adecuado

C4: Poco adecuado, C5: Inadecuado

\begin{tabular}{|l|l|l|l|l|l|l|}
\hline No & ASPECTO A VALORAR & C1 & C2 & C3 & C4 & C5 \\
\hline 1 & $\begin{array}{l}\text { Correspondencia entre el modelo educativo y } \\
\text { preventivo del embarazo, sus subsistemas y } \\
\text { componentes declarados. }\end{array}$ & & & & \\
\hline 2 & Pertinencia de las relaciones que dimanan & & & & & \\
\hline
\end{tabular}




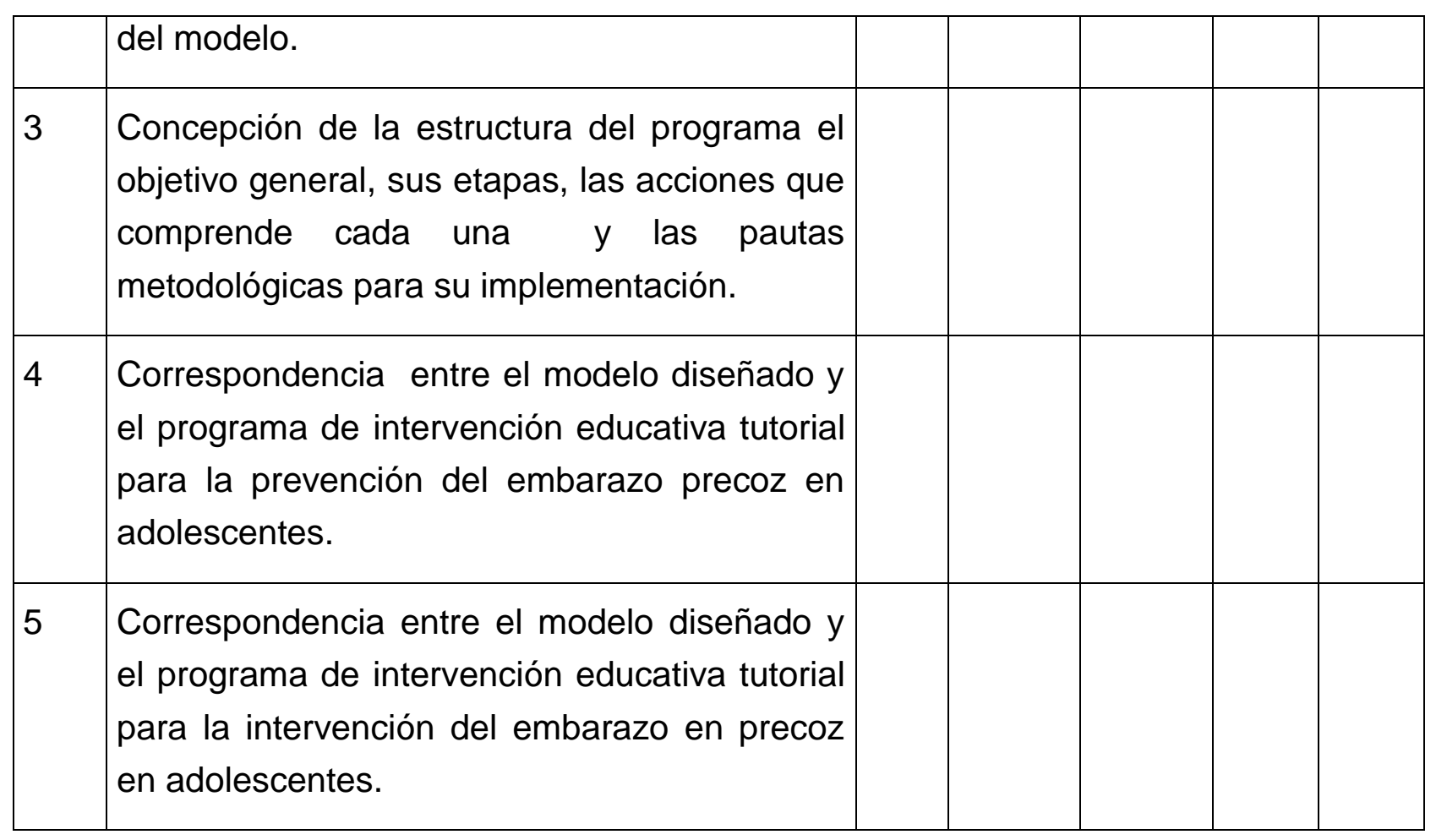

Nota: Se le agradece cualquier comentario. Muchas gracias por su colaboración. 
Anexo 7

Entrevista grupal a profesores de nivel de educación básica superior (diagnóstico fáctico)

Objetivo: Identificar el proceso de atención psicopedagógica tutorial que realizan los docentes para prevenir el embarazo en adolescentes en el nivel de educación básica superior

Preguntas:

1. ¿Cómo valora el trabajo que realiza la institución educativa en materia de prevención del embarazo precoz en adolescentes?

2. ¿Qué elementos se priorizan para la atención psicopedagógica de los adolescentes para evitar el embarazo?

3. ¿Qué entiende por intervención educativa tutorial?

4. ¿Cómo inciden las actividades, tareas y ejercicios que se realizan en el aula de clases para prevenir el embarazo en las adolescentes?

5. ¿Cuáles son las disciplinas que se imparten en el currículo de la educación básica superior que brindan el escenario propicio para ayudar a prevenir el embarazo adolescente?

6. ¿Cómo desde las diferentes asignaturas se puede realizar una intervención educativa tutorial para prevenir el embarazo en adolescentes?

7. ¿Cómo ha contribuido la familia en la prevención del embarazo precoz de las adolescentes?

8. ¿Qué recomienda ud. para mejorar la acción preventiva del embarazo desde la institución educativa?

9. Valore las actividades integradoras realizadas por los docentes de la institución para prevenir el embarazo precoz en las adolescentes. 


\section{Anexo 8}

\section{Resultados de la Entrevista grupal a profesores de básica superior (diagnóstico fáctico)}

1. De manera general se valora de regular, pues el tema de la sexualidad y sobre todo del embarazo en la adolescencia, es un tema sobre el cual, se evita conversar.

2. Para la atención psicopedagógica de los adolescentes se priorizan los tiempos libres y la ayuda institucional y en menor medida la familiar.

3. Todos afirman que se refiere a una ayuda psicológica y pedagógica para buscar soluciones a problemas académicos, emocionales o familiares y que repercuten en los resultados del alumno

4. Las tareas y actividades relacionadas con el tema de prevención de embarazo son casi nulos, de manera general en el aula se evita hablar de temas relacionados con la sexualidad

5. La mayoría considera que todas las asignaturas brindan la posibilidad de tratar el tema y teniendo en cuenta los ejes transversales, pero las más propicias son las de Ciencias naturales y las sociales

6. Se puede realizar una intervención educativa tutorial para prevenir el embarazo en adolescentes, a partir del análisis de los ejes transversales y al planificar la clase.

7. El $100 \%$ coincide que la familia omite hablar sobre el tema, ya que consideran que no es la edad apropiada y sugieren buscar respuestas a su curiosidad por sí solos o preguntar a los amigos.

8. Las principales recomendaciones para mejorar la acción preventiva son:

- Realizar talleres semanales con los alumnos

- Involucrar a los padres en la realización de los talleres

9. La mayoría considera que se realizan pocas actividades integradoras para prevenir el embarazo precoz en los adolescentes, cada profesor actúa por separado según su perspectiva y consideración al respecto. 
Anexo 9

\section{Composición a estudiantes}

Estimado estudiante:

Estamos realizando una investigación sobre la educación de la sexualidad y la prevención del embarazo precoz en los estudiantes. Necesitamos de su colaboración, por lo que te solicitamos realices una composición, es importante que escriba las ideas con sinceridad y claridad. Muchas gracias por su colaboración.

El título dela composición es el siguiente: "El embarazo y los estudios en la adolescencia"

Las categorías para el análisis del contenido de la composición fueron:

1. Conocimiento del contenido de la educación de la sexualidad y la prevención del embarazo precoz.

2. Vínculo afectivo del estudiante con el contenido expresado.

3. Elaboración personal sobre el contenido expresado. 


\section{Anexo 10}

Resultados de la composición a estudiantes después de la aplicación del programa

Tema: "El embarazo y los estudios en la adolescencia"

Sobre conocimiento del contenido de la educación de la sexualidad y la prevención del embarazo precoz, se evidenció que la mayoría de los estudiantes adquirieron información fidedigna sobre el tema y lo expresan de la siguiente forma:

"Se precisa de usar métodos anticonceptivos"

"Se necesita protegerse para evitar embarazos e infecciones

"El embarazo en la adolescencia es una irresponsabilidad, falta de información."

"Es una responsabilidad de los padres trasmitir información sobre la prevención del embarazo. "

Sobre el vínculo afectivo del estudiante con el contenido expresado.

"Le cambiaría la vida por completo a ambos"

"Limita la vida, ella no podría graduarse"

"Si sale embarazada, debe estar con el bebé."

Elaboración personal

"Es una gran responsabilidad"

"Es una responsabilidad de los dos. 


\section{Anexo 11}

\section{Completamiento de frases}

Objetivo: Identificar las principales preocupaciones, expectativas y aspiraciones de los adolescentes.

Estimado estudiante: Necesitamos que con sinceridad, nos completes las siguientes frases, las mismas nos serán de gran utilidad para la investigación que estamos realizando sobre la educación de la sexualidad de los adolescentes y la prevención del embarazo precoz. Muchas gracias por su colaboración.

Frases:

Me preocupa

El colegio.

El estudio

Quisiera

Mi salud

Mi futuro

La mayor aspiración

La familia. 


\section{Anexo 12}

\section{Resultados de la encuesta 2 a los estudiantes}

Pregunta 1-¿Cuál cree Ud. que es el mejor momento para recibir información sobre educación sexual?

\begin{tabular}{|l|l|l|l|}
\hline & & Frecuencia & $\%$ \\
\hline a & A partir de los 12 años & 11 & 45.8 \\
\hline b & De los 15 años en adelante & 10 & 41.7 \\
\hline c & Desde la niñez & 3 & 12.5 \\
\hline d & Nunca & 0 & 0 \\
\hline & Total & 24 & 100 \\
\hline
\end{tabular}

\section{Mejor momento para recibir información sobre educación sexual}

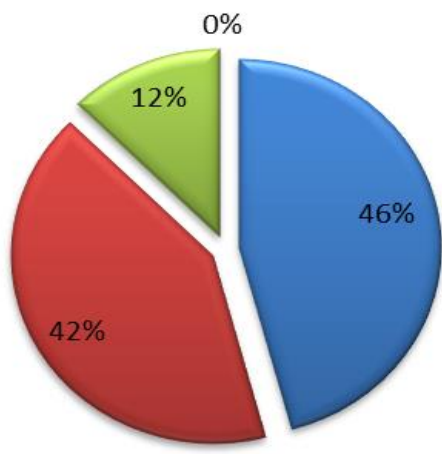

A partir de los 12 años

๑De los 15 años en adelante

$\square$ Desde la niñez

Dunca

Pregunta 2 ¿Quién considera que es la persona más idónea para informarle sobre educación sexual?

\begin{tabular}{|l|l|l|l|}
\hline & Alternativas & Frecuencia & $\%$ \\
\hline a & Padres & 22 & $92 \%$ \\
\hline b & Amigos & 0 & $0 \%$ \\
\hline c & Maestros y orientadores & 2 & $8 \%$ \\
\hline d & Hermanos o primos & 0 & - \\
\hline e & ninguno & 0 & - \\
\hline & Total & 24 & 100 \\
\hline
\end{tabular}




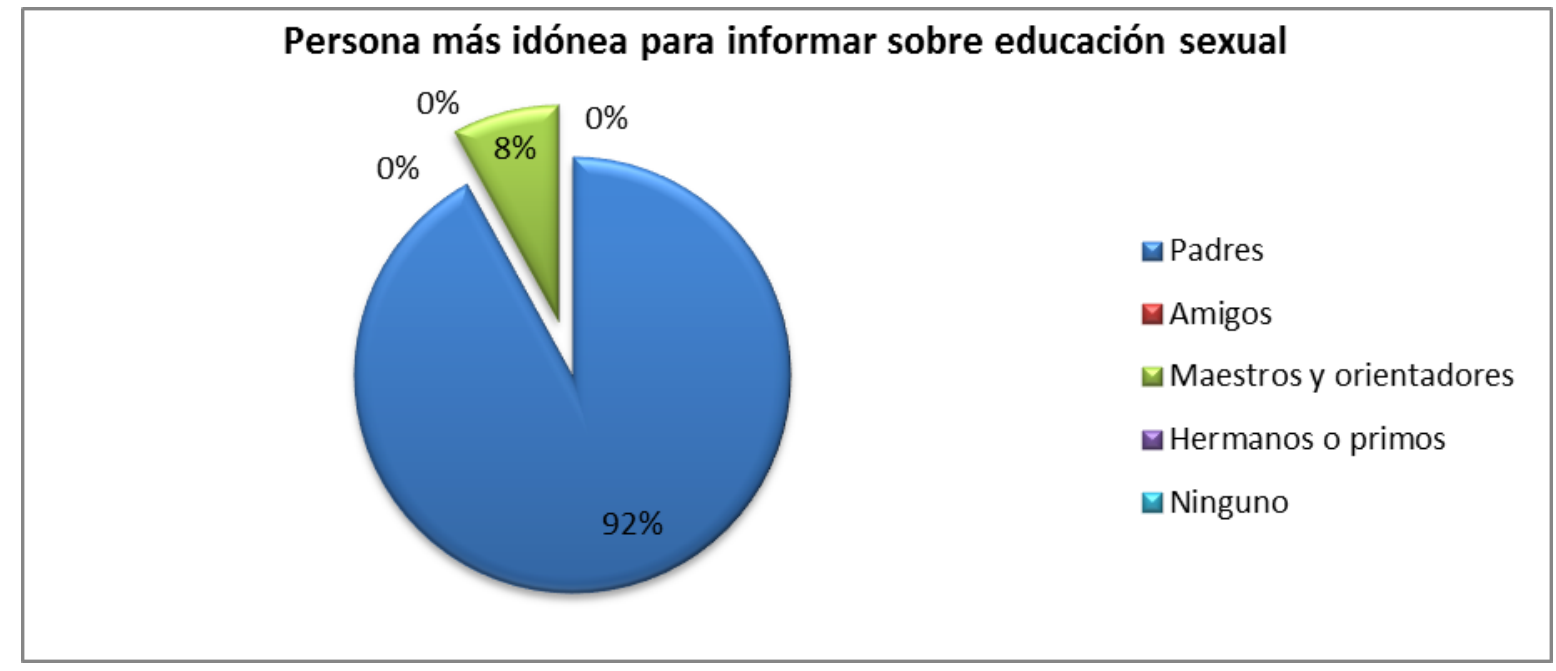

Pregunta 3 ¿Cómo prefiere que sean las clases sobre Educación de la sexualidad?

\begin{tabular}{|l|l|l|l|}
\hline & Alternativas & Frecuencia & $\%$ \\
\hline a & Información vivencial & 11 & 46 \\
\hline b & Información teórica & 4 & 17 \\
\hline c & Material interactivo & 9 & 37 \\
\hline d & Que no se enseñen estos temas & 0 & - \\
\hline & Total & 24 & 100 \\
\hline
\end{tabular}

Preferencia de las clases sobre Educación de la sexualidad

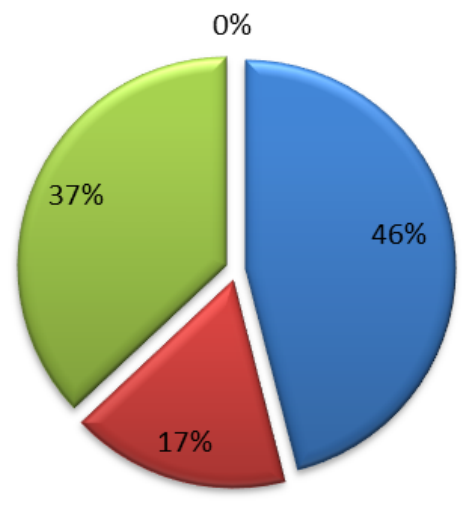

—Información vivencial

— Información teórica

$\square$ Material interactivo

口 Que no se enseñen estos temas 
Pregunta 4 ¿Qué tan satisfecho está ud. con la información sobre la educación de la sexualidad que se le brinda en el colegio?

\begin{tabular}{|l|l|l|l|}
\hline & Alternativas & Frecuencia & $\%$ \\
\hline a & Mucho & 9 & 38 \\
\hline b & Poco & 13 & 54 \\
\hline c & Nada & 2 & 8 \\
\hline & Total & 24 & 100 \\
\hline
\end{tabular}

Satisfacción sobre la información de la educación de la sexualidad que se brinda en el colegio

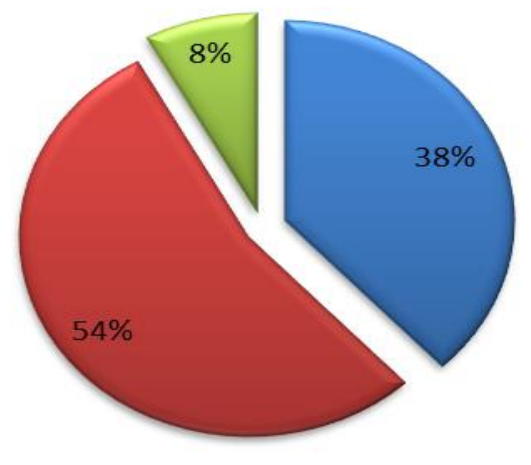

Mucho

$\square$ Poco

$\square$ Nada

Pregunta 5-Escriba cinco temas en orden de prioridad sobre Educación de la sexualidad que le gustaría que sus maestros profundicen más.

1. Infecciones de transmisión sexual

2. Aborto y prevención

3. Embarazos no deseados

4. Aborto y sus consecuencias

5. Información general sobre sexualidad, el sexo y la responsabilidad que se debe asumir ante ello. 


\section{Anexo13}

Cuestionario a los estudiantes sobre el tema de la prevención del embarazo precoz

Objetivo: Comprobar los conocimientos que poseen los estudiantes sobre la sexualidad y la prevención del embarazo precoz.

Estimado estudiante: Se necesita de su colaboración para la investigación que se realiza y responda con honestidad y sinceridad el siguiente cuestionario. Muchas gracias.

\section{PREGUNTAS:}

1. ¿Qué diferencia existe entre adolescencia y pubertad?

2. ¿A qué edad comienzan los cambios anatomofisiológicos?

3. ¿Cuáles son los cambios corporales más significativos que ocurren durante la adolescencia?

4. ¿Cuáles son las zonas erógenas y de mayor respuesta sexual?

5. ¿Cómo ocurre la fecundación?

6. ¿Cómo se define el embarazo?

7. ¿Cómo prevenir el embarazo no deseado?

8. ¿Considera ud. que el aborto es un método anticonceptivo?

9. Mencione métodos anticonceptivos femeninos y masculinos.

10. Diga algunas consecuencias del embarazo precoz en la adolescencia. 
Anexo 14

Planificación (cronograma) del programa preventivo-educativo

\begin{tabular}{|l|l|l|l|l|}
\hline \multicolumn{2}{|c|}{ OBJETIVOS } & \multicolumn{2}{|c|}{ AÑO 2 } \\
DERIVADOS DE LAS \\
DIRECTRICES DE \\
INTERVENCIÓN
\end{tabular}




\section{Anexo 15}

\section{Glosario de términos}

Sexualidad: Es una dimensión de la personalidad que se construye y expresa, desde el nacimiento y a lo largo de toda la vida, a través del conjunto de representaciones conceptos, pensamientos, emociones, necesidades, sentimientos, actitudes y comportamientos que conforman el hecho de ser psicológica y físicamente "sexuado", masculino o femenino, lo que trasciende la relación de pareja para manifestarse en todo lo que la persona "es" y "hace" como hombre o mujer en su vida personal, familiar y social. La sexualidad es personalizada y la personalidad sexuada. (González y Castellanos, 2003).

Sexualidad: manifestación psicológica rectora de la personalidad, que tiene como núcleo el sentimiento y la conciencia de la propia masculinidad, femineidad o ambivalencia, cuando no se identifica plenamente con los patrones de su sexo. (González, A. 2003; pág. 172).

Personalidad: "una organización estable y sistémica de los contenidos y funciones psicológicas que caracterizan la expresión integral del sujeto en su funciones reguladora y autorreguladora del comportamiento" (González, F.,1995, p.19).

Sexo: se refiere de forma específica a las características biológicas y físicas que identifican a un individuo como femenino o masculino en el momento del nacimiento, las que le confieren determinadas funciones ante el otro sexo, especialmente en el acto sexual y en la reproducción. (Castellanos, 1994).

Información sexual: supone la transmisión de hechos y datos acerca de cómo funciona el cuerpo y cómo se pueden prevenir situaciones que a menudo se asocian o generan problemas de salud. La información sexual se encamina al atesoramiento de hechos y datos que son recibidos de manera acrítica.

La educación sexual se orienta a desarrollar y favorecer las aptitudes y actitudes en la interrelación entre las personas en una sociedad determinada. Así en los procesos de educación sexual los hechos y los datos aprendidos potencian la reflexión y el análisis anticipatorio, evitando el predominio de la acción irreflexiva sobre el pensamiento lógico.

Educación sexual: Debe ser y es un hecho, un proceso continuo que comienza con el nacimiento y termina con la muerte. $Y$ no se puede entender qué es la sexualidad si no se relaciona con el ajuste total del sujeto sea hombre o mujer dentro de la época en que 
vive, dentro de su familia y dentro de la sociedad; es decir situar al sujeto en el contexto en que vive se desarrolla; ya que cada sociedad, cada cultura de acuerdo a su economía, sus creencias, su concepción de ser humano, elabora normas de comportamiento para sus gentes, las leyes, los castigos y los derechos. Cardinal (2005,p. 88).

Educación sexual desde un Enfoque Alternativo y Participativo como "el proceso activo que potencia al individuo para el encuentro libre, pleno y responsable con el otro sexo y con la propia sexualidad, en correspondencia con sus necesidades y las del contexto, garantizando el protagonismo y la capacidad de elegir los límites personales de la sexualidad, así como el respeto a la de las personas con que se relaciona". (González y Castellanos (2003; p. 161).

Adolescencia: El vocablo "adolescencia" deriva de la voz latina "adolece" que significa crecer y desarrollarse hacia la madurez. Esta etapa comprende edades muy variables de un niño a otro, pero se acepta como intervalos aproximados los 10 y 19 años. La adolescencia es una etapa compleja de la vida que presenta una serie de problemas importantes que resolver, los que deben ser correctamente encarados para llegar a una vida adulta normal.

La "pubertad describe una de las fases de la adolescencia, la encargada del desarrollo de la capacidad de procrear que se inicia con la primera emisión de líquido seminal en el varón, y con la menstruación en la mujer.

La prevención: La Organización de Naciones Unidas (ONU) en su Programa de Acción Mundial considera que es un propósito central y como la adopción de medidas encaminadas a impedir que se produzcan deficiencias físicas, mentales y sensoriales, o a evitar que, de producirse tengan consecuencias físicas, psicológicas y sociales negativas tales como la discapacidad y la minusvalía.

Embarazo es el término que comprende el periodo de gestación del ciclo reproductivo humano. El embarazo comienza cuando el espermatozoide de un hombre fecunda el óvulo de la mujer, y este óvulo fecundado se implanta en la pared del útero. Como el embarazo altera los esquemas hormonales de una mujer, uno de los primeros síntomas del embarazo es la pérdida del periodo menstrual. Otros síntomas son: aumento de la sensibilidad de las mamas, cansancio, náuseas, sensibilidad a los olores, mayor frecuencia en la micción, cambios de humor y aumento de peso, ciertas mujeres también experimentan deseos de sustancias pocos usuales, como hielo, arcilla, etc., esta situación llamada pica, puede ser indicativa de una insuficiencia de hierro u otros nutrientes.(Ramos, A.). 
Embarazo en la adolescencia es aquella gestación que ocurre durante los dos primeros años de edad ginecológica (edad ginecológica=edad de la menarquia) y /o cuando la adolescente mantiene la total dependencia social y económica de la familia parental.

Embarazo precoz: Estado de gravidez de una fémina, que se produce entre los inicios de la adolescencia (pubertad), durante y al final de esta. Por lo general se establece entre los 10 y 19 años. También se les adjudica este término a aquellas mujeres que no han alcanzado la edad adulta legal, en correspondencia con las leyes de cada país o en el caso en que estas se encuentran bajo la dependencia económica y social de sus padres.

Prevención primaria (o primer nivel de prevención) se aplica en un marco supuestamente sano compuesto por individuos de grupos de riesgo, o sea, individuos que presentan un mínimo importante de factores causales de orden biológico, psicosocial, económico y ambiental, [...] los que en su conjunto podrían provocar una alteración determinada que afecte el desarrollo normal de los niños/as. p. 37.

Prevención educativa: es un proceso dialéctico, de orientación sistemática, anticipatorio, continuo y que atiende a la diversidad, que parte del diagnóstico sistémico y holístico del sujeto, dirigido conscientemente a la formación y fortalecimiento de cualidades, motivos, intereses, sentimientos, valores, capacidades intelectuales y actitudinales en los adolescentes, donde se integra lo curricular y familiar, en un contexto interactivo socializado.( Díaz, C. 2001, p.47).

Resiliencia se define como un proceso de identificación y desarrollo de recursos para manejar los factores estresantes a fin de obtener resultados positivos. La resiliencia se sustenta en una serie de recursos que permiten superar los contratiempos cotidianos, pero no todos cuentan con los mismos recursos para resolver los infortunios que aparecen a lo largo de la vida. (Lozoya, J. (2013, p.1).)

Resiliencia sexual es el proceso mediante el cual el adolescente utiliza recursos protectores disponibles para contrarrestar los factores de riesgo sexual. Es un mecanismo que reduce el impacto de riesgo, ya que el adolescente está en constante estado de vulnerabilidad y los factores de protección le permiten la toma de decisiones adecuada (Haaser).

Responsabilidad, constituye un modo de sentir, pensar y actuar a partir de una actitud que se asume ante los resultados, las consecuencias enriquecedoras o nocivas de la actuación personal social sobre la propia persona y con las que se relaciona así como de su contexto. (Roca, A., Alejandro y González, A.). 
Responsabilidad, en la vida sexual y personal social en general, se manifiesta al basar las relaciones de amistad, de pareja, familiar y social en el amor, la honestidad, la honradez, la equidad, la solidaridad, en el respeto y la aceptación.

de la diversidad y las diferencias humanas, sexuales y socioculturales y, a su vez el rechazo, combate de conductas y actitudes inadecuadas, inhumanas, contrarias a los valores más elevados y humanos de la ética y la moral, que se manifiestan en las relaciones entre varones y mujeres en la vida sexual, de pareja, de amistad, familiar y social. (Roca, A. A. y González, A.).

Educación de la sexualidad responsable es un proceso que se da en la escuela en sentido estrecho, con profesionales armados con los fundamentos científicos de la pedagogía, pero en sentido amplio en este proceso interviene la familia y toda la sociedad, si es con la guía de la escuela mejor serán los resultados.

Tutoría: proceso de acompañamiento de tipo personal y académico, a lo largo del proceso formativo, para mejorar el rendimiento académico, solucionar problemas escolares, desarrollar hábitos de estudio, trabajo, reflexión y convivencia social. (ANUIES, 2000)

La acción tutorial, se considera uno de los ámbitos de la orientación educativa que contribuye a la maduración de la personalidad de cada alumno concreto y su camino en la vida, por lo que incide en lo que se ha dado en llamar educación integral y personalizada. (Luna, M. G., 2015).

Educación integral en sexualidad -tendrá una amplia perspectiva basada en los derechos humanos y en el respeto a los valores de una sociedad plural y democrática en la que las familias y las comunidades se desarrollen plenamente. Esta educación incluirá aspectos éticos, biológicos, emocionales, sociales, culturales y de género, así como temas referentes a la diversidad de orientaciones e identidades sexuales conforme al marco legal de cada país, para así generar el respeto a las diferencias, el rechazo a toda forma de discriminación y para promover entre los jóvenes la toma de decisiones responsables e informadas con relación al inicio d sus relaciones sexuales. (Declaración Ministerial, México 2008). 


\section{Anexo 16 \\ Ley sobre educación de la sexualidad en Ecuador CONGRESO NACIONAL EL PLENARIO DE LAS COMISIONES LEGISLATIVAS}

Considerando:

Que el artículo 32 de la Constitución Política de la República establece el deber de proteger a la familia como célula fundamental de la sociedad, garantizándole las condiciones morales, culturales y económicas que favorezcan la consecución de sus fines, y protege el matrimonio, la maternidad y el haber familiar.

Que la Sociedad Mundial y la Ecuatoriana en particular, reclaman la vigencia de leyes que involucren políticas de mejoramiento de la calidad de Educación, para solucionar los problemas de la niñez, adolescencia, juventud, sobre todo en el área de la Sexualidad.

Que la sexualidad es una realidad humana presente desde la concepción, sujeta a procesos de maduración que son claves para el equilibrio de la personalidad, por lo que es de vital importancia expedir una Ley de Educación de la Sexualidad y el Amor, que permita la formación de generaciones de hombres y mujeres íntegros y responsables de su comportamiento sexual frente a sí mismos y a la sociedad.

Que es necesario garantizar el respeto a la libertad de pensamiento y promover la participación consciente de la comunidad educativa: profesores, padres de familia y alumnos en la identificación de las necesidades de aprendizaje sobre sexualidad humana; $y$, En ejercicio de sus facultades constitucionales y legales, expide la siguiente:

LEY SOBRE LA EDUCACIÓN DE LA SEXUALIDAD Y EL AMOR.

Art. 1. La Educación en Sexualidad y el Amor será un eje transversal de los planes y programas de estudios en todos los centros educativos oficiales o privados de nivel preprimario, primario secundario y técnico.

Art. 2. La Educación sobre la Sexualidad y el Amor se fundará en el respeto de la dignidad de los seres humanos, de la vida, los valores éticos y morales conforme a las culturas existentes, como un elemento que contribuya al mejoramiento de la educación y eleve la calidad del aprendizaje en el campo de la sexualidad.

Art. 3. La Educación de la Sexualidad y el Amor, deberá responder al medio, a la edad de los educandos y al rol esencial de los padres de familia, como orientadores netos de sus hijos. 
Art. 4. El Ministerio de Educación será el encargado de elaborar planes y programas abiertos y flexibles de Educación sobre la Sexualidad y el Amor, previa consulta con instituciones privadas y públicas que conozcan el tema.

Cada centro educacional deberá adaptar dichos planes y programas a su realidad cultural y someterlos a conocimiento, consideración y aprobación del Departamento de Orientación y de los Padres de Familia de dicho plantel.

El Ministerio de Educación no limitará su acción a los educandos, involucrará a la familia, para que esta participe activamente en un proceso de diálogo, reflexión y acción con toda la comunidad educativa.

Art. 5. Todos los maestros deberán ser capacitados en el tema de la Sexualidad y el Amor, para lo cual el Ministerio de Educación, coordinará esta actividad con las Universidades, Institutos Pedagógicos y otras entidades conocedoras del tema.

Todas las instituciones encargadas de la formación de Docentes, deberán incluir como Eje Transversal de sus Planes y Programas el tratamiento de la Sexualidad y el Amor.

Art. 6. El Ministerio de Educación, establecerá y realizará el monitoreo de los proyectos educativos que desarrollen todos los establecimientos, siempre en coordinación con los padres de familia y considerando su impacto en la vida personal, familiar y comunitaria.

Art. 7. El Ministerio de Educación será el encargado de coordinar con los medios de comunicación la difusión de programas referentes al tema de educación en sexualidad a fin de evitar que se distorsione lo establecido en el Sistema Educativo. El Ministerio de Educación controlará la calidad en el contenido de los programas que se emitan en forma pública en lo que se refiera a la sexualidad y el amor.

Art. 8. Todas las Instituciones Públicas y Privadas deberán seguir los planes y programas que se emitan en forma pública en lo que se refiera a la Sexualidad y al Amor.

Dada en la ciudad de San Francisco de Quito, Distrito Metropolitano, en la Sala de Sesiones del Plenario de las Comisiones Legislativas del Congreso Nacional del Ecuador, a los cuatro días del mes de marzo de mil novecientos noventa y ocho. 


\section{Anexo 17}

\section{ESCALA VALORATIVA}

OBJETIVO: Obtener información sobre los indicadores seleccionados,

Estimado alumno: Ubica del 1 al 5 la proposición que más te caracteriza, el 1 indica el valor más bajo y el 5 es el valor más alto. Muchas gracias

Indicador : Intencionalidad comunicativa

\begin{tabular}{|c|c|c|c|c|c|}
\hline (Proposiciones) & 1 & 2 & 3 & 4 & 5 \\
\hline 1.Comparte sus inquietudes sexuales con sus compañeros más allegados & & & & & \\
\hline 2. Dialoga con su tutor acerca de dudas sobre el funcionamiento sexual & & & & & \\
\hline 3. Interroga acerca de cómo evitar embarazarse o embarazar a su pareja & & & & & \\
\hline $\begin{array}{l}\text { 4. Escucha atentamente cuando el profesor se refiere a información } \\
\text { sobre la sexualidad }\end{array}$ & & & & & \\
\hline 5. Participa activamente en el dialogo sobre Sexualidad & & & & & \\
\hline 6. Expresa sentimientos sobre la pareja & & & & & \\
\hline
\end{tabular}

Indicador: Disposición para asumir actitudes responsables y resilientes

\begin{tabular}{|c|c|c|c|c|c|}
\hline Proposiciones & 1 & 2 & 3 & 4 & 5 \\
\hline 7. Evita ceder ante las presiones del grupo sobre la iniciación sexual. & & & & & \\
\hline $\begin{array}{l}\text { 8. Demuestra responsabilidad en la relación con su pareja. } \\
\text { 8. Procura información de manera voluntaria sobre la prevención y } \\
\text { riesgos del embarazo precoz. }\end{array}$ & & & & & \\
\hline 9. Considera que el embarazo precoz es una responsabilidad de la pareja. & & & & & \\
\hline $\begin{array}{l}\text { 10. Toma la iniciativa en la selección del método anticonceptivo más } \\
\text { idóneo para la pareja. }\end{array}$ & & & & & \\
\hline
\end{tabular}




Didáctica e Innovación educativa 